\title{
WOWERN AMPROPBMENTS
}

\section{IN FISHING TACHEE}

\section{UC-NRLF}

||||||||||||||||-||||||||||||||||||||||||

|||||||||||||||||||||||||||||||||||||||||||||||

+B 2?】 7ь9

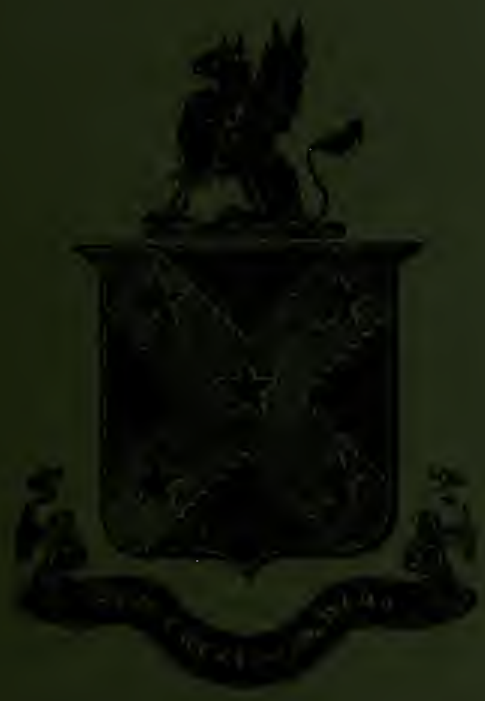




\section{BERKELEY GENERAL LIBRARY UNIVErSSITY OF CALIFORNIA}

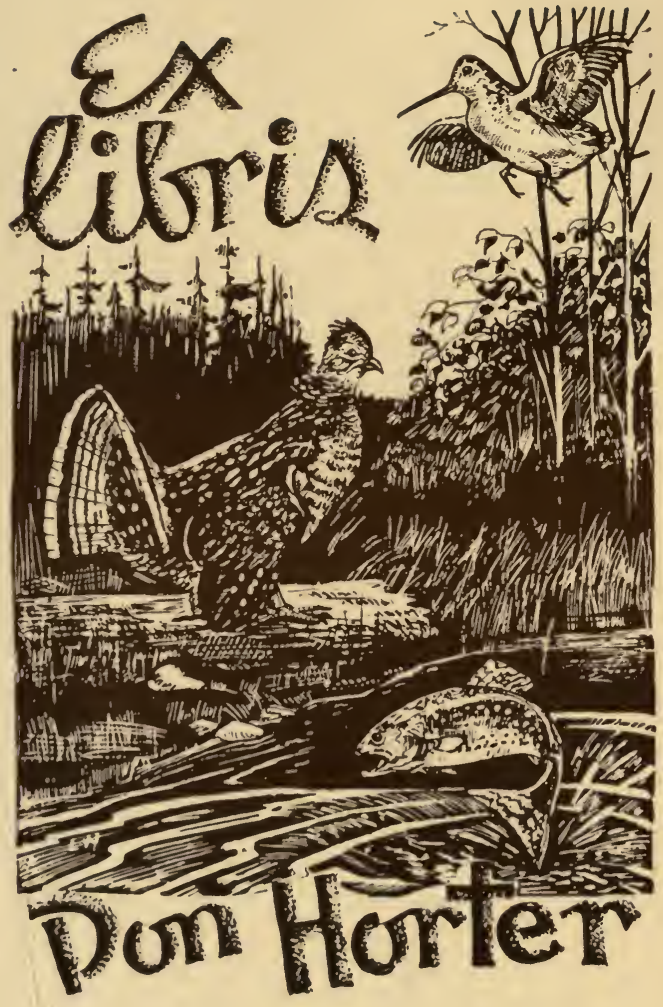






\section{MODERN IMPROVEMENTS}

\section{F ISH I N G T C K LE}

AND

F ISH - HOO KS. 

Digitized by the Internet Archive in 2007 with funding from Microsoft Corporation 

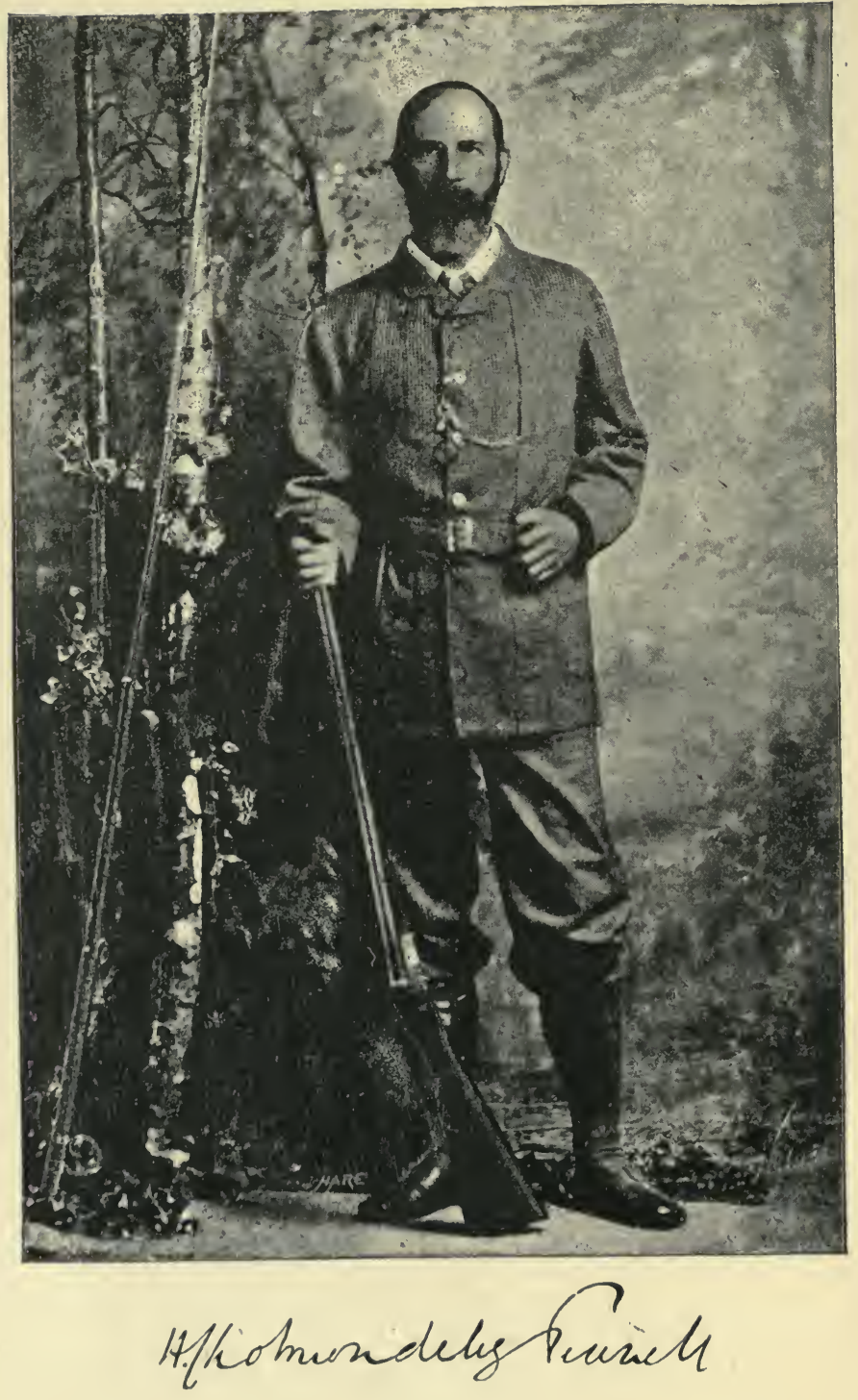


\section{MODERN IMPROVEMENTS}

IN

\section{F I S H I N G T A C K L E}

AND

F I S H H $00 \mathrm{KS}$,

BY

\section{H. CHOLMONDELEY-PENNELL,}

Late H.M. Inspector of Sea Fisheries,

Author of "The Sporting Fish of Great Britain," "(Fishing) The Badminton Library of Sports," "The Modern Practical Angler," "The Book of the Pike," "The Angler-Naturalist," \&c., \&c.

\section{Ilustrated by 250 Wood Engravings.}

LONDON :

Sampson low, Marston, Searle \& Rivington, CROWN BUILDINGS, 188, FLEET STREET. 



\section{$S^{\prime} H 451$ \\ $\mathrm{P}_{4}$}

\section{Dedicated by Permission}

то

His Grace the Duke of Beaufort, K.G., \&C., \&C., \&C.,

Editor of the "Badminton LibraRy of Sports." 


\section{T H E \\ SPORTING FISH OF GREAT BRITAIN \\ With Notes on Ichthyology. \\ Illustrated by Sixteen Lithographs of Fish in Gold, Silver and Colours.}

Saturday Review. - "Mr. Pennell's experience with regard to salmon has been so large, owing to his inspectorship of sea fisheries, that his remarks on this fish carry considerable weight. In fact, it is to him and to Mr. Buckland, as was remarked some years ago in an article which appeared in this journal, that should be given the credit of the legislative reforms which have done so much for the salmon fisheries."

Field. - "Mr. Pennell has carefully modernised his conclusions and brought his facts down to date. The illustrations are unique in this country."

Spectator.-"A fascinating volume. . . . Mr. Cholmondeley-Pennell is a recognised authority not only on the nature and habits of the sporting fish of Great Britain, but also on the art of catching them. For he is himself a practical sportsman of great experience and established reputation."

Fishing Gazette.- "We know no work which gives such exact descriptions of British sportir $\mathrm{g}$ fish, - . - and no illustrations of fishes which are so true to nature."

Vanity Fair.- " 185 pages of admirably clear written matter. . . . Mr. Cholmondeley-Pennell brings to the treatment of his subject a varied knowledge acquired as an angler, an official, and an enthusiastic ichthyologist."

Truth.- "More exquisitely delicate illustrations than these were never before printed, whilst the name of such an expert as Mr. Cholmondeley-Pennell is an adequate guarantee of their trustworthiness."

The County Gentleman._- "There is no man living better qualified than Mr. CholmondeleyPennell to speak upon every variety of piscatorial topic. graceful and forcible style has seldom been more strikingly displayed.

Globe.- "A volume which is as readable as it is informing.

St. James's Gazette. - "The most satisfactory book-pictures of fish ever produced."

Guardian.- "No naturalist or angler should be without it.'

Morning Post. - "Difficult to pick a fault."

Liverpool Courier.- "Delightfully coloured and gilt illustrations. Cholmondeley-Pennell conveys the greatest information in the most agreeable shape."

Mr.

Illustrated London Nerws._ "The best of the kindever produced by an English publisher."

Pall Mall Gazette.-“ • . . In Mr. Pennell's pages anglers will find in convenient and consecutive form all the available information regarding the natural history of the scaly beauties among which they enjoy so many pleasant hours by lake, river, or loch side."

North British Daily Mail.-_" Exquisite.

No coloured illustrations of fish, either sea or fresh water, have as yet been published in this country which approach these either in delicacy or fidelity to nature."

Manchester Guardian.- "Unnecessary to say that the merits and interest of the book are not limited to the pictures. . . In a supplementary chapter on ichthyology the author presents also what may be spoken of as a ground plan of a knowledge of the science,"

Liverpool Daily Post. - "A book on which it would be difficult to bestow too high praise. The name of the author should be sufficient guarantee of his capacity for dealing with the subject.

Sporting and Dramatic Nerws. - "Must tempt all who are interested in fish and fishing."

Now Ready at all Booksellers' and Libraries. Alarge paper edition, printed on Dutch hand-made paper, limited to 100 copies for England and 50 for America, price 30 . Small-paper edition, demy 8vo, first edition, limited to 500 copies, price 15s.

SAMPSON LOW, MARSTON AND RIVINGTON,

Crown Buildings, Fleet Street, London. 


\section{WHY IS IT WRITTEN ?}

Two reasons why-

(Firstly) Because this is pre-eminently an age when men desire to pursue their sport, whatever it be, with their brains as well as with their muscles, and I think that lovers of the angle will be glad of a brief record, in a diagramatic form, of the advances-both numerous and noteworthy-which this art has lately made in all that relates to Fishing-Tackle and Fish-hooks.

(Secondly) Because, as regards the latter, I wish to make as widely known as possible my own system of Eyed-hooks and method of attachment direct to the line, - a system which is, as I verily believe, destined to wholly supersede the old tedious, and in fifty ways objectionable, plan of lapping hooks on to separate strands of gut.

If $I$ am a true reader of the signs of the times-and the sale of 30,000 of my hooks in a few weeks by one London Tackle Maker, would seem to show which way the wind blows - this near revolution so vitally affecting all fishermen, and especially the fly-fisher, and that at every turn, and in every department of his art, dwarfs by comparison all other 'improvements' in fishing gear actual, or I may say possible.

"The whole art and paraphernalia of angling have for their objects, first to hook fish and afterwards to keep them hooked."

H. Cholmondeley-Pennell. 


\section{B Y THE SAME AUTHOR.}

\section{The "Pennell Series;" 3s. 6d. each, Cloth.}

Fifth Thousand, revised.

\section{THE MODERN PRACTICAL ANGLER.}

A Complete Guide to Fly-fishing, Float-fishing, and Trolling. Profusely illustrated.

"Mr. Pennell is not only well known as a Senior Angler, but as one of the straightest riders and straightest shots in England, and whatever he writes is well worthy of the consideration of sportsmen."-Baily's Magazine.

Fourth Edition. Enlarged.

\section{THE BOOK OF THE PIKE.}

A Treatise on practical Pike-fishing and Pike lore. Illustrated with 50 wood-cuts.

"Exhausts the subject. . . . . Mr. Pennell leaves nothing for other writers to add." - Field.

New Edition.

\section{THE ANGLER-NATURALIST.}

A text-book for Anglers and Students of Fish-science. Copiously illustrated throughout.

" The most complete history of British fresh-water Fish of the present day.' - Field.

Illustrated Shilling Series, New Editions :

FLY-FISHING AND "WORM-FISHING."

F LOA T - F ISH IN G.

TROLLING FOR PIKE, SALMON AND TROUT.

Now Ready.

THE SPORTING FISH OF GREAT BRITAIN,

WITH NOTES ON ICHTHYOLOGY.

Illustrated with $\times 6$ Lithographs in Gold, Silver and Colours.

Demy 8v0., price 15s. Post Free.

"Mr. Pennell has carefully modernised his conclusions, and brought his facts down to date. The illustrations are unique in this country."-Field. 


\section{O N T E N T S.}

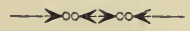

PAGE.

IMPROVEMENTS IN FISH HOOKS, AND THE AUTHOR'S

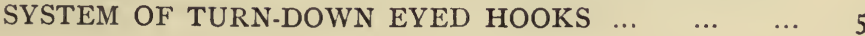

IMPROVEMENTS IN FLY-FISHING AND SPINNING TACKLE,

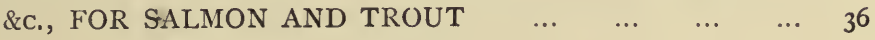

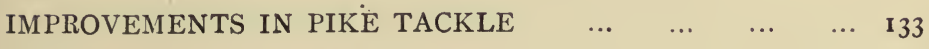

IMPROVEMENTS IN FLOAT - FISHING TACKLE, AND $\begin{array}{llllllll}\text { ANGLING MISCELLANEA } & \ldots & \ldots & \ldots & \ldots & \ldots & \mathbf{1 6 0}\end{array}$

APPENDIX-TESTIMONY IN FAVOUR OF THE EYED $\begin{array}{lllllllll}\text { HOOK SYSTEM } & \ldots & \ldots & \ldots & \ldots & \ldots & \ldots & \ldots & \mathbf{1 7 5}\end{array}$

$\begin{array}{llllllllllll}\operatorname{INDEX} \ldots & \ldots & \ldots & \ldots & \ldots & \ldots & \ldots & \ldots & \ldots & \ldots & \text { I9I }\end{array}$ 
"TELL me what your tackle is, and I'll tell you what your basket is."Angling Paraphrases. 


\section{MODERN IMPROVEMENTS}

\section{IN \\ TACKLE AND FISH-HOOKS.}

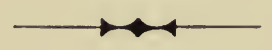

E Y E D H O O K S.

First, and a long way 'foremost,' amongst modern improvements in Tackle, and applicable equally to almost every description of angling-fly-fishing, float-fishing and sea-fishing-stands indubitably the EYED HOUK.

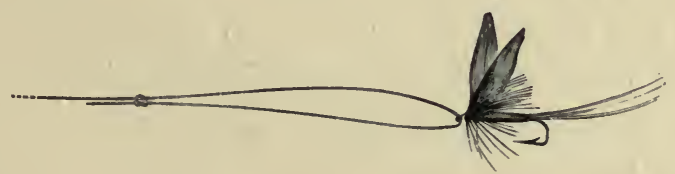

THE EYED HOOK.

The speciality of the Eyed Hook is its attachment direct to the line, instead of, as hitherto, by means of an intermediate length of gut on to which it is lapped. The great practical disadvantages of this "lapping on" system are :- 
A. That when once the 'gut hook' or artificial fly gets "worn at the head" - which in actual work very soon occurs-it becomes thenceforth worthless.

в. And when another gut-hook, or fly, is substituted, the gut must be soaked first (in practice generally in the saliva of the mouth) to enable it to be properly knotted on. If this soaking be not thoroughly done, a plain hook is unsafe for use, and a fly will most likely whip off.

c. But even after properly knotting the two gut links together, it is ten to one that the link on which the fly or hook is lapped, does not correspond with that at the end of the line : it is too thick, or too thin; too dark, or too light. From this results a linear disfigurement, or an inharmoniousness of tint (or both) at the very point where a perfect taper and complete uniformity of color are of vital consequence.

These, I say, are the most salient defects of the system, almost universally adopted until the last few years, of lapping on hooks and flies to separate strands of gut. Of minor, but still serious drawbacks, must be reckoned the difficulty of carrying about a sufficient supply of "gut hooks "- or still more of fliesof all needful sizes, and the destructive effects of time upon the contents of the 'store box.' Apart from 'moth,' this happens partly owing to the 'rotting' of the gut at the point of contact with the steel hook-shank, and partly to the dessication (drying up) of the wax on the lapping by which the gut is attached.

Now all these defects-defects inherent in the principle of lapped-on hooks, and which cannot be gainsaid-are at once overcome by the new eyed-hook system. . . And in speaking of the eyed hook here and throughout these pages, I would be understood as referring exclusively to that form of it-patented in the United States and registered by a "Trade Mark" in this country - which is generally associated with my name as the "Turndown Eyed Hook." 
There have, it is well-known, been numerous attempts in former and in recent years to introduce some form of direct attachment between the trace and its steel appendage (the advantages of which are so self-evident), and many forms of eyed-hooks have been invented with that object: hooks with turnup eyes, hooks with 'needle' eyes, hooks with 'straight' eyes, hooks with 'crooked' eyes-cum multis aliis; but none of these have obtained any very general or ready acceptance on the part of the fishing public. Indeed I may say that all the patterns of eyed-hooks I have personally examined and tested are open to serious practical objections of one sort or another-either in connection with the make or position of the eye, or in regard to the mode of knotting it on to the line,--objections which doubtless explain their partial or non-success. I trust, however, that their inventors-pioneers, explorers and discoverers in the new field, to whose labours I more than any one else am indebted * -will not imagine that I desire for one moment to depreciate in any way their excellent work; still less to exalt my own small efforts at their expense. Indeed it is want of space simply, and not want of courtesy, which precludes my attempting, within the limits of this little brochure, to pourtray and describe their several ingenious plans - the progenitors, so to speak, of my own systemand especially the turn-up eyed-hook of my friend Mr. H. S. Hall, which is now used by many first-rate fly-fishers, whose enthusiasm carries them triumphantly over all obstacles, or what I regard as defects. . . I have, nevertheless, a plain task set before me of which I must acquit myself in a plain businesslike way. What I have to say-and without the saying of which this

* To the Editor also of the Fishing Gazette, the columns of which have for several years been frankly and freely opened to the discussion of this allimportant angler's quastio vexata, the thanks of the angling public, and my own in particular, are also largely due. Without such sympathetic and discriminating assistance 1 have no hesitation in saying that the matter would not now have reached its present practical and complete form. 
leaflet would never have appeared-is that in my judgment all these systems of eyed-hooks are defective, and that their defects are a bar to their general adoption; whereas, on the other hand, I believe that the system which I now present for judgment to the parliament of anglers, is, as a system, wholly 'free from blemishes ;' that it is a thoroughly workable and practical system, complete in all its details; and that sooner or later these qualifications will force its universal acceptance and recognition, if not by this generation of fishermen by that which will follow it.

It is to my own "Turned-down eyed hook," then, combined with its appropriate system of attachment, to which I refer when I say that by it all the disadvantages attaching either to the artificial fly or plain hook lapped on separate strands of gut are entirely got rid of.

By knotting on the fly or hook direct to the main line (' gut-trace,' ' collar,' ' casting-line,' ' bottom-line,' ' foot-line'-) the fly or hook that has become worn at the head can be removed, and in a few seconds re-attached to the same already well-soaked, well-tapered, and evenly tinted line; thereafter remaining as serviceable as ever.

The minor drawbacks alluded to of the old system are also obviated by the new, as the necessary selection of flies and hooks can be kept in stock for years without any fear of deterioration. The economy in the matter of space, both in the stock-box and fly-book, is, moreover, considerable. As many flies or hooks as are required for a day's fishing could be carried, I might almost say, in the waistcoat pocket.

In connection with the Turn-down eyed-hook, I have designed two new pattern hook-bends-modifications of my own or of existing patterns. These are manufactured, and sold in most of the larger tackle shops, under the name of the "PennellSneck" and "Pennell-Limerick" bends. 
" PENNELL-LIMERICK" TURN-DOWN EYED-HOOKS.

(Patent U.S.A.)

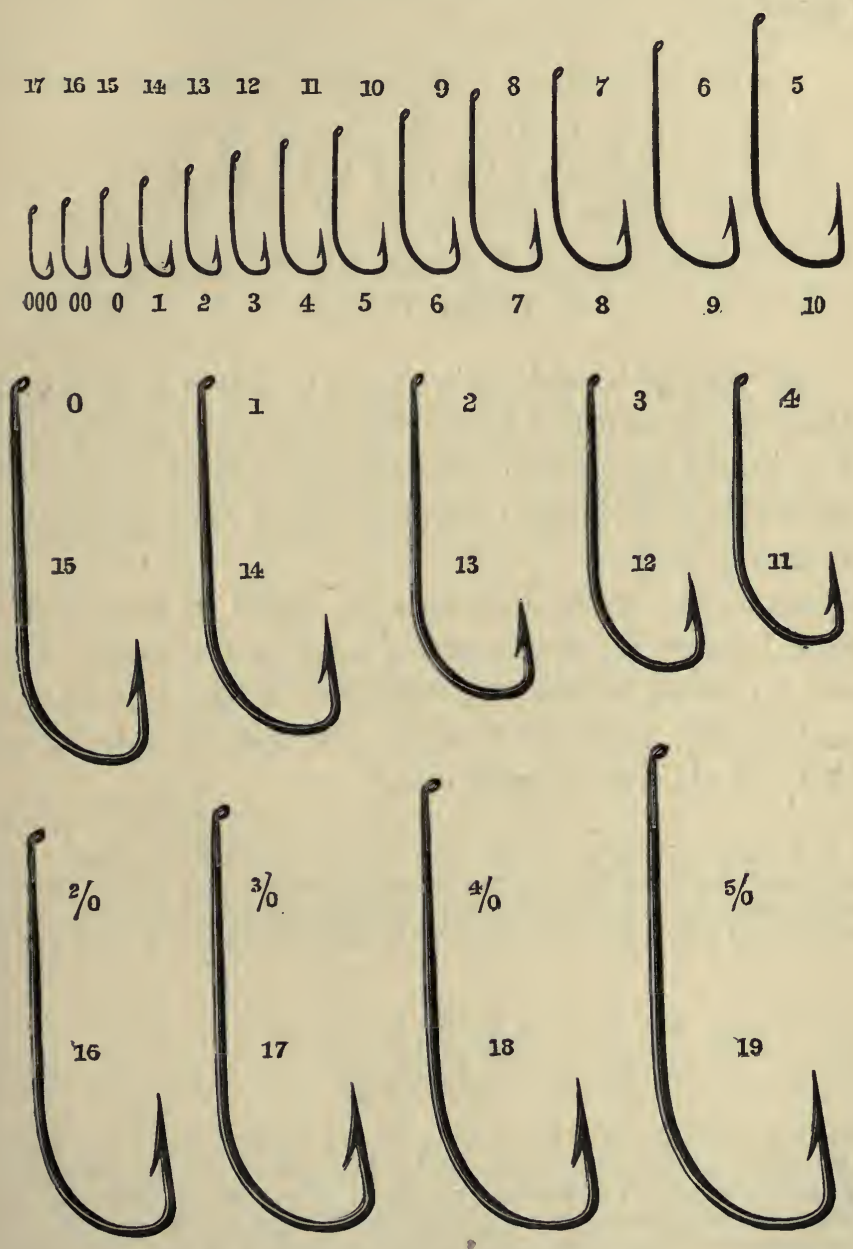

Upper figures 'Redditch' Scale; lower figures 'New' Scale. 
The latter bend (vide cut) is, from No. 8 ('New' Scale) upwards, especially calculated for Salmon and Grilse Flies, for heavy Sea-trout fishing, or for other purposes where great strength is desirable.

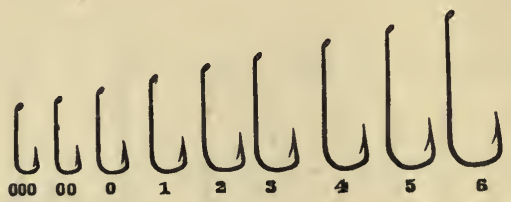

"PENNELL-SNECK" HOOKS, TURNED-DOWN EYES.

(Patent U.S.A.)

The "Sneck" is restricted in its sizes to what in the float-fisher's parlance would be called small perch hooks and roach hooks, or for fly-fishing purposes to river and lake-flies of the sizes more commonly used for brown trout (salmo fario) or to grayling, dace and chub flies.

Outside the above limitations (in regard to heavy fish) the choice between the two bends of hook in the smaller sizes is really very much a matter of individual fancy. I have myself used both with apparently equal success and I hardly know to which I should give the preference.*

* To meet the taste of those who, either from habit or choice, retained a preference for hooks with the eyes turned up, rather than turned down, the smaller sizes of the "Sneck" were originally made in both ways, but the unmistakable preference since shown by fly-fishers for the Turn-down Eye, and

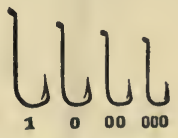

the advantages it undoubtedly possesses in other respects, have recently led me to think it unnecessary further to consider the Turn-up Eyed pattern, though my Agents, Messrs. Wm. Bartleet and Sons, Abbey Mills, Redditch, would doubtless be prepared to execute special orders, if given for a sufficient number through the retail channels. The mode of attachment by the Jam Knot, remains, of course, the same. 
Both these bends of hooks-up to No. I3 (new scale) of the "Limerick"-are attachable to the gut line by what I term the "Jam knot,"-this includes, of course, the whole of the sizes of the "Sneck" bend. The larger sizes of the "Limerick," on the contrary, from No. 14 (inclusive) upwards, are always attached by what may be called the "Slip-Knot" - single or double.

Further, to meet the requirements of small-sized flies for salmon and grilse, the "Limericks" from No. 8 (new scale) to No. I3, inclusive, are duplicated-made, that is, not only with eyes suitable for the jam-knot, but also with large eyes adapted to the slip-knot attachment.

The 'Limerick' bend, from No. 8 (new scale) upwards, is also manufactured in the double form, now very constantly used in the case of the smaller-sized salmon flies. These hooks are attached by the "slip-knot," in the same way as the single hooks.

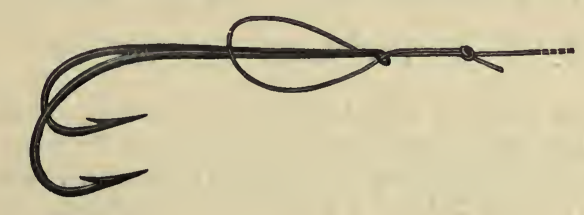

DOUBLE TURN-DOWN EYED SALMON HOOK:

For knotting on the line to the bare hook, as used in floatfishing, sea-fishing, \&c., there is a third attachment, specially suited to the purpose.

All this may sound complicated; but in practice it is as simple as ABC. I could attach all three different classes of hooks by the 
three different kinds of attachment in a minute and a half. The distinctions, moreover, are all really vitally necessary to the perfection of the system, of which they form an integral part, the hooks being manufactured accordingly. In short the fisherman who proposes to adopt my eyed hooks must also be good enough to adopt the knots for which they are designed. If he lacks either wit enough or will enough to do this, he had much better leave the whole thing alone and go on moistening his gut-hooks by salivary suction till the Greek Kalends. . .

Published testimonies to the success of the eyed hook principle are too numerous to attempt even to give a summary of them all here. Mr. H. S. Hall, one of our very best clear stream flyfishers, who has lately written an ably-practical essay on the Dry fly, ${ }^{1}$ has, it is well known, given his entire adhesion to eyed hooks, with which, indeed, his name has been long identified. Mr. Frederic M. Halford, author of the lately published charming monograph on "Floating Flies and how to dress them,"' is another apostle of the new culte. His first chapter is devoted to eyed hooks, and the opening sentence runs thus :

"Before many years are passed the old-fashioned fly, dressed on a hook attached to a length of gut, will be practically obsolete, the advantages of the Eyed Hook being so manifest that even the most conservative adherents of the old school must, in time, be imbued with this most salutary reform."

After enumerating several of the more obvious advantages already noticed, Mr. Halford continues :

"Flies dressed on eyed-hooks float better and with less drying than those constructed on the old system. . . . . Another and, in my opinion, paramount benefit is, that at the very earliest symptom of weakness at the point of juncture

I. "Badminton Library of Sport," edited by The Duke of Beaufort (1885): Longmans. New Edition.

2. "Floating Flies and how to dress them" (I886): Sampson Low, Marston, Searle, and Rivington. 
of the head of the fly and gut (the point at which the maximum wear and tear takes place) it is only necessary in the case of the eyed fly to break it off and tie on afresh, sacrificing at most a couple of inches of the fine end of the cast ; while in the case of the hook on gut, the fly has become absolutely useless and beyond repair. It must also be remembered that with eyed hooks the angler can use gut as coarse or as fine as he may fancy for the particular day, while with flies on gut he would require to have each pattern dressed on two or three different thicknesses."

Of course books on Fishing ( $\mathrm{I}$ do not refer to catch-penny productions, or to trade circulars) do not appear every day, or every year, and those I have quoted from are, so far as I know, the most recent, and therefore authoritative, on subjects the importance of which has only lately begun to be recognised. Some further quotations from the published letters of practical sportsmen will be found in the appendix. But to return to my text.

All the sizes, both of the "Pennell-Sneck" and "PennellLimerick," are also manufactured plain (i.e., with tapered shanks) for attachment to the hook by lapping on in the old-fashioned way: The Tapered "Snecks" are figured below.

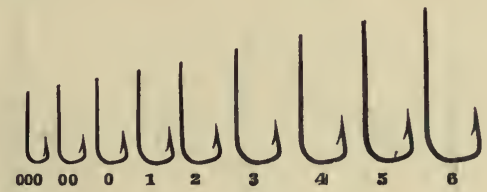

"PENNELL-SNECK" HOOKS, TAPERED SHANK.

A word as to the bends of my hooks themselves. Into the general question of fish-hooks, their vices and virtues, and the mechanical principles on which they should be (but unfortunately seldom are !) constructed, as well as to what are the 'points' of a perfect hook, I have already entered fully in the pages of the Modern Practical Angler; and have since had the pleasure of finding the views there set forth very generally endorsed by the 
"PENNELL-LIMERICK" BEND, TAPERED SHANKS.
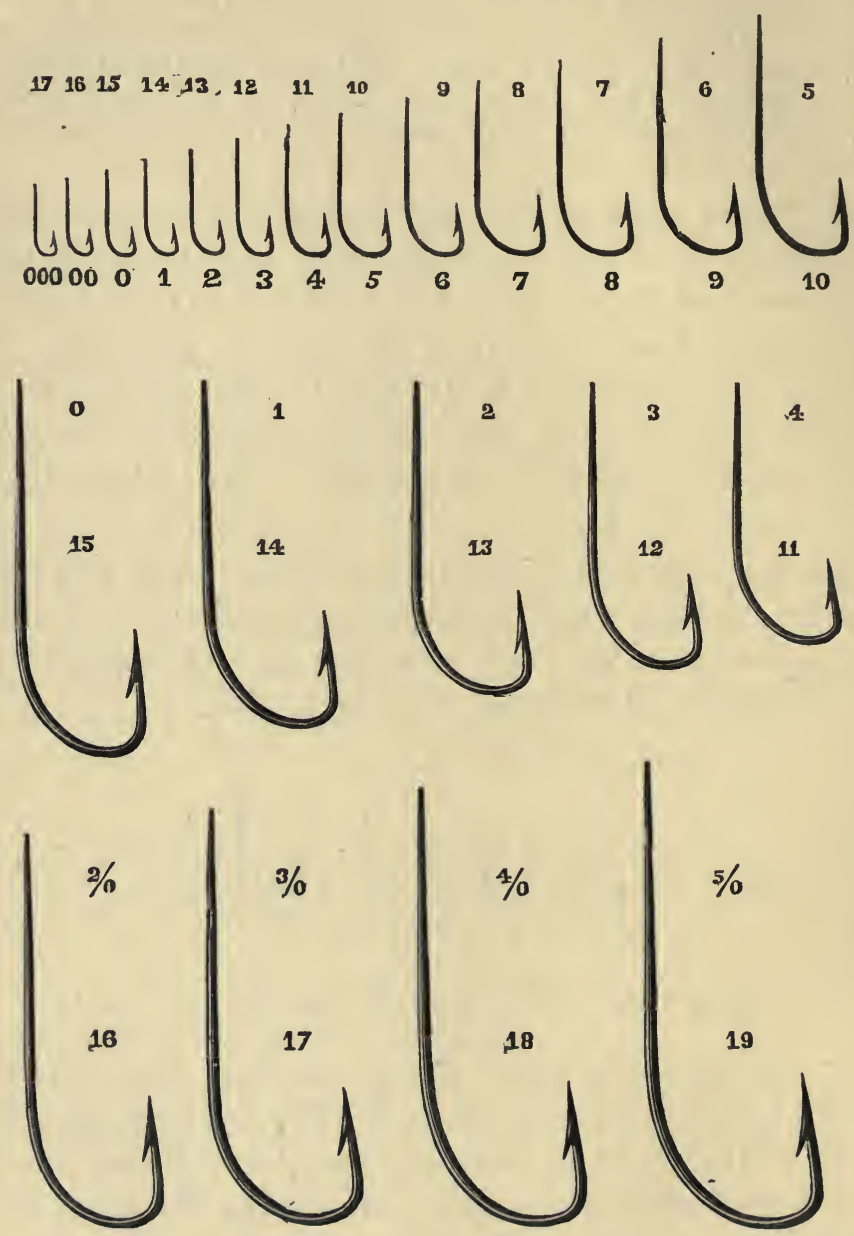

Upper figures, ' Redditch' Scale; lower figures, 'New' Scale. 
thinking portion of the angling public, and notably, during the last year or two, by American writers on the subject-e.g., Mr. H. P. Wells, the latest and most famous exponent of scientific fishing, author of "The American Salmon Fisherman," "Fly Rods and Fly Tackle," \&c.; as also by Mr. Nelson A. Cheney, President of the New York Fish and Game Protection Association, and the talented co-author of the admirable American treatise "Fishing with the fly." Without recapitulating the argument, as somewhat beyond the scope of this essay, I will merely observe here that the three cardinal principles which govern the "killing" (i.e., striking, penetrating and holding power of a fish-hook) are (I) the length of the shank compared with the width of the bend; (2) the angle at which the short, or point-side, of the hook stands in relation to the shank; and (3) the shape of the point and barb themselves. In proportion as the point is fine, and conically tapered (which necessarily includes the barb not being too " rank "), so, other things being equal, will be its tendency to bury itself in whatever it comes in contact with; as the direction of this barbed point, and the angle of the short or point-side, coincides with the direction of the applied force (i.e., in this case the 'pull' of the line) "so will be its hooking and penetrating inclination; and as the shank is long in proportion to the width of the bend, so will be the general power it gives the hook in striking a fish and in holding him when struck.

It may be added that, as the greatest strain is always borne by the top angle of the bend, such angle should be formed, not 'square,' but in the strongest shape known to mechanics, viz., a curve (or the segment of a circle) sharper or more gradual according to the other conditions desiderated.

Although it is very difficult to give an accurate rendering of fish-hooks by means of wood-engraving, a glance at the preceding diagrams will I hope convince the 'educated' eye that 
an attempt, at least, has been made to combine these various essentials-giving to each its due weight and proportion-so as to bring out a mechanically reliable result.

Space does not admit of my re-producing the numerous testimonies by which the success of this effort to combine theory with practice have been publicly acknowledged-a success also vouched for by the large and growing demand for and sale of the hooks; but in the Appendix will be found some extracts from press criticisms, and a few quotations from the works of the American authors alluded to, which I read with the more pleasure because our cousins are proverbially the quickest nation in the world in appreciating and utilising new inventions.

\section{THE JAM KNOT FOK TROUT-FLIES.}

The engraving below-enlarged for the sake of readier apprehension-illustrates the principle of the Jam Knot attachment before the line is drawn tight-The tightening, of course producing the 'jam.'

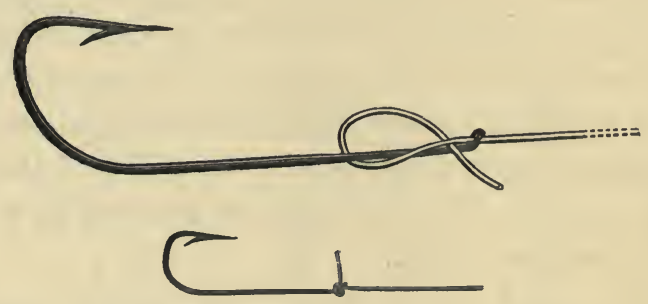

PRINCIPLE OF THE JAM KNOT.

As this cannot be so readily seen when a fly is dressed on the hook, it is represented on a hook bare.* The lower figure shows the same knot drawn tight (hook unmagnified).

* Actually, however, this knot is quite unsuited to a bare hook, as where there is no fly to keep it in its place it is possible for it to slip up the hookshank and thus loosen the jam. 
AUTOMATIC METHOD OF TYING THE JAM KNOT.

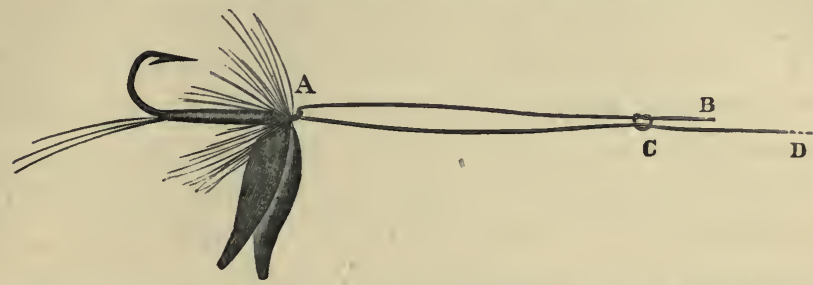

The fly being held in the left hand with the metal eye (A) turned upwards, 3 or 4 inches of the gut line are pushed through it from below. The Fly is then "let go" and a slip Knot (C) made with the gut-end (B) round the line (D). [This is the point at which the process is seen in the cut.] The slip knot is not drawn quite tight, but left as shown-just open enough to pass comfortably over the metal eye. The fly is now taken again with the left hand, and the line pulled steadily by the right, until-aided by the thumb and finger-the noose of the slip Knot passes over the metal eye of the hook, when, on the line being pulled tight, the jam Knot forms

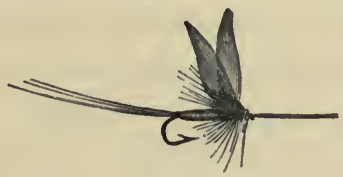

\section{JAM KNOT COMPLETE.}

itself; and the process is completed by cutting oft the waste gut-end to within $\frac{1}{8}$ or $\frac{3}{16}$ of an inch according to the size of the fly, and fineness of the gut. The finer the gut the longer should be the end left over.*

* There is no advantage in cutting off the gut too close, as the free gut end which should be left over mingles naturally with the tackles of the fly. After cutting off the waste gut it is convenient to nip the free end down with the thumb nail in the direction of the hook-bend. This may be repeated whenever the flies are examined, which, of course-as with ordinary gut-fliesthey should be at intervals, to see that the gut has not frayed at all at the head, and also that the free end has not by any accident been drawn in or shortened to the "unsafe" point. 
During the last two seasons, $1885^{-6}$, I have caught between six and seven hundred trout, weighing from a few ounces up to nearly 2 lbs., in both stream and loch, with flies dressed on the Turn down eyed hook, and attached by the jam Knot-sometimes on traces fine even to the fineness of "Bullmer's gossamer gut"and I cannot call to mind a single instance in which the Knot has been proved to have failed. Moreover (a hint to the novice) flies thus attached are very difficult to fick off.

With small flies the simplest way, when the gut becomes frayed at the head by wear and tear, is to cut or break the fly off close, disengage the waste end from the eye of the hook, and re-knot. With larger flies and stout gut the jam can generally be loosened by merely pushing the gut backwards through the eye, but this is a matter of unimportance as in either case the operation is only one of a few seconds.

The perfecting of the Jam Knot for the Trout-fly was the ingenious discovery of Mr. Alex. J. Campbell, and without it I do not hesitate to say that the general acceptance of the system of the Turn-down eyed hook which I am now sanguine enough to hope for, could never have been anticipated. The inconvenience - trifling though it was in comparison with previous methods of attaching eyed hooks - of tying the jam Knot in the presence of the fly-wings and hackles, was originally the great obstacle to be overcome. This "Knotting-on difficulty" it is, in fact, which has mainly hitherto operated to prevent eyed hooks becoming universally popular. Even in my own hook the difficulty was only incompletely met at first by an invention called a "Fly protector," to which, as it has now become superfluous, further reference is needless. The present method is simplicity itself"automatic," in fact-and so easy of manipulation in practice that the veriest tyro ought to master it in five minutes, and after a few essays to tie it by the river side, as I can myself, in 20 seconds. 
I dismiss this part of my subject with one or two brief extracts from the opinions of practical fly-fishers who have tested and adopted the foregoing system for trout flies :-

\section{“Mr. Cholmondeley-Pennell's Turn-Down Eyed}

\section{Trout Hooks.}

"Having," the writer states, "made a thorough trial of flies dressed on these hooks, against flies dressed on ordinary hooks with gut lappings," he thus sums up :-

"The result of the Week's Fishing, during which my worst day was Four Brace, and my best Nine Brace, is, on every point, favourable to the flies tied on to turn-down eyed hooks. I may summarise these points as follows :

"r. The flies never 'flick' off.

"2. They can be changed-attached and detached-in less than half the time.

" 3. They are stronger; because whenever the gut gets at all frayed at the head it can be at once shifted (re-knotted on) whereas with flies lapped on gut the weakening at the head commences very soon, and any change involves sacrificing the fly; consequently the fly is, in many cases, used long after it has become weak. But beyond this there is, I think, an actual extra strength imparted by the form of knotting to the eyed-hooks (Mr. Pennell's ' jam knot') as compared with the ordinary lapping.

"4. The Turn-down Eyed Hooks appear to me to hook more fish in proportion to rises, and to lose fewer fish after being hooked.

"I have never met with an instance of the knot slipping.

\section{Another fly-fisher writes :-}

"The 'jam knot' is the simplest and probably the strongest fastening for trout and grayling flies ever invented; whilst at the same time-owing to the hook-eye having only to be large enough to pass the gut once through it-it is also the smallest and the neatest.

"The combination of Mr. Cholmondeley-Pennell's Turn-down Eyed Hooks, with the 'Jam Knot' produces an absolutely perfect attachment, and finally solves the great Eyed-Hook problem." fly."

"The greatest boon to Trout Fishers since the invention of the artificial

For some further letters and extracts vide appendix. 
ATTACHMENT FOR BARE HOOKS.

(Sea-fishing and float-fishing).

The jam knot, as pointed out, is only applicable to flies. For attachment to a bare hook I have been hitherto in the habit of using a very ingenious knot invented by Major Turle, and known under his name.* Attached to the turn-down eyed hook it answers excellently well, as I can testify, from experience, having used nothing else for many weeks in sea and river fishing, when the catch amounted to some thousands of whiting, mackerel, gurnets, flat-fish, \&c., and also in legering and float-fishing on the Thames and Norfolk Broads for bream, roach, barbel, chub, perch, and gudgeon. But a knot has been published in the Fishing Gazette almost as I write this (under the initials "J.H.W.") which appears, I must say, to be even simpler, certainly neater, and according to the best judgment I can form without actual 'ordeal by water,'

* Major Turle's knot is tied as follows :-

1

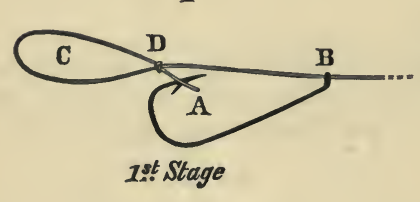

2.

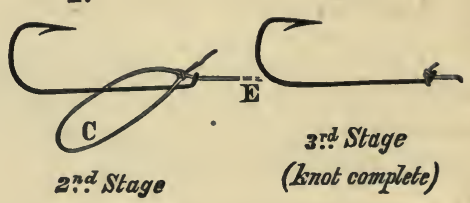

" rst Stage": Pass the end of the line (A) through the hook-eye (B), and run the hook a few inches up the line out of the way; then make a "running noose" (C) with a slip knot (D), and draw the said knot as tight as possible. "2nd Stage" : Run down the hook again (to the position shown in Fig. I), and passing the noose (C) over it, pull the line (E) quite tight-cutting off the spare end. This completes the knot- "3rd Stage." 
quite as secure as the Turle knot; and on these grounds, therefore, entitled to preference.

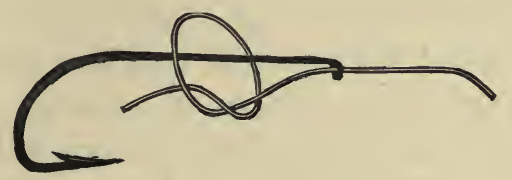

"HALF-HITCH JAM" KNOT

FOR ATTACHING A GUT-LINE TO A BARE-HOOK.

The modus operandi in tying the knot-which is really a 'jam,' with the extra security of a 'half-hitch,' to prevent it slipping up the bare shank-is so self-evident that nothing beyond the diagram -representing the knot half finished-appears to be necessary by way of explanation or instruction. When drawn tight the end may be cut off close, especially in the case of very small hooks. The knot will then, of course, rest just round inside the neck of the hook, into the eye of which it fits naturally. To prevent the 'loop slipping over the eye (outside) when tightening up, it is best to hold the gut-end with the nail or finger against the hookshank during the operation.

As I do not know its inventor's name, I will, with his permission, christen the new knot the "Half-hitch Jam."

A propos of cutting off the gut-end, I may here mention that for my own convenience, as well as, I may hope, that of other fly-fishers-and especially those using eyed hooks-I have lately designed and patented a combined tweezers (or pliers) and cutters, intended to be attached to the button-hole or carried in the waistcoat pocket (the former much best). Something of this kind, either separate or in combination, is, I may say, a positive 
necessity in the use of eyed hooks to prevent the destruction of the flies in extracting them by the fingers from the cork or felt, in which they are usually stuck for convenience of carriage ; also for cutting off worn flies, superfluous gut-ends, \&c., \&c. I think my 'combination pliers' will be found to answer the purpose effectually; at any rate, I can aver that they were the comfort of my life on a recent trouting foray amongst the Sutherland Lochs. Diagrams of the pliers (p. 45), and of the best forms of box for carrying and keeping in stock eyed-hook flies, are given later on.

I have more than once in the course of the foregoing remarks had occasion to refer to sea-fishing; and in this connection an ingenious invention of R. B. Marston, editor of the Fishing Gazette-the inventor also of the Marston Fly-rod, \&c.-deserves special notice. Mr. Marston's invention is called the "sliced hook," and, as shown in the cut, there is a second or supplemental

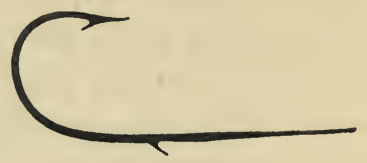

MR. R. B. MARSTON'S SLICED HOOK.

barb on the back of the hook-shank the object of which is to prevent the soft, flabby baits, such as lug worms and mussels, slipping 'down' and off as they do with an ordinary hook. I hope some day to see these hooks made with a turn-down eye and with the barb not sliced out of the shank as at present but either brazed on, or otherwise independently attached, as the experience I have had with them in sea-fishing leads me to form a high opinion, for the special purpose referred to, of the principle they embody. The sliced hooks are manufactured by Messrs. Henry Milward and Sons, and Messrs. Wm. Bartleet and Sons, of Redditch. 
Several hooks with duplicated barbs have been invented in order to give increased holding power when they have struck in a fish. Whether they fulfil this object I cannot say, not having had an opportunity of giving them a practical trial, but the most promising looking amongst them is the hook patented by Messrs. Terry and Sons, Redditch, in which there is a second or supplementary barb, at the side of and close above the hook-point.

\section{DETACHED-BODIED FLIES.}

Before taking leave of the subject of hooks for fly-fishing, and trout flies, a few words must not be omitted on the subject of "Detached-bodied flies," as adapted especially for " dry-fly fishing." These are a product of very recent years, and from the dry-fly fishers' point of view, at any rate, are doubtless entitled to be classed amongst " modern improvements."

If not the actual inventor of the system of detached-bodied flies, Mr. H. S. Hall is distinctly its most conspicuous champion and exponent, and under his auspices Mr. Holland, of 96, Crane Street, Salisbury, has carried this branch of fly-tying to great excellence.

The cut shows the general appearance of a detached-bodied fly ; the 'body' in this case being composed of light reddishbrown indiarubber.

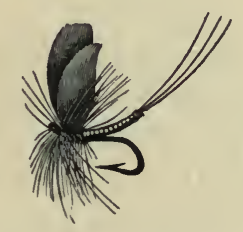

\section{DETACHED-BODIED FLY.}

The bodies are made sometimes of indiarubber, and sometimes of horsehair. The rubber-bodies appear to be preferred for the duns generally, the wings and hackles being selected so as to 
match with the colour of the rubber. Mr. Hall, however, uses horsehair in the bodies of some of the paler and more delicatetinted "intermediate duns," as he has christened them; also for the 'Jenny Spinner' and 'Red Spinner.' Speaking of the indiarubber-bodied "olive dun," Mr. Hall says :

" This, if carefully made, is a most killing pattern in April. Every year since I first discovered its merits on the Winnal Club water at Winchester I have found it useful, frequently killing with it when the usual favourites have been tried in vain over rising fish. The rubber body was not my own idea, though I believe I was the first to try it and prove its value.

The fly is made lighter or darker according to the colour of the rubber, and wings and hackle must be chosen to match the body. The hackle should be of a brownish olive to harmonise with the body, which, when held up to the light, has a translucent appearance, as like to the body of a natural dun as it is possible to obtain. It is only in the early spring that I ever do much with this fly, and then I use it on a No. oo hook. It is extremely difficult to tie it small and delicate enough for summer use, but I have killed with it in August on a ooo, the smallest size made. For late summer and autumn I generally adopt horsehair bodies, as the hair can be dyed different shades, and can be used of a pale watery hue which cannot be got in indiarubber. I am never without a few of these detached-bodied duns, and they have again and again procured me sport when all else failed; but it must be distinctly understood that they are only killing because of their close resemblance in colour and transparency to the natural insect. Some people seem to think that it is the detached projecting body which makes the fly attractive, and so they tie detached bodies of quill and silk, which are, of course, dull and opaque, and very inferior to hair or rubber. In fact, I consider it is labour wasted to tie detached bodies except of translucent material ; and if silk or quill be used, it is far better to use it on the hook in the ordinary way."

The rubber-bodied fly in the engraving is tied on one of $\mathrm{Mr}$. Hall's own patterns of hooks, with the eyes turned up, and large enough to allow the gut to pass through twice (in and out). They are attached by the "single slip knot," the principle of which is explained at page 32 . This knot when tied is perfectly secure, but the tying of it, especially by the river side, or when perhaps a 'half a gale ' is blowing, has always appeared to me a practically insuperable objection, so far as the ordinary run of fly-fishers are concerned. 
Detached-bodied floating flies can be obtained from Mr. Holland and other fly-tyers and tackle makers dressed either on Mr. Hall's Hooks or on mine.

\section{PIKE-SCALE FLIES.}

The Pike-scale, used as a substitute for the wing-feather in certain flies, is another modern innovation. That it is an ' improvement' my experience does not enable me to avouch; but it has strong advocates for dressing the "Black gnat," to which, as it has been pointed out, the ordinary "fluffy little lump" does not bear the slightest resemblance. The late Mr. Jas. Macnee, of Bohally, Pitlochry, N.B., who was the "inventor" of the Pike-scale wings, wrote to me recently that he found they were not a success with large flies, but that they did well on "a number of the Spinners" and on the Black gnat. Of flies that will take the Pike-scale wing, the best, Mr. Macnee says, is the "Marston'-" it will kill any time after May."

\section{"INVISIBLE DOUBLE HOOKS."}

One other ingenious novelty may be briefly noticed-Messrs. D. and W. H. Foster's so-called "Invisible Double Hook," to

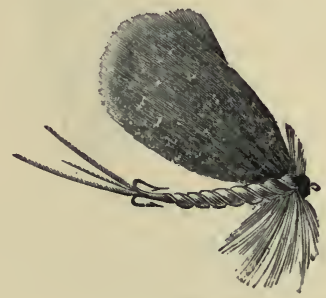

which various advantages are ascribed. The most prominent is indicated in its name. A May-fly dressed on these hooks is here represented, and the other cuts illustrate the appearance of the fly and position of the double hooks in relation 
to wings, \&c., when seen (A) from above, and (B) from below. The inventors claim that in the latter case "the hooks taking a

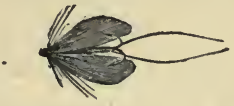

A.

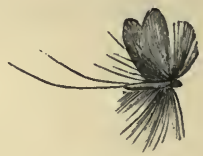

B.

horizontal position, whilst the wings and legs are outlined perpendicularly, the former are not 'outlined' at all."

FLIES WITH THE HOOK-POINT TURNED UP.

A fascinatingly novel suggestion has been made by the Editor of the Fishing Gazette, for tying floating flies on turn-down eyed hooks with the hook point turned $u p$, so that the hook would, according to recent theories of fish-sight, be entirely out of their range of vision.

The plan is thus described :-

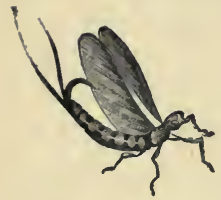

A.

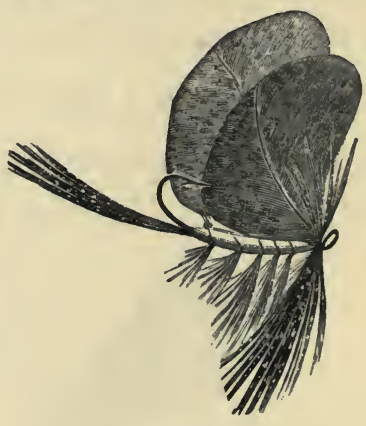

B.

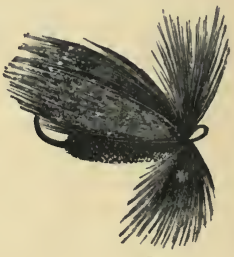

C.

When Mr. Cholmondeley-Pennell brought out his turned-down eyed hooks last year, we wrote to him suggesting that it might be a good plan to dress flies on this hook with the point turned up towards the wings, and we got Messrs. Woodfield, of Easemore Works, Redditch, to make some hooks for us specially for dressing flies with the hook in this position. Mr. Holland dressed some flies on them for us, and we found that they floated splendidly, and in ten casts out of a dozen " cocked" on the water, wings up, like life, the point of the hook being out of the water, and, therefore, less visible to the fish. Fig. A represents a Natural Dun with our artificial hook in it, and is only given to 
show that a fly dressed on this hook looks more natural than one on an ordinary hook. Fig. B represents a May Fly, from Mr. Halford's book "Floating Flies," dressed on one of our hooks, and Fig. C represents the Alder, which suits the hook best of all, because on it and the other flat-winged flies the wings almost entirely hide the hook. We cannot say that we found these flies kill better than the ordinary kind, but our experience of them has been but small at present. Mr. Holland says they are more difficult to dress, and he has to charge 3 s. a dozen for them.

This certainly does not seem an excessive price for any kind of fly tied by such an artist in his profession as Mr. Holland. Moreover, as I have often pointed out to tackle-makers, price, in reference to eyed-hooks and flies dressed on them, is practically of ' no consequence.' In the first place, people will have the best thing whatever it costs; and, in the second place, flies tied on eyed hooks out-last so many times those tied on gut that, "fly for fly," they must always be in the result infinitely cheaper. Thus, if there really were any valid reason why "eyed-flies" should be dearer than "gut-flies"-even to the extent of costing doubleno one need hesitate as to which was the more economical investment. But the whole talk about the "extra trouble and extra expense," entailing "extra price," is, in fact, the veriest moonshine ; and instead of being dearer, eyed-hook flies ought on every commercial ground to be rather the cheaper. Here is a simple sum in arithmetic: The figures refer to fies of the ordinary small sizes used in stream fishing, and the prices quoted are, of course, those of the wholesale dealers.

[As I am told I have no business to divulge ' trade secrets,' I have omitted from the press sheets the figures of my little arithmetical calculation; they conclusively showed, however, that trout flies dressed on eyed hooks ought to be cheaper by about 20 per cent. than the same flies tied on gut.] 
As with the 'cost,' so, in my experience, with the 'trouble'-it is less, not greater-an opinion corroborated by other amateur fly-tyers. In fact it is almost a self-evident proposition that a process in which there is less to be done, must, cateris paribus, be quicker than one in which there is more. The process is shortened and simplified by there being no gut lapping to do; and it is made easier in the presence of the hook-eye, which facilitates the tying of the wings, and "finishing off,"-forming a sort of 'head' over which the lapping cannot slip. . . .

However, it is no part of the design of this book to enter, as a general thing, into questions of cost. Fishermen are quite well able to take care of themselves, and I have done my part if I can advise them what is the best thing to get. The price at which they get it is a matter beyond my province.

\section{SALMON HOOKS.}

Some, at least, of the advantages which in the preceding pages are claimed for the turn-down eyed hook as applied to Trout flies and smaller sized hooks generally, may also be thought to belong to it for the dressing of salmon and grilse flies, and generally for all hooks which are used of large sizes and intended for heavy work. The most obvious advantage is that the fly-often an expensive affair-will certainly last as long as silk and feathers hold together, instead of its life being limited by the duration of the gut-link or gut-loop to which it is attached. 
The advantages, however, of extreme rapidity and facility of attachment which the trout-fisher, using smaller hooks, derives by virtue of the Jam Knot, are not here attainable, as it is not found in practice that the principle of the Jam knot can be satisfactorily extended to salmon hooks.*

Such as they are, however, the conveniences incident to the use of tnrned-down eyed hooks attached direct to the casting-line have already found them many adopters and advocates amongst salmon-fishers, whilst the mechanical advantages already explained in regard to my special pattern-the "Pennell Limerick"-in striking and holding power, remain in full force.

With regard to the knot for attaching the eyed salmon and grilse hook to the line, the strongest, as well as on the whole the easiest of manipulation, is shown in the engraving :

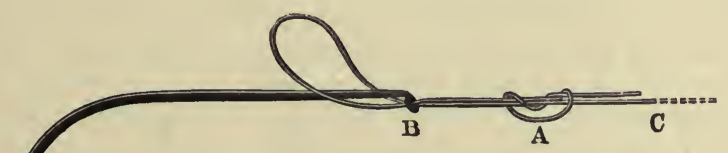

DOUBLE SLIP KNOT ATTACHMENT FOR SALMON FLIES.

The knot which may be called the "Double Slip," can be actually manipulated in several ways, one of which, in very

* Except N.B. where a casting line entirely of twisted gut is used, in which case the Jam Knot is not only the best, but often the only really workmanlike mode of attachment. 
common use, is given in the foot-note.* But where the gut is not of very unusual thickness (so thick in fact that, when doubled, the doubled end will not pass the eye) the following will be found in practice the quickest and easiest mode of tying it. The knot itself when finished is the same in both cases :

Take the end of the gut line and make with the last 4 or 5 inches of it a loop, with a double slip knot [as described in the last paragraph of the foot-note below]. Draw the slip knot itself quite tight, and straighten out the loop between the finger and thumb so that the doubled end of it is as small or pointed as may be. Push this end into the eye (in the direction shown in the last diagram) and draw the whole of it through until the slip knot presses into and against the outside of the eye, where, after 'spreading' out the loop upwards over the fly, hold the knot firmly between the nails of the thumb and fore-finger of the left hand,

* Take the hook by the bend between the finger and thumb of the left hand, and with the eye turned downwards in the position shown in the diagram; then-the gut being first thoroughly well soaked-push the end, with three or four inches or so, down through the eye (B) (towards the point of the hook); then pass it round over the shank of the hook, and again, from the opposite side, downwards through the eye in a direction away from the hook's point (the gut end and the main line will now be lying parallel); make the double slip knot $(A)$ round the main line $(C)$, and pull the said knot itself perfectly tight; then draw the whole loop of gut, together with the knot $(A)$, backwards (towards the tail of the fly) until the knot presses tightly into, and against, the metal eye of the hook $(B)$, where hold it firmly with the nails of the fore-finger and thumb of the left hand, whilst with the right hand the main line is drawn tight, thus taking in the "slack" of the knot. When finished, cut the superfluous gut end off close.

[To tie a Double Slip Knot: Make a single slip knot $(a)$ and, before drawing it close, pass the

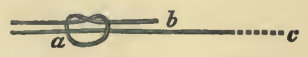
gut end $(b)$ a second time round the main line $(c)$, and then again through the .oop $(a)$, when the knot will be like (A) in the larger diagram. To finish, pull the end of the gut (b) - gradually, and at last very tightly-straight away; in a line, that is, with the main line $(c)$.] To tie this, and all other water-knots, the gut must, of course, be thoroughly well soaked. 
whilst with the right hand the main line is gradually drawn quite tight. Now cut off the superfluous gut and the knot is finished.

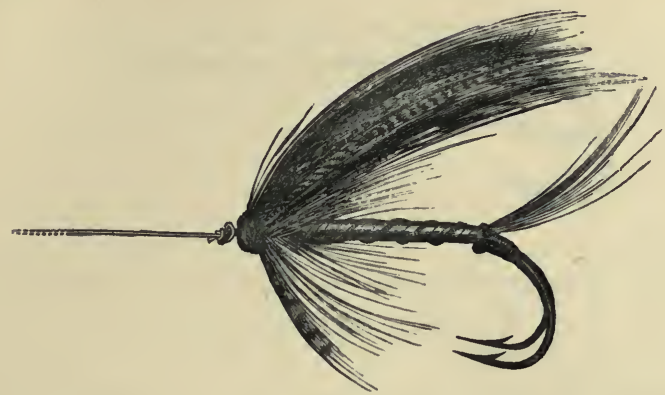

TURN-DOWN EYED SALMON FLY, ATTACHED BY DOUBLE SLIP KNOT.

This is the strongest knot that can be tied, as the gut is doubled at the point where the greatest strain and friction occur, and it will be observed by the diagram-a facsimile-that it is in every respect smaller and neater than the knot formed by attaching the casting line to a gut loop, especially if the loop be one of twisted gut. In tying the 'slip knot' according to the instructions given, the point which demands care is not to enclose any of the feathers or hackles in the loop whilst the 'slack' is being drawn in. Precisely the same care, however, is necessary where this knot-the only one, N.B., that is thoroughly sound and workmanlike-is applied to a salmon fly dressed with a loop of gut; and in the case of the metal-eyed salmon fly I can easily tie the whole thing complete under a minute.

Some salmon-fishers are satisfied with a single slip knot instead of a double one, but I prefer the latter as it is decidedly stronger, and the fractional difference on the score of neatness is hardly noticeable. 
The attachment with a single slip knot in process of completion is seen in the wood-cut (repeated here for the sake of

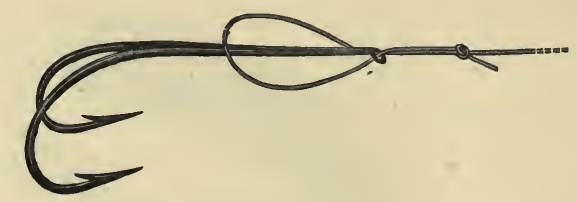

DOUBLE TURN-DOWN EYED SALMON HOOK, AND SINGLE SLIP KNOT HALF FINISHED.

convenience), where a double-hook, bare, is represented as showing more clearly the form of knot. I may here repeat that all the sizes of my Limerick bend above No. 8 ('New' Scale) can be obtained double.

An important improvement in the way of making the eyes of my salmon hooks has recently been introduced at the suggestion of $\mathrm{Mr}$. J. A. W. Whitmore. That gentleman pointed out that any objections which might be made to the eye of the hook on the ground of the tapered end by possibly fraying against or cutting the gut, would be obviated by manufacturing the eye with the tapered end turned backwards along the shank, in the manner shown in the engraving,

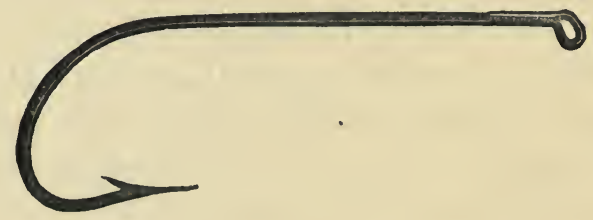

instead of being finished off abruptly as in the original pattern.

This I think cannot but fail to be a decided advantage, and I propose in future to have all the sizes of the "Pennell Limerick" intended for salmon and grilse flies manufactured accordingly. 
Mr. Whitmore's invention furnishes another illustration of the number of small points which in the aggregate go to the making up of a perfect hook.

In the successful manufacture of eyed hooks especially, the utmost nicety, care, and attention are required on the part of the makers, the slightest deviation either in the angle at which the hook-eye is set, or in the diameter of the eye itself, making the whole difference between success and failure-between perfection or imperfection in the knot, and in the accuracy or inaccuracy of the horizontal line at which it is all-important the fly should stand in relation to the gut. A different angle, again, is necessary for the eyes of large flies, to be attached by the slip knot above described, and for the smaller sizes attachable by the jam knot. That there must be a marked difference in the diameter of the eyes is, of course, obvious, as in one case the eye should only be large enough to allow fine gut to pass through it once, and in the other to admit of very stout gut being readily passed through it twice.

The same attention and care are also required in maintaining the exact bend of the hooks themselves, and for my own satisfaction, and the security of those who may be disposed to give my system a trial, I have found it absolutely necessary to appoint as sole manufacturers, Messrs. Wm. Bartleet and Sons, the wellknown and long-established hook-making firm of Abbey Mills, Redditch (London House, H. Walker and Co., 53, Gresham Street, E.C.), who have for some time past supplied the wholesale trade. At almost all the more important tackle shops my hooks can now be obtained, and I venture to advise intending essayists to ask for, and, as the advertisements say, 'see that they get,' the real thing. To facilitate this, as well as for my own protection, I have lately registered a "Trade-Mark," (facsimile annexed) which should be exhibited on every genuine packet or box of hooks, with the name of "Wm. Bartleet and Sons," underneath. 
REGISTERED TRADE MARK.

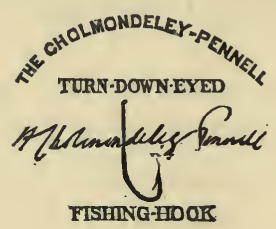

MANUFACTURED SOLELY BY WM. BARTLEET AND SONS,

ABBEY MILLS, REDDITCH.

As I mentioned, I have secured a patent for the turn-down eyed hook in America, where the hooks can now be obtained of Mr. Thos. J. Conroy, the principal Fishing Tackle Maker, of New York, of Mr. Charles F. Orvis, Manchester, Vermont, and at other of the more important establishments in different parts of the United States.

A letter recently published in the Fishing Gazette explains the principle on which the 'new numbering' is based-viz., a correspondence between small hooks and low numbers, and large hooks and high numbers. Thus it will be seen the scale ascends from oo० (the smallest), ০০, ০, I, 2, 3, \&c., up to I9, the largest sized salmon hook for which I could find room in the engraving. This last number (I9) corresponds with about No. 5/0 of the ordinary Redditch scale ; whilst my 000 is equal to No. I 7, and my No. I to No. ${ }_{4}$ 'old style' :-

A UNIFORM SYSTEM OF NUMBERING HOOKS.

The following are copies of letters we have received on this subject :-

From H. Cholmondeley-Pennell, Esq.

SIR, - I most cordially concur in the Editorial endorsement of the sug. gestion made by your correspondents, "F.R.C.S." and "M.R.C.S.," as to the present state of "intolerable confusion" that reigns in regard to the numbering of hooks. It also appears to me that the system suggested by you of counting upwards from $000,00,0,1,2,3$, \&c., right on to the largest 
sized salmon hooks, is that which is on every ground the most desirable for adoption, forming as it does a uniform standard for all hooks of the sizes most commonly in use, with a convenient elasticity at each end of the scale for the addition of exceptional sizes, whether large or small.

This plan is at present adopted, I am informed, only by one firm of hook makers, but they are recognised as being amongst those of the highest and longest standing. I refer to Messrs. Hutchinson and Son, of Kendal. For many years this firm made my special bend of hooks, which were, of course, numbered as above, with, I believe, every advantage on the score of simplicity and convenience to all concerned. I also adopted this system in the limited number of sizes of the "Pennell-Sneck," originally published in the columns of the Fishing Gazette. But in the latest of my patterns of hook-bend, the " Pennell Limerick," as made both with tapered shanks (plain) and with turndown eyes, I allowed myself in a weak moment to be over-persuaded into re-adopting the old-fashioned, crude, and illogical method of numbering, beginning with 17 for the smallest number, and reducing for the largest size down to No. I, thence remounting with $0,2 / 0,3 / 0,4 / 0,5 / 0$, \&c. - this last another outrage not only on one's sense of the "fitness of things," but also on the previous part of the same scale.

Peccavi! Convinced, however, of the error of my ways-or, rather, of the latest of them-by the unanswerable Editorial logic and the indignant eloquence of your correspondents, I am now prepared to recant my heresy, and as an earnest of my conversion, or rather reversion, to a better mind, I have directed the offending numbers to be forthwith expunged; and in the little brochure I am now writing, "Modern Improvements in Fishing Tackle and Fish-hooks," they will appear in the amended [as well as in the original] form.

I am all for progress-progress always and in everything, even in small things-and I gladly enrol myself in the (apparently) somewhat select, but doubtless determined, band of " Hook Numbering" reformers. - Your obedient servant,

\section{H. Cholmondeley-Pennell.}

From Messrs. Hutchinson and Son, of Kendal.

DEAR SiR, - In reply to your favour in reference to numbering of fishhooks, we have pleasure in stating that the superfine Kendal fish-hooks, manufactured by our firm for over a century, have always been, and continue to be, numbered from the smallest size upwards. Our sneck bend hooks commence at 000 ; round, Kirby, and Limerick bends at No. 00 ; Sproat's and Pennell's bends at No. I.* Of course, the No. I of the various shapes are about equal in size. We beg to inclose drawings of a few kinds of hooks, with numbers attached, and remain, faithfully yours,

Hutchinson AND Son.

* This bend is now obsolete. The 3 smallest sizes, coo, $\infty$, and $\circ$, were never made. 
The other hook-makers, with one consent, agree in a general non possumus! However, this is a matter which anglers, and especially angling authors, have practically in their own hands; and I don't doubt that hook-makers will eventually find themselves obliged, for their own interest's sake, to adopt one logical and uniform system of numbers.

The so-called "Redditch Scale" is, in reality, no 'scale' at all, because every Redditch Hook Maker introduces apparently his own variations, and with the remarkable result that in some cases there are positively several sizes of difference between hooks of the same bend and bearing identical numbers ! If I am asked to give 'Chapter and Verse' for this somewhat startling statement, I refer the reader to a letter published in the Fishing Gazette of the 25th Dec., $\mathbf{1 8 8 6}$, in which I adduce actual examples of the discrepancies alluded to.

\section{BOXES FOR EYED-FLIES.}

The growing demand for eyed-flies has produced a corresponding supply of the requisites especially appropriate for their use. First amongst these are suitable boxes for storing flies, and for carrying them in the pocket at the water side-a distinction however which in many instances resolves itself into one simply of size.

A full sized box for Trout-flies-intended for pocket purposes, the invention of Chas. Farlow and Co., I9r, Strand, London-is made of japanned tin (black outside and white inside), divided with strips of cork, each piece of cork supported by and fitted into a tin groove to prevent its moving as well as to enable the cork to be replaced when worn out. Weight of box, 6 oz. ; length, 6 in. ; width, $3 \frac{1}{2}$ in. ; depth when closed, $\frac{3}{4}$ in. Arranged to hold 7 doz. flies (registered). 
Among the advantages of this box it will be noticed that when the flies are stuck in the cork, the wings and hackles come between the divisions, thus preventing the flies from being in any way crushed-an advantage, it may be observed in passing, much more important than is often imagined. Flies that have been well

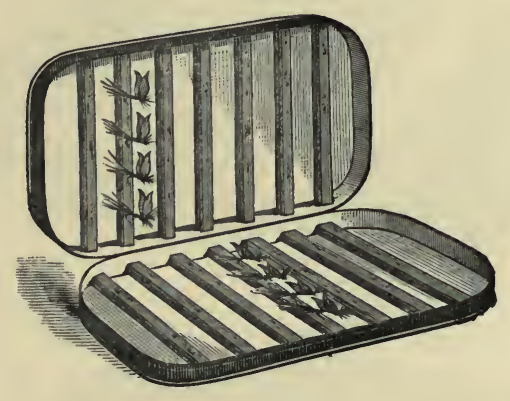

EYED TROUT FLY BOX.

squeezed in a fly-book certainly lose some of their original 'crispness' and life-like play of wing and hackle, especially when first put on the casting-line, and it may be much doubted whether they ever entirely regain what has been thus lost.

The fly-box figured can of course be made of any size, to suit the purpose either of a stock box for trout flies, or of a pocket box for carrying salmon flies.

Several fly-books, constructed with a box between the leaves, and lined either with cork or felt, are also made. One of the best I have met with is the registered (or patented) invention of Messrs. Wm. Bartleet and Sons, of Redditch (explanatory illustrations appended). I adopted a somewhat similar plan a few years 
ago for the purpose of carrying artificial minnows in my fly-book, and $\mathrm{I}$ found the arrangement in every way a convenient one.
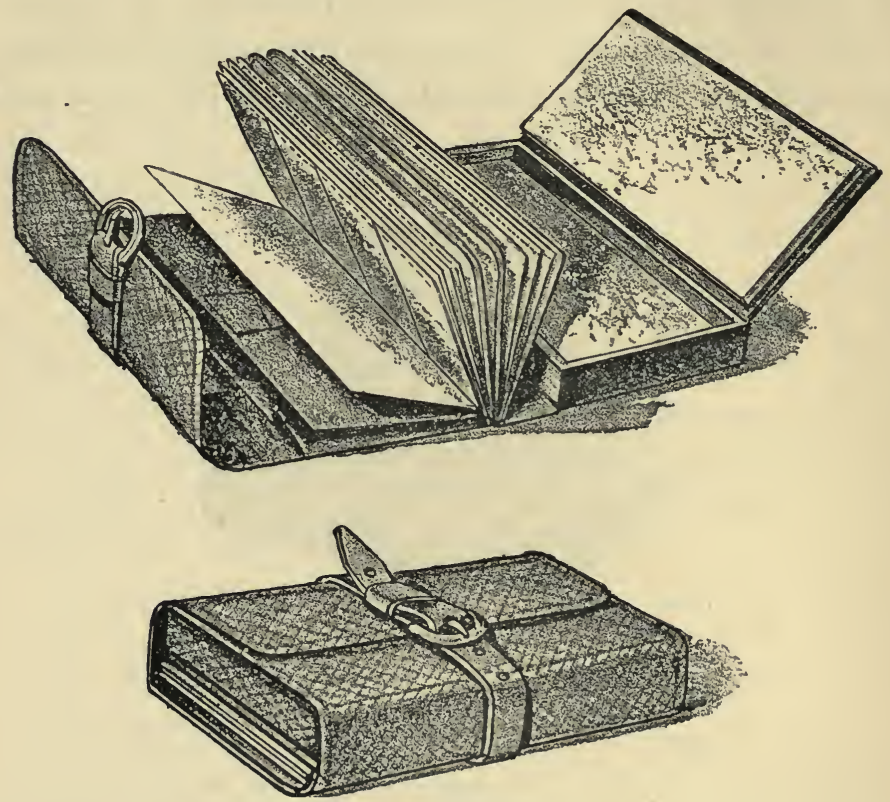

FLY BOOK CONTAINING BOX.

It should be here observed that cork linings for fly boxes are in every way preferable to linings of felt, as when flies or hooks get stuck at all deep into felt they are exceedingly difficult to get out again, even with the assistance of tweezers or pliers, and by the fingers are almost impossible of extrication. This fact I discovered by practical experiences the reverse of agreeable on getting my first supply of eyed fly boxes. They were in shape oval; about $3 \frac{1}{2}$ inches long by $2 \frac{3}{4}$ broad, and admirably adapted for carrying in the pocket the selection of flies necessary for a day's fishing. These boxes, which I obtained from the inventors, 
Messrs. Chevalier Bowness and Bowness, of 230, Strand, are now lined all over-or more correctly, all inside-with corrugated cork-i.e., cork cut across and across in 'ruts.'

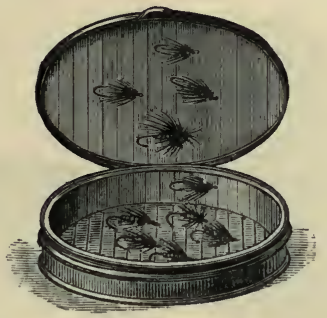

BOWNESS'S 'POCKET BOX' FOR EYED-FLIES.

I may notice in this connection-although intended for use not with eyed flies but with 'gut flies' - an ingenious patent of Messrs. F. T. Williams, Fishing Tackle Makers, of ro, Great Queen Street, London, the object of which is to keep the gut-or at any rate that part of it nearest the fly-straight and ready for use, instead of curled up and often entangled, as is the case with flies carried in the ordinary fly-book. The box is of japanned tin, with rounded corners, for convenience in carrying in the pockets, and

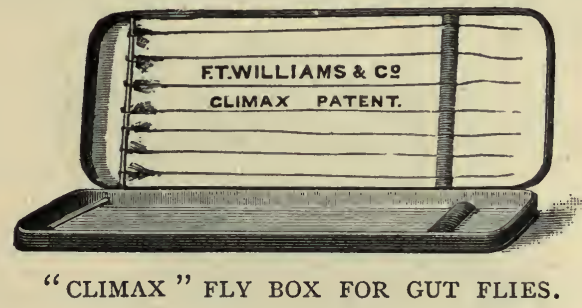

inside are arranged springs, as shown on the right hand side of the diagram, which keep the links of gut stretched and each in its separate place.

Messrs. Williams are also the inventors of a fly-carrying box designed, by means of felt linings, to keep the gut links of the flies 
always damped and ready for use ; and of a further modification of the same idea as regards casting lines by means of a succession of circular tin boxes, fitting one within the other, and coated with

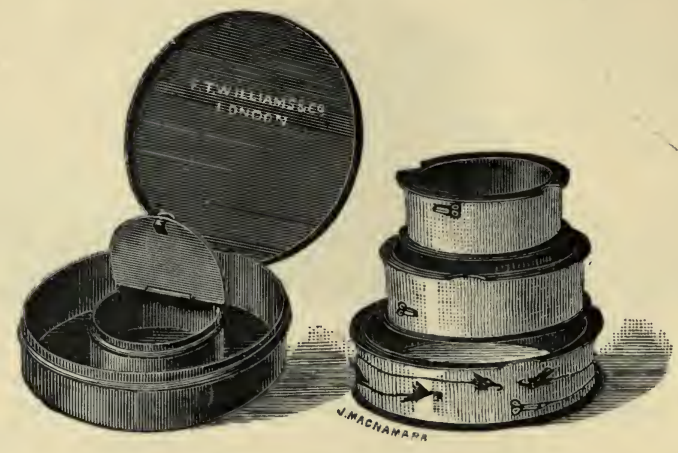

THE "LATHAN" CAST BOX.

felt which may be kept either wet or dry. The outside box measures $3 \frac{1}{2}$ inches in diameter by $\mathrm{I} \frac{1}{2}$ in height, so that it is not at all unwieldy or over-large for pocket or pannier. To the flyfisher using gut flies this ought to prove really valuable, as he can thus carry half a dozen casts already damped for use, should he want a change.

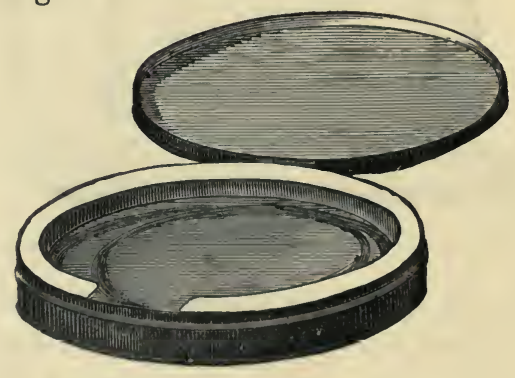

THE "SAFETY" CAST BOX.

Another ingenious novelty is the 'safety cast box,' made by 
Farlow. The all-round rim keeps the casts in when not wanted to be taken out, and the break in front facilitates their being taken out when not wanted to be kept in.

Many years ago I had in my possession a book for gut flies, containing also the names and descriptions of the flies, taken from Ronald's Fly fisher's Entomology, with the months for which they were most appropriate - a plan that, for the disciples of the "Exact Imitation School," possessed advantages. Whether Ronald's fly book is still "published" I am unable to say, but I do not remember having met with it of late years. More recently a fly book on an analogous plan was brought out by the then angling Editor of the Field newspaper. This also is, I believe,

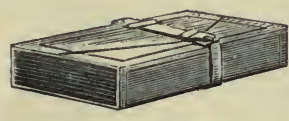

FOSTER'S

NEW FLY BOOK

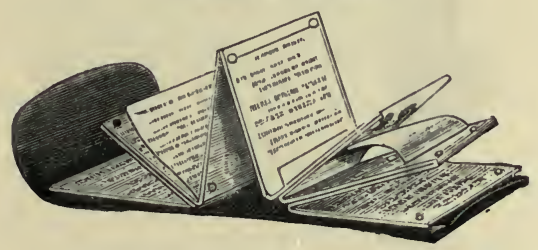

now "out of print." Mr. Farlow, however, sells a book in all respects similar, the name of the author only excepted; and more recently still, Messrs. Foster, of Ashbourne, have registered, or patented, two books on similar principles, the one for trout and grayling flies, and the other for salmon flies. An illustration of the latter open and closed is annexed. 
Of 'stock boxes' for eyed salmon flies, Messrs. Farlow have lately brought out two-or rather they manufacture two boxes of the same kind but of different sizes. 'The measurements of the larger are: Length, I $3 \frac{1}{4}$ inches; width, $10 \frac{1}{4}$ inches; depth, 6 inches.. This box, which is made of oak, and air-tight to preserve the flies from deterioration by damp, contains 6 trays, like that shown in the engraving, 3 with 6 strips of cork, and 3 with 5 strips. It is calculated to hold two gross of flies.

The smaller size, the ' make' of which is in all respects similar, is 10 inches long, by 7 inches wide and $5 \frac{3}{4}$ inches deep. It

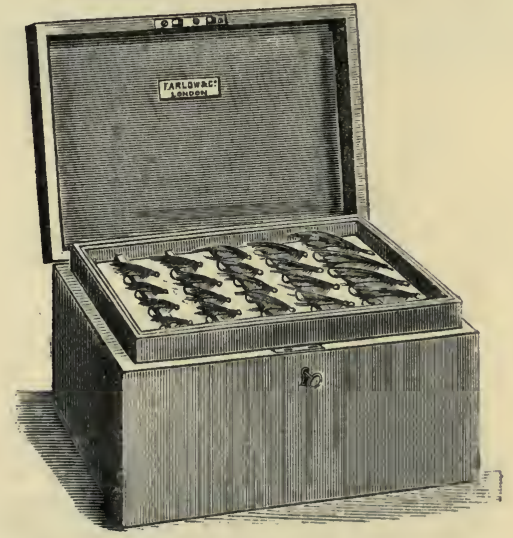

STOCK-BOX FOR EYED SALMON-FLIES.

contains 6 trays -3 with 6 strips of cork, and 3 with 4 strips suited for the largest sized flies. This box will hold about fifteen dozen flies. Outside cases of leather are fitted if desired to ensure extra safety in travelling, \&c.

For carrying double-hooked salmon and grilse flies in actual use, I can cordially recommend a very capital fly-box invented by Mr. J. Ashley Dodd, figured in the wood-cut. The box, which is 
practically water-tight, 8 inches long, by 4 inches wide, and $\mathrm{I} \frac{1}{2}$ deep, is of Japanned block tin, lined with cork, and the little strokes or line-marks, seen in the engraving, represent so many metal points or pins projecting from the cork in a sloping direction (say at an angle of about $25^{\circ}$ ), and over which the loop or eye of the hook slips. A slight pressure backwards then imbeds the

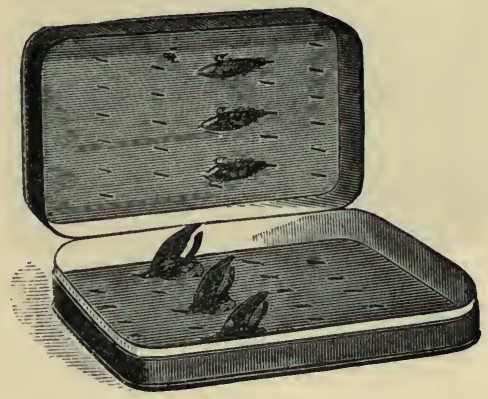

DOUBLE EYED-HOOK SALMON FLY BOX.

points of the hooks in the cork. This double attachment forms a perfectly secure 'hold,' whilst admitting of the flies being taken out and replaced with the utmost facility and rapidity.

As double-hooks for flies, especially of the smaller sizes, are coming more and more into popular favour, Mr. Ashley Dodd's clever invention (which is manufactured by Messrs. Farlow) supplies a want likely to be increasingly felt by salmon-fishers. For single-hooked flies the box is equally good.

Another capital salmon fly box on a somewhat larger scale, capable of holding about roo flies, the ingenious invention of $\mathrm{Mr}$. P. D. Malloch, of Perth, is figured in the wood cut over leaf.

In this case no cork, nor substitute for it, is employed. Each fly is held securely in its place by the bend of the hook slipping over a 'notched' steel spring, which forms (by being soldered or 
brazed on) a part of the solid framework of the box. Mr. Malloch's invention, it will be seen, presents some excellent features, as well as serving either for a small stock-box or a large

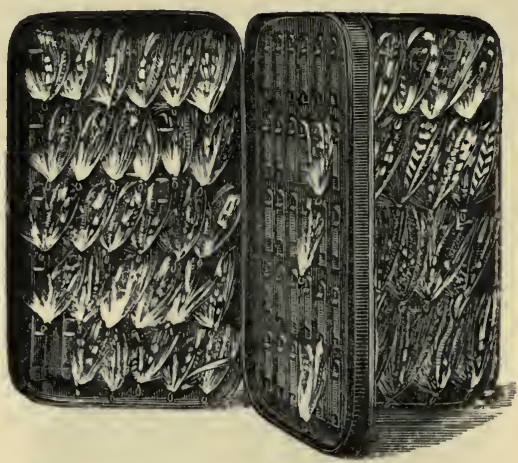

PORTABLE SALMON-FLY BOX.

pocket-box. It is made of Japanned tin, the measurements being: length 8 inches; width 5 inches; depth $1 \frac{1}{8}$ inch.

Several new designs for general tackle-boxes and for spinning and other pike-tackle are described in connection with the latter subject.

COMBINED CUTTERS AND PLIERS FOR EYED-HOOKS.

In quitting the subject of improved " tackle-requisites" more immediately connected with fly-fishing, and called into existence by the increasing popularity of eyed-hook flies, I may mention a little device I have elaborated and patented, designed for the double purpose of (firstly) extracting eyed flies from their cork or felt beds, and (secondly) for cutting off the waste gut-ends after the flies are knotted on to the line. As regards the gut-cutting part of the invention, something of the sort is, in fact, really a sine qu$\hat{a}$ non in all kinds of fly-fishing, where, on every change of flies, the waste gut ends of the knot, or attachment, must be got rid of 
somehow or other. To be obliged to ferret out one's pocket tweezers, and then to get at one's knife and open it and shut it and put it back again, or still worse to extract one's fly-book from the depths of coat-pocket or creel, and out of that again one's tweezers and scissors-involves an aggravating waste of precious moments, and is also trying to the temper.

For these several very sufficient reasons I tried at all the tackle shops to discover such a contrivance as was wanted-equal, that is, to the double functions of "cutting and extracting "-and which could be attached to the button-hole or carried in the waistcoat pocket. But nothing even approximately or professedly fulfilling these conditions was forthcoming, so I decided to invent one myself, and here it is.

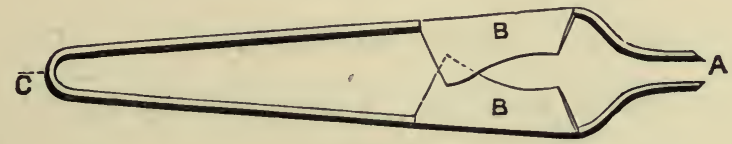

"EYED-FLY GUT-CUTTER AND TWEEZERS" (PATENT).

(ACTUAL SIZE.)

' $A$ ' in the diagram represents the Tweezers - or, as they might rather be called, very fine pliers-and ' $\mathrm{B}$ ' is the ' cutter.' At the point marked ' $\mathrm{C}$ ' a hole is drilled through the steel spring by means of which, and the intermediary of a piece of string, an attachment can be made to the button-hole. When not in use the implement conveniently occupies a place in the fly-box or book, vice scissors 'superseded.' There is a little dodge in the 'cutters,' as to which I feel some paternal pride. The spring sides (D.D.) are bevelled off, at conflicting or opposite angles, the effect of which is that when the said springs are compressed by the 
finger and thumb in the act of cutting, the edges of the cutters are brought necessarily and automatically into close contact (the same effect that is produced, in fact, in the case of scissors, by the thumb pushing one way and the finger pulling the other), and without which neither scissors nor cutters would cut.

By the time this is in print I hope the combination Pliers and Cutters will be obtainable at Farlow's and all the principal tackle shops. The agents for the wholesale manufacture are Messrs. Wm. Bartleet and Sons, Abbey Mills, Redditch; London House, H. Walker and Co., 53, Gresham Street, E.C.

\section{LANDING NETS.}

Of nets for the float-fisher, or sitter-down by the water-side, who can lay his net beside him, and seldom wants to carry it far, as well as of nets for the punt-fisher, who always gets his carried for him (as does also the salmon-fisher when he uses a net at all), there is an embarras de richesses; nets of every conceivable size, shape, and principle of construction.

These anglers stand in no need either of improvement or suggestion. 'Big enough, and long enough, and strong enough' are the simple axioms they have to bear in mind in choosing a landing net.* The Pike-fisher on the contrary—or at any rate the

* A wooden-hoop pear-shaped net, about 22 inches across by 26 ' lengthwise,' with a handle seven feet long, will be found a very good medium size for salmon. This gives a total length of $9 \mathrm{ft}$. 2 inches. Nets of this pattern and of still larger size are made, and I have handled one with a total length of $9 \mathrm{ft}$. 8 , and 26 by 32 in the 'ring'; but the latter needs a very powerful man to wield it effectively ' in action,' and I should recommend the medium size in preference under ordinary circumstances. Both sizes are, however, kept in stock at Farlow's. 
spinner-and especially the bank-spinner-should not use any net at all, but a gaff. His requirements need no consideration, therefore, under the head of "Landing Nets." But it is the case of the peripatetic and generally solitary trout-fisher, whose rod occupies his right hand, whilst his left is not infrequently employed in holding on to the support of a stump or stone, that has to be considered and catered for. It is the man who, whether with fly or worm, spends the greater part of his time up to his waist in water, and to whom return to bank, even if sure of there 'hitting off' his left net, would mean disturbance of his sport and loss of his time. It is, I say, to these fishermen that the question "what is the most perfect landing net for me?" is of real interest and of real importance. . . . I will do my best to answer the question.

There are at least four primary conditions to be fulfilled in such a "perfect net :" lightness; portability - by which is meant a "carrying position" that does not incumber the carrier or impede his freedom of movement ; facility of immediate extrication from carrying apparatus when wanted; disinclination to tumble out of it when not wanted.

One or all of the following recent inventions-or new combinations of old ones, amounting to the same thing-will be found to satisfy the requirements stipulated. To take the simplest first. This is what may be called a pocket net, made entirely of wood, and weighing only $3 \mathrm{oz}$. The diameter of the pear-shape ring is from 8 inches, its length $10 \frac{1}{2}$ inches, and that of the handle $x 4 \frac{1}{2}$ inches-total length of net and handle, 25 inches. This is the net I recommended in the "Modern Practical Angler," and it has been termed a "pocket net " because the intention is that in carrying it the bottom end of the handle, after passing through a small strap attached to the 
back of the coat under and behind the left arm, should rest eventually in the left-side coat-pocket. In this position the net is entirely out of the way. It will be found at its best in the case of the worm-fisher or fly-fisher when wading, and requiring to use the net rapidly and without leaving the water.

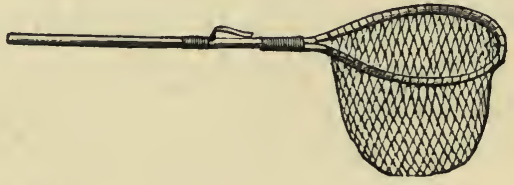

FLY-FISHER'S “ POCKET NET."

A good alternative mode of "carrying" has been added by Messrs. Farlow (who manufacture these nets), and is shown in the preceding illustration. It is a "spring hook" by which the net, instead of being supported in the pocket, hoop upwards, can be suspended from the strap of the creel or fish-bag in a reverse position. This latter arrangement is more conveniently adopted when the maker's special shoulder strap is also worn. (See cut next page.)

The measurements given above are those best suited to a net intended to be carried only in the pocket in the manner first described, and a net of this size will readily land a two-or even at a pinch and with some little ' humouring '-a three pound fish; but where the alternative method of support from the creel-strap is adopted, a larger size is very often preferred. Thus the total length of the net from which the foregoing figure is taken was 3 ft. 3 in. ; width of net, 12 inches ; 'length' $14 \frac{1}{2}$ inches; weight $5 \mathrm{oz}$. This is a good medium size. The next size smaller has a total length of $2 \mathrm{ft}$. $6 \mathrm{in}$., with a net 9 inches across by I I long. A larger size than either of the foregoing is also made. 
The net itself should in these and all other cases be made of some material dressed with oil, both for purposes of preservationavoidance of the saturation which saturates also the angler's garments-and prevention of entanglement with hooks and flies. I daresay we can most of us recollect the time when this now very generally introduced improvement in fishing tackle was practically unknown.

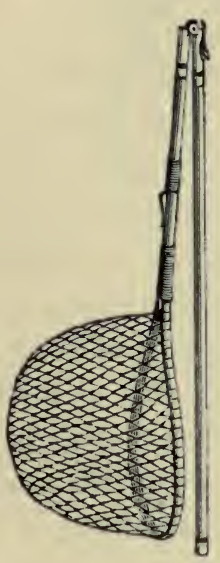

SPRING-JOINTED NET

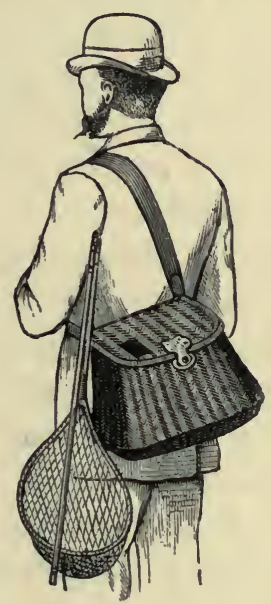

AND
MODE OF CARRYING.

A still longer handle is obtained, and without any very serious sacrifice on the score of portability, by doubling up the net-handle with a folding spring-joint (see cut, left hand figure).

The idea of this folding handle originated, I believe, with Messrs. Ogden, of Cheltenham, but it has recently been greatly improved upon by Messrs. Farlow, and in especial the "jointing" has been so much simplified and bettered-whilst being at the same time reduced in weight-as to entitle the latter firm to no small share of the honors of the invention. 
The spring hook-which, in combination with the joint, enables the net to be carried from the creel strap-is one of the improvements. By this it is suspended behind the left shoulder in the position shown in the right hand figure, which also shows the new Creel Strap already referred to.

When brought into action, say with the left hand, the spring joint admits of the handle being instantly extended-and when extended securely fixed-by simply jerking the net forwards. When the fish is landed, a pressure on the spring of the jointfigured at the top of the left hand figure-at once restores the net to its folded position, and this can be readily accomplished by the one hand simply.

The last diagrams represented folding handles and fixed nets. Nets, that is, the rings of which are always in full circumference, and always attached to their handles. There is, however, a large class of "collapsing and detachable" net-rings, some of wood, some of steel, some of whalebone, and all possessing at least one common merit-that of portability,_ " portability," that is, as it applies to the case of the traveller, or the tourist; when it is wanted for carriage in the pocket or in the rod case-whenever, in short, the net is not needed for use. In minor details, however, wide differences exist in the different degrees of merit of the different arrangements, not only as to the material of which the ring is made, but notably as to the mechanism of the attachment between the ring and the net handle. Having regard to these very important points, certainly one of the best nets now made is that invented by Messrs. Hardy Brothers, of Alnwick.

The side supports of this net are of flexible wood, and when stretched out into position-and so retained by the metal socket into which the right hand support slips-a cord stretched between the opposite points keeps them at the regulated distance, as a bow is kept bent by the bow-string. 
This net may be fitted into any kind of handle, but a handle which is the invention of Messrs. F. T. Williams and Co., ro,

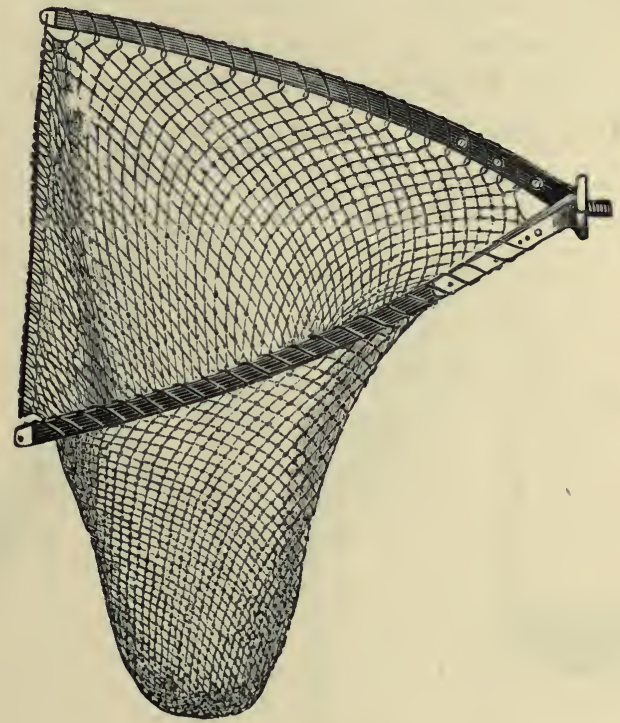

COLLAPSING V SHAPED NET.

Great Queen Street, W.C., makes, in combination with Messrs. Hardy's V shaped net, a most perfect and admirable weapon, as I can testify, having repeatedly had practical experience of its many excellencies. The flat shape of the net support at the top admits of its being more readily suspended under the fisher's left arm, or behind the elbow-the positions in which I have usually carried it myself. I may say, however, that an excellent practical angler writes to me that he finds greater comfort and security in suspending the net by a somewhat shorter strap, so that it hangs nearly against the middle of the back, just below the shoulders. 
A leather sling over the right shoulder, with a metal 'belt,' or loose sling ( $\mathrm{E}$ in engraving), in which the net hangs free, and suspended only by balance, completes the 'carrying' part of the matter. The handle (D) is of bamboo and some solid wood of the ordinary 'telescope' pattern, 2 joints. Round the ferrule of the lower (exterior) joint is a metal rim or 'stop' (C), which

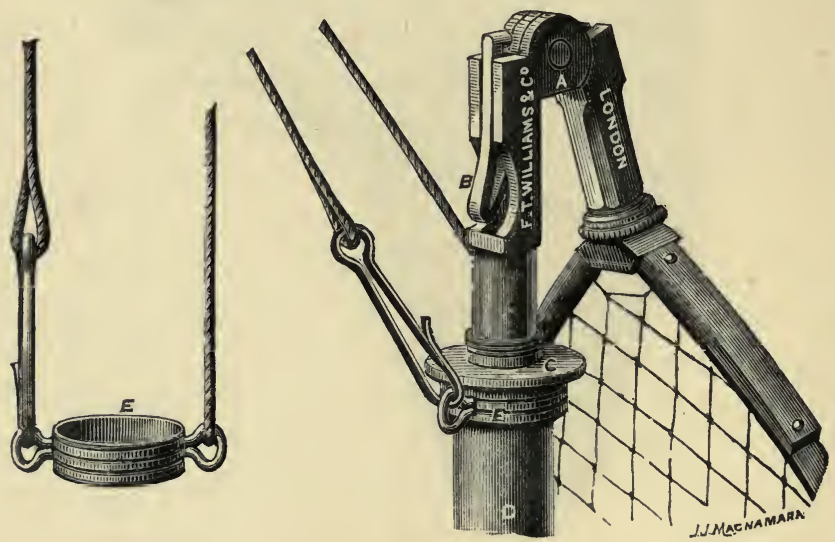

keeps the handle from slipping through the metal belt $(\mathrm{E})$. When lifted out of the sling and the handle grasped by the fisher, a sharp forward and then backward 'jerk' extends the net to its full length.

So far my description of this excellent net, not inaptly termed "The Combination" (three people having had a hand in its perfecting), tallies with the engraving.

But a further alteration has been introduced by Messrs. Williams in making the net head with a "knuckle" (A), opening and shutting by a spring joint at B. This may very possibly be an improvement; but I prefer to confine myself in describing and recommending the Combination Net to the terra firma of my 
own actual experience. The form of net I have tried is figured below.

When extended, the total length of the handle alone is 3 feet Io inches, and the net and handle combined about 4 feet ro inches. A small gaff, suited for pike fishing or other light work, can be substituted for the net at pleasure, when required.

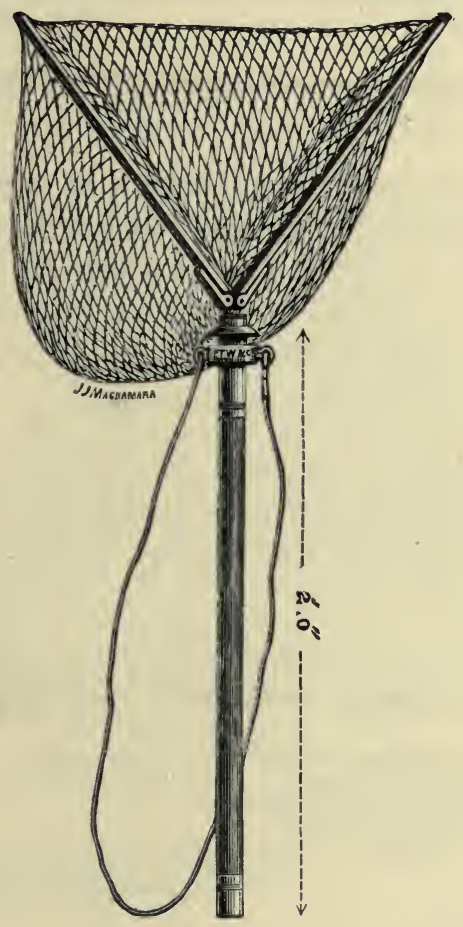

The " COMbination" Net.

The supporting sides of Hardy's $V$ net are of wood: steel is, in many cases, however, at least an equally good material. 
COLLAPSING DETACHABLE NET WITH TELESCOPE HANDLE.

The illustration represents a collapsing net with steel side supports (forming an oval when in position), the supports being 'out of action' and rolled up in their own net-folds. The figure

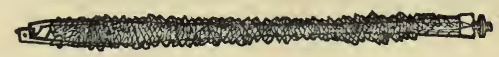

underneath it shows the simplest form of telescope net-handle with spring hook fastener. Its total length when closed and hanging on the strap is $3 \mathrm{ft}$. 3 in., of which 14 inches are represented by the net. When fully extended in use the total length is $4 \mathrm{ft}$. I $\mathrm{I}$ in. This is another very serviceable and handy net for those who prefer one with a longish reach.

Figured below is a further variety, combining two of the principles already described separately,-the net is collapsing, and the handle doubling up with a spring joint.

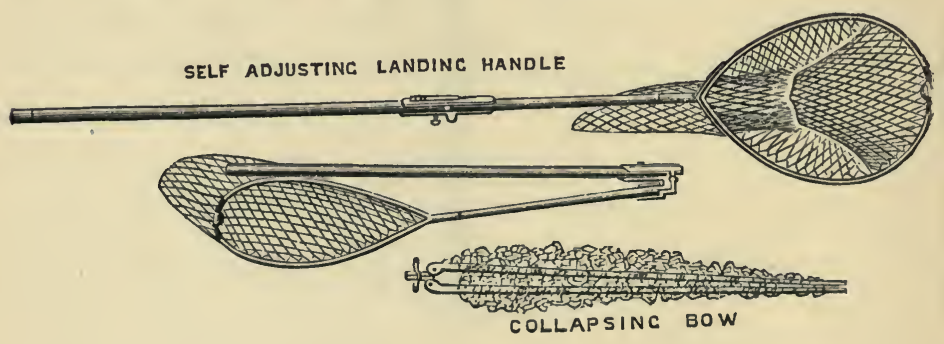

FOSTER'S COLLAPSING DETACHABLE NET WITH FOLDING HANDLE.

This very useful net is manufactured by Messis. D. and W. H. Foster, of Ashbourne. 
FISH-CREELS AND CARRIERS.

The victims, or as they have been facetiously called "net proceeds," of our skill having been duly "banked," the next question which presents itself in a most practical fashion is how are they to be carried.

In this respect fishers have no cause to complain of the advances made-and principally, to their credit be it acknowledged, by Tackle Makers-during the past few years. Messrs. Hardy Brothers, of Alnwick, led the way with their " Carry-all "Creel, in which the novelty consists in making the creel in two separate

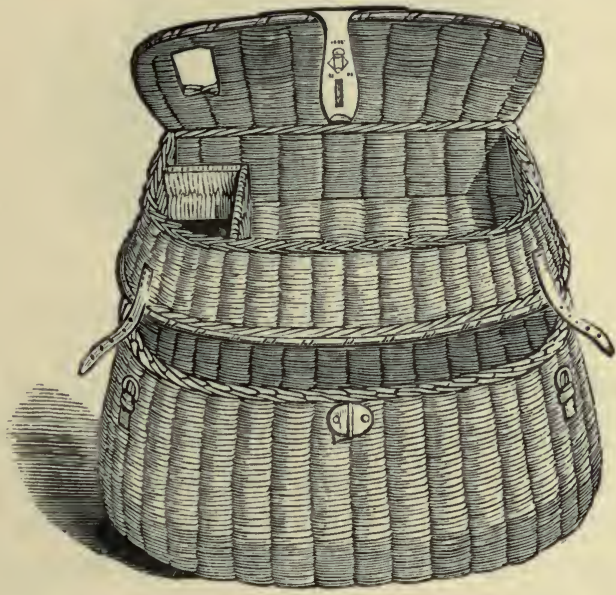

THE "CARRY-ALL" CREeL, OPEN.

parts, the lower part being intended for the fish and the upper part for containing lunch, fly-book, or other angling requisites. The upper half is pierced with an opening at the side, through which the fish can pass, as heretofore, directly into the lower half of the basket. The two halves are closed by straps at the side, when the Creel presents very much the external appearance of an ordinary wicker pannier. 
Messrs. Farlow shortly followed by registering another invention, having the same object, but effected on a different principle. The space for luncheon box, fly-book, and pocket flask is here obtained by means of a compartment partitioned off at the back of the basket.

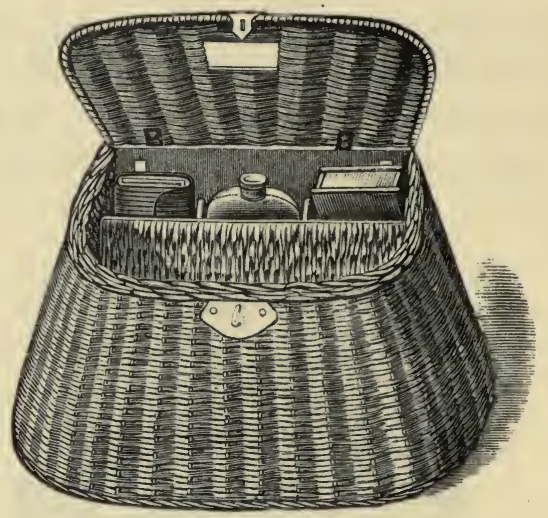

THE “ DESIDERATUM" FISHING BASKET.

In combination with their new fish carrier, though applicable to other models, Messrs. Farlow have recently registered a novel basket-carrier-a special system, that is, of straps (webbing) for securing the basket to the fisher's shoulder and waist. This prevents the creel "capsizing." In other words, having once gotten the fish into the basket, it is sought to make it impossible for him to get out again.

This latter desideratum has never been quite satisfactorily fulfilled by the ordinary single shoulder strap. In the actual business of fishing, and especially of fly-fishing, a certain amount of gymnastics, voluntary or involuntary, are often called into requisition, and in such cases the old-fashioned creel-or rather the creel slung in the old-fashioned way-had a knack of getting into awkward attitudes, incommodious to the wearer of the creel and often- 
times leading to the topsyturvying of its contents. With the method of slinging by a double strap or webbing represented in the

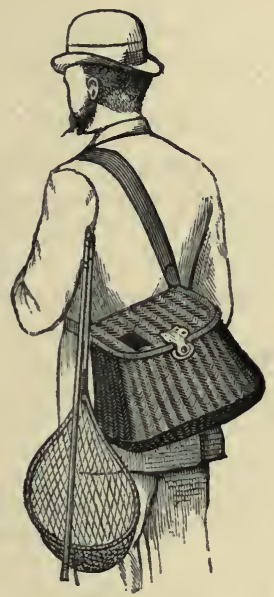

NEW METHOD OF CARRYING FISHING CREEL.

engraving (repeated here for convenience-sake) these inconvenient effects are rendered impossible. The shoulder-strap keeps the basket from falling, and the waist-strap from shifting its position, however erratic the gyrations of the wearer. Thus in order to obtain a really satisfactory 'capsize,' it would be needful that the fisher should stand on his head. . .

The waist belt, besides adding to comfort and safety in the manner described, operates to materially reduce the strain of the weight by dividing and 'distributing' it. On the whole this carrier and basket may be said to combine in a very high degree all the requirements of the fly-fisher.

How far the time-honoured wicker-work is to be regarded as the best, or final, material for the construction of a fish-creel, may be open to question. Creels of various other materials, such as 
japanned tin, wood, leather, and even papier mâché, have all their advocates. That a change of taste in this matter may occur is quite within the range of possibility, if not probability, as will be seen by the following communication published in the Fishing Gazette, by that thoroughly practical writer on angling, $\mathrm{Mr}$. Francis M. Walbran:

SIR, - I have read with some interest the recent correspondence in your columns respecting creels, and believe that in course of time hardly any angler will adhere to the wicker pannier. I have myself long since discontinued using one, and now always employ either the tin creel, that you will recollect I purchased at Gillett's, or a wooden one which was procured from J. Routledge; 35, Scotch Street, Carlisle. This latter is most beautifully made, will hold $20 \mathrm{lb}$. of fish, and only weighs $2 \mathrm{lb}$. Io oz.; it makes a capital seat when you are eating your lunch or smoking a meditative pipe, and one great advantage that it has over the tin one is, that it does not attract the rays of the sun, and consequently keeps the fish much cooler.

I shall await anxiously the reply of some competent judge of the merits or demerits of papier máché, as it would undoubtedly be a wonderfully light material.

As you are aware, the Cumbrian anglers all use wooden creels of the pattern I have mentioned; but I only know among all my acquaintance one angler who possesses a leathern receptacle of the pattern you describe having seen at Ripon. The friend in question resides at Hawes, and when you remember that the mighty "Herne" also came from that district, it is only fair to assume that the two creels were made locally-probably by one man. I hope to be there shortly, and will then inquire. Anyhow, both wood or tin are a long way better than leather, as the former can be rinsed out as clean as a dish ; but the latter retains the smell of the fish.-I am, \&c.,

Oct. 30, I 886.

FRANCIS M. WALBRAN.

The Editor of the Fishing Gazette.

Mr. T. E. Pritt, the author of that very beautiful and interesting monograph "North Country Flies," will have nothing to do with what he calls " the tin-pot arrangement," lately advocated by several writers on fishing, unless, as he humorously adds, it is desired to "combine the advantages of a creel and a slow cooking stove.' . . . "I have," says Mr. Pritt, " an old tin creel

* Sampson Low, Marston \& Co. 
which once belonged to a famous Ribblesdale angler-old Harry Wallis. He gave it to me when he was himself being played by the busy angler-Death. I don't use it, because it dries up the fish so in fine weather. And I have a wooden one (which was also his-he gave me all he had, except his skill), painted green outside and white within; it is still coated thickly with the scales of salmon smolts, which Wallis-long since dead and turned to clay-caught five-and-thirty years ago. And I have a macintosh bag which, for diffusing a delightful aroma-a combination of bisulphide of carbon, dead cats, and stale mushrooms-I will back against any instrument of olfactory torture ever invented. It is warranted to clear a room of objectionable anglers in less time than a steam fire-engine in full employment. That is the reason why I sometimes find locks, bolts, and bars all applied against me when I am seen approaching in company with the macintosh. And, for my own personal fancy, I would not give half-a-crown a dozen for the wicker baskets."

Mr. Pritt 'plumps ' for the Carlisle wooden creel ; and it must be confessed that, even if it possessed no other merits, the notion of using one's creel for a camp stool when lunching or smoking is decidedly fascinating to the natural man.

For my own part, however, and despite Mr. Pritt's unkind remarks on its odoriferousness, I confess to a preference-on the double ground of lightness and portability-for a fishing bagwaterproof of course-rather than a fishing basket or box, no matter how complete and perfect they may be in their construction. Many ingenious forms of fishing bag have been invented during the last ten years, some-like that figured, made by Messrs. Cording of 125, Regent Street-expanding at the sides, to admit of the carrying, on an emergency, of extra large fish; others non-expanding but partially open at the corners, and others again merely "Sacs," covered by an over-hanging flap, - and for each variety some special advantage is claimed. 


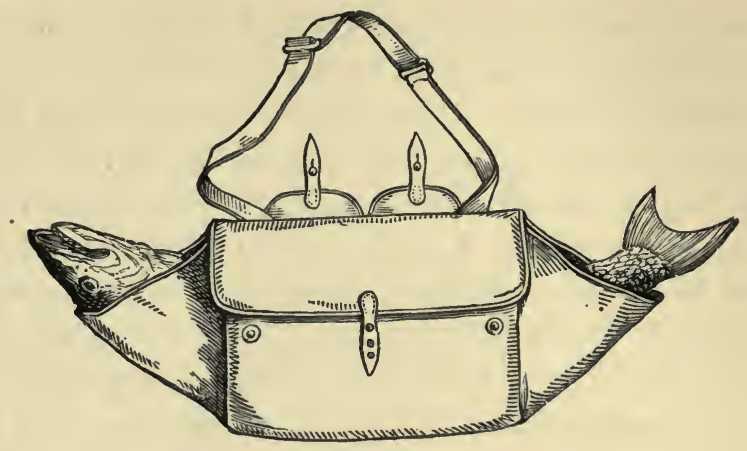

EXPANDING FISHING BAG.

On the whole, though a rival "inventor" myself, I am inclined to give a vote in favour of the pattern known as the "Freke bag," which is divided into two large separate compartments, one for fish and the other for tackle, lunch, \&c.,-the openings or mouths of the inside bag being automatically closed by the action of its own weight bearing on the shoulder strap, which is fixed to one side and passes freely through a loose ring attached to the other. This obviates all necessity for separate strappings, buttonings and so forth, except in regard to the outside compartment, or pocket, destined (unless at a pinch) to "dry goods" only. Some patterns of the Freke bag are now made so that the underneath, or fishcarrying, bag, can, if wished, be separated entirely from the other for purposes of washing, \&c. ; but this, of course, makes the bag slightly heavier, and destroys to some extent its extreme simplicity which is one of its great recommendations. Still, the advantage of facility in cleaning or washing may incline many to prefer this form. The Freke Bag, an illustration of which is appended, is now sold in various sizes by most tackle makers. It should be observed that in the diagram the underneath, or fish-carrying, half of the bag is shown on the outside, whereas when slung over the 
shoulder this part is commonly carried next the wearer. The other, or tackle bag, is not open at the corners, but completely covered in to the mouth by an over-hanging flap. The pro-

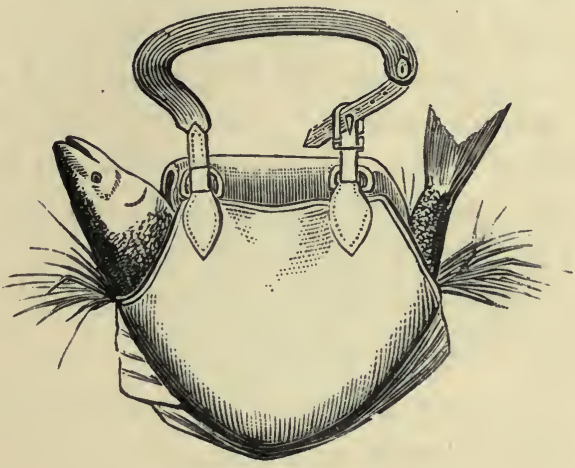

THE FREKE FISHING BAG.

('INSIDE' COMPARTMENT.)

prietors of the invention are Messrs. Cording, whose shop is at the corner of Air Street, Piccadilly.

Combined baskets and bags have also their admirers. A very neat Basket and Bag of this form was shown at the late Fisheries Exhibition by Mr. Henry Whitty (late Edmonson's),

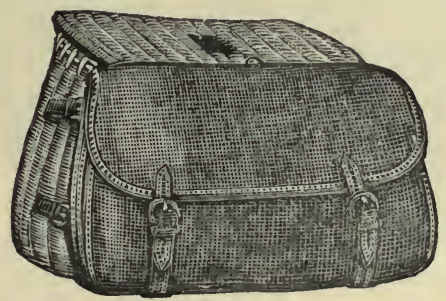

COMBINED BAG AND BASKET.

of I5, Basnett Street, Church Street, Liverpool. It deserves mention, if only as indicating how much " awake" fishing tackle makers now are to every improvement which can in any possible 
way conduce to the fisherman's comfort or efficiency. The proprietors of the invention are, I believe, Messrs. Allcock, fishing tackle manufacturers, of Redditch.

I have omitted, I think, to mention a little addition to the bag or basket (most easily applied to the former) from which I have found much convenience. It consists of two small extra straps at the top of the bag-or, better, attached to the webbing supports-in which a light waterproof can be strapped, rolled up. This proved a feature-though possibly not a new one-in my own bag, and I have since seen it fitted on several other fishing bags and baskets.

A 'seat basket,' with waterproof attached, is made by Messrs. $\mathrm{J}$. Ogden, of which an engraving is annexed.

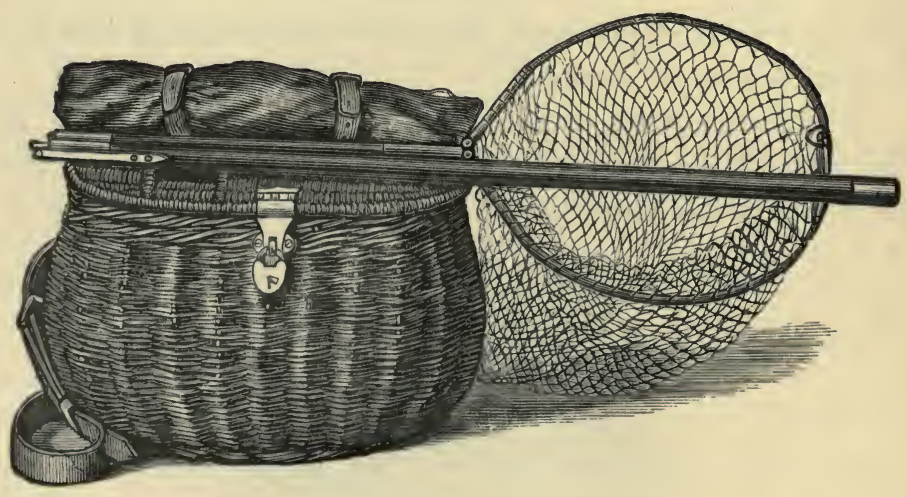

I usually have a similar arrangement attached to my cartridge bag when shooting, -in which case there is the further advantage that the extra weight, such as it is, is generally carried by a keeper or beater. 
For the salmon fisher, who will of course never carry his own creel if he can help it, I can strongly recommend a very simple and efficacious carrier-manufactured by Messrs. Farlow, but by whom invented I know not-called the "Usk Salmon Basket." A basket of this form 32 inches long by about ${ }^{2} 5$ deep will

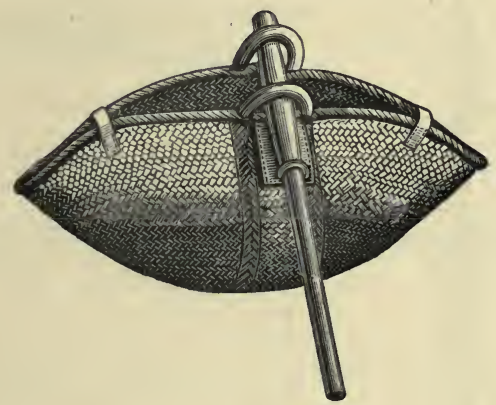

THE "USK SALMON BASKET."

carry half a dozen fish comfortably - the comfort including that of the attendant, on whose shoulders the mechanical adjustment of the crutch or handle, having a soft leather shoulder pad under it, makes it sit as lightly as possible. The length of the handle is about 2 feet.

\section{GAFFS.}

I have mentioned that the "Combination Net" handle forms a convenient gaff handle for Pike and other light fishing. For Salmon, however, where a really powerful weapon is necessary, it is unsuited. A good idea has lately been conceived and carried into practice by Messrs. Hardy. They call it their "Adjustable Combined Wading Staff and Gaff." It comprises 


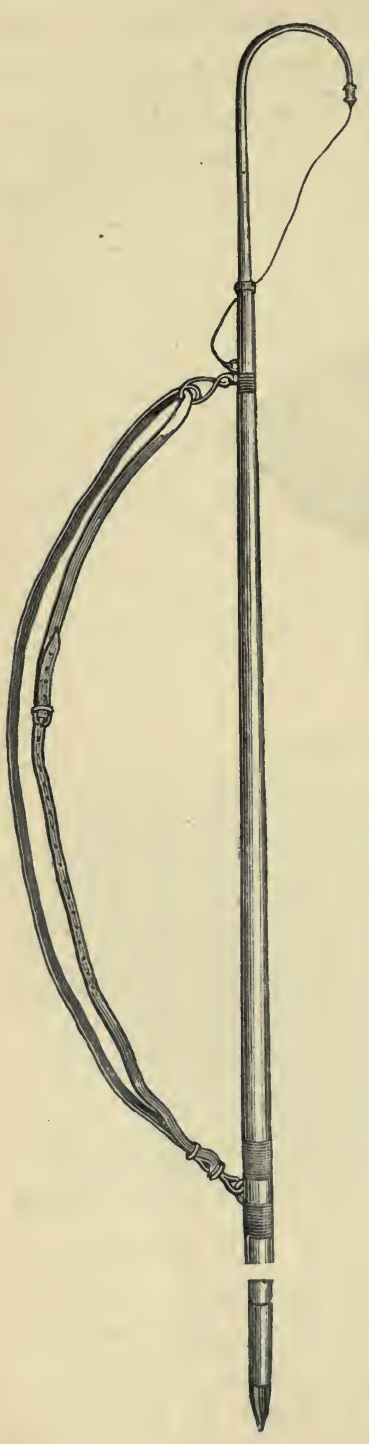

in a single unjointed piece, a strong gaff $9 \mathrm{ft}$. 9 in. long, with a staff intended to assist the wader when "in difficulties," and which is likely to be generally useful where rough rocky bottoms have to be encountered. The strap enables it to be carried easily over the shoulder. I give the inventors' further description of the method of using it in their own words :

We consider it indispensable, more especially when fishing where the wading is rough, and where the angler, after hooking his fish, requires to leave the water quickly, as it is as good or better than a third leg, and there is little fear of falling. It should be carried in the hand, fastened by the leather strap over the right shoulder, which admits of its being carried at arm's length as a staff in the left hand, and after wading into position in the pool, may be allowed to hang by the strap, until that part of the cast is fished, when it should be taken in the hand to make the next step, and so on. It is also useful to guage the depth when the water is coloured. In fishing from the bank the strap can be adjusted, so that it can be worn slung over the shoulder, in which position it is quite out of the way. In either position it can easily be detached with one hand by the spring clip, to bring it into play as a gaff.

Another excellent invention is Mr. Basil Field's Gaff with an automatic point-protector. The inconveniences, to use a mild expression, of an unprotected gaff-point are well 
known to most of us by personal experience. It is hardly necessary to insist, therefore, that a really efficient protector, which in no way hampers or impedes the movements of the gaff or of the gaffer, is a consummation devoutly to be wished.
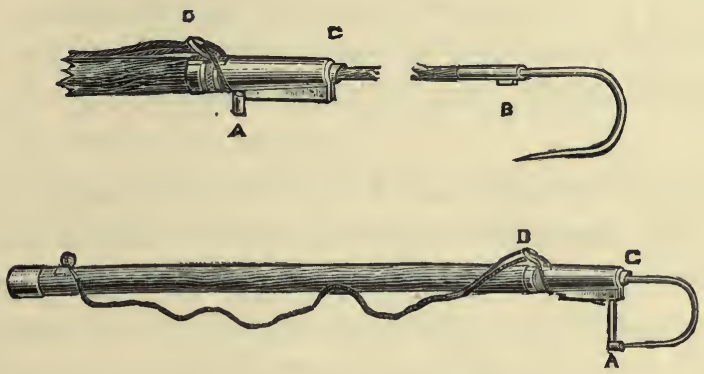

IMPROVED GAFF WITH AUTOMATIC POINT PROTECTOR.

Looking at the cuts, the lower figure shows the gaff complete and effectually "muzzled;" the upper one, a portion of the gaff with the position of the protector mechanism when the gaff is extended in use.

Mr. Henry Bawcombe, of No. 2 A, Victoria Road, Hollowaythe manufacturer and vendor of the gaff, as distinguished from the inventor-describes the mechanism thus :

A is the Point Protector, or lever, which is brought out of its rest by the lug or projection $\mathrm{B}$, acting upon its tail when the telescopic rod is pressed back into its case. When the telescopic part is extended a small spring (not shown in the cut) acts in an opposite direction and brings it to the position of the upper diagram, so that it is out of the way of the line, \&c. C is a circular double inclined plane of steel. When the telescopic rod is being sheathed in its case, if the lug, B, should happen not to be in position to enter its slot, it slides down one or the other of the inclined planes, being thus automatically brought into its proper position, and a slight pressure at the top of the hook drives the rod home, the parts assuming the position shown in the lower diagram, when the point of the hook enters a little cup at the end of the lever A. D is a brass lop that allows one end of the shoulder cord (for carrying) to be readily 
released when desired. The telescopic part is quite free to slide in and out for the whole length between the top and a conical brass ferrule at the bottom which wedges in a brass collar at the top of the case when the gaff is extended, and so prevents its rotation whilst in use. The case is made of Bamboo, and the telescopic Rod of Lancewood; all the steel parts are nickel plated.

Mr. Basil Field tells me that the gaff and protector work capitally in practice, and that for years he has had one in actual use, which is still as good as new, and has never got out of order, although it has gaffed some hundreds of fish.

FLY RODS.

I pass on to Rods. And here I feel that I am getting on to very ticklish ground and must 'walk warily.' Most tackle makers are either the patentees, agents for, or vendors of some special description of fly-rod, either for trout or salmon or both; whilst on the other hand nearly every fisherman has his own pet wand, unique in proportion, exceptional in wood, unapproachable in balance, which he swears by, and will hear of no other! . . Consequently it is of little practical use to write about or recommend particular forms or special descriptions of rods ; makers and users alike turn a deaf ear to the voice of the charmer charm he never so wisely. Accordingly my remarks on rods-rods themselves, apart from their fittings, that is - will be few, and, for the most part, general. The fittings-i.e., the joints, reel-attachments, rings, and so forth - are more 'open' subjects, and on them I shall have something to say, which may, I hope, have a better chance of being at least given a hearing.

But first as regards the rods themselves.

Everyone knows that the latest fashion is split-cane; and, it might be added, "a very pretty fashion too." Indeed, it cannot be gainsaid that split-cane rods are in many cases masterpieces of mechanical skill, as to the way in which they are built up and put together ; a perfection of workmanship which, whether we are amongst their advocates or their opponents in the field, must command a high meed of admiration. 
As all my readers may not have seen the modus operandi in this modern manufacture, I give a short description of the process, illustrating it with diagrams of the several parts of the steel and cane which go to the manufacture of one of Messrs. Hardy's celebrated split-cane rods, with and without steel centre. The steel centre itself, of which Messrs. Hardy claim the authorship (if not also the monopoly), is again amongst fishers often a bone of amicable contention, and fierce, though friendly, are the disputations of the rival partizans. . .

But to my diagrams. This is a section of bamboo cane, and the V-shaped part, marked A, represents that portion of the cane

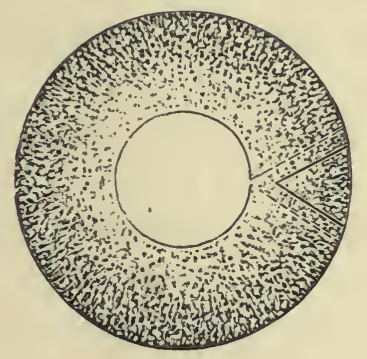

SECTION I.

which only is used by the rod-maker-the outside, or dotted V, showing the size of the strip when first roughly cut out, and the inner line its size when planed down and ready for fitting. These strips, taking nearly the form of an equallateral triangle, are, it will be observed, so cut as to utilize to the utmost the outer part of the cane, which is the hardest and strongest, the inside being little better than pulp.

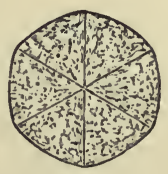

SECTION 2. 
Section 2 shows the position of the strips of cane when glued, or cemented, together. In order to obtain still greater strength, Messrs. Hardy make the butt-joints of their cane rods

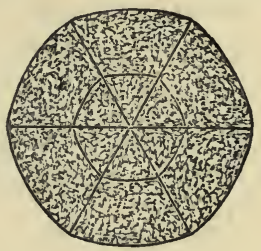

SECTION 3 .

double-an 'outer' and an 'inner' circle. They are thus composed of 12 sections instead of six. (Section 3).

The foregoing are sections of cane rods of the ordinary make, and without any metal centre. The diagram, which for the sake of not breaking continually, I will call Section 4, shows the appearance and position of the same rod plus the steel centre or core.

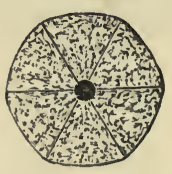

SECTION 4 (STEEL CENTRE).

Sections 5 and 6 show the butt, or double-built joint, with steel centre, before and after being cemented together.

BEFORE CEMENTING.

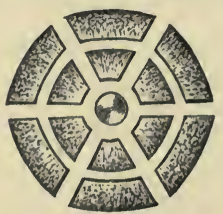

SECTION 5 (STEEL CENTRE).
AFTER CEMENTING.

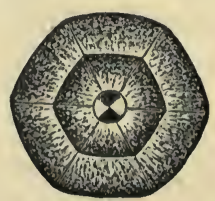

SECTION 6 (STEEL CENTRE). 
These rods possess great casting power, and will stand an immense amount of hard work. A gentleman of great practical experience with whom I am acquainted, Mr. M. Burnet, of the Fly-fisher's club, killed this season, I886, the extraordinary number of 599 salmon and grilse, and a heavy total last season* on one of these steel-centre rods, using the same top joint all the time; and although the top ring has been twice worn away the joint itself is only in a very slight degree bent. I am not authorised (for sufficiently obvious reasons!) to mention the name of the "happy hunting ground" on which this feat was performed, but it may interest my readers to know that on five days (not consecutive) Mr. Burnet's catches were 25, 27, 29, 29 and 37 fish-a truly magnificent record, and one not easily beaten. The most I ever did myself, with the fly, was 15 spring salmon in one day, and at the end of it, as I can well recollect, the muscles of my arm and back cried "hold, enough!" This was on a river in the North of Ireland. I was then using an 18 foot rod; I have since learnt wisdom in this particular and now never use a rod of any kind over about $\mathrm{I} 4$ feet. With such a weapon, made, of course, expressly for the purpose, I have caught hundreds of salmon, many of them over $20 \mathrm{lbs}$., and whilst I find practically little or no diminution in the efficiency of the shorter rod for killing or casting purposes, the additional pleasure and comfort derived have been great. In saying that I have found little or no practical difference in the 'casting' powers of the shorter rod, I do not of course mean to assert that a $\mathrm{r} 4$ foot rod will cast as far as one of 18 or 20 feet,

* Since this was written the following paragraph has been published in the columns of a sporting journal ; it adds some details which I had omitted :"Mr. M. Burnett caught his five hundred and ninety-nine salmon on one of Messrs. Hardy's $18 \mathrm{ft}$. steel-centre, built-cane salmon rods. Only one top was used-i.e., the same top killed all the fish, and the previous season Mr. Burnett had used it in killing one hundred and twenty-two salmon. The fish averaged rolb., so that this gives a total weight of over 7,000 lb. brought to gaff with one and the same top. This speaks well for English-made built-cane rods." 


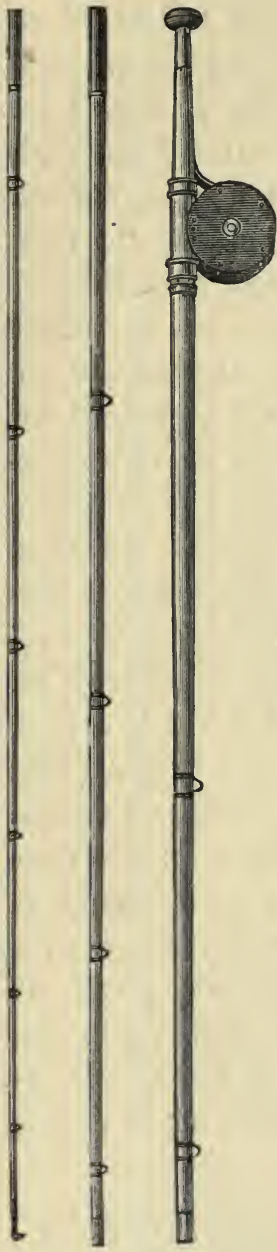

but that, having regard to the real distance required to be covered in most cases, I find the I4 feet rod - with which I can cast, at a pinch, over 30 yards-in effect sufficient.

There are of course some rivers, and many well-known "casts" on them where a longer rod is of advantageperhaps in some instances a necessity$\leftrightarrow$ but where the difference cannot be made 淟 up by wading, there is generally the alternative of a more practicable cast above or below. I have had two rods made of the length recommended (about I4 ft.), one of Greenheart, by Farlow, and the other by Hardy, of Splitcane with steel centre. In the former case the top joint is extra stout, especially towards the point, which I find gives both greater strength, and greater casting power with the heavy lines used in salmon fishing. Both these rods I have described in the Badminton Library of Sports, "Salmon and Trout Fishing," and the Editor, his Grace the Duke of Beaufort, than whom I know no better judge of the qualifications of a salmon rod, expresses his entire concurrence in my advocacy of short rods. "I fully agree" (he says, in a foot-note) "an ordinary fly-fisher seldom casts more than twenty yards properly." The greenheart salmon rod in question, which, as well as the lake trout rod, 
mentioned further on, Mr. Farlow makes according to my model and sells as my pattern, is figured in the engraving.*

I quote the following from my remarks in the Badminton Volume :-

"It is all very well to talk lightly of casting forty yards, and so forth, with a twenty-foot Castle Connell, but the man who wishes to do it-and to go on doing it all day-must be of stronger mould or greater height than the ordinary run of mortals. In my opinion a twenty-foot rod requires a seven-foot fisherman to wield it with comfort, and I am quite satisfied that for all ordinary purposes the salmon-fisher would get more comfort and more 'sport' too with a rod such as that I have described than with a longer and more fatiguing and unwieldy weapon. . .

It should be borne in mind as a mechanical axiom in this matter of the length of rod, that exactly in proportion as you gain in casting power by the increased leverage, so (the motive force being equal) do you lose in the propelling power by which only the leverage can be utilised-the practical deduction from which proposition is that every man has a length of rod exactly proportioned to his physical strength-a rod out of which, that is, he can get the maximum of casting force compatible with sustained muscular effort-and that it should be his object to ascertain what that length is."

* The dimensions, \&c., of the salmon rod are :

Length when put together .

Weight with ferrules and rings, but without indiarubber

knob on butt .

Circumference of butt at reel

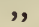

9

צ9

9

,

,

,

of butt at reel
of large joint at bottom
ferrule
of top joint at bottom
2 in. from top ring

of extra stout top joint, 2 in. from top ring .

$13 \mathrm{ft} .10 \frac{1}{2}$ in.

I lb. 9 oz.

in. 16 ths.

The indiarubber knob weighs $30 z s$. more, but it is of great practical comfort and convenience, and no salmon rod should be without one. 
Mr. H. P. Wells, in his chapter on American and English salmon rods, propounds views almost identical:

"If a rod for trout-fishing was in view, no American angler of the slightest experience would dream of buying any but an American rod, or of being influenced in its selection by any foreign work on angling. But so little, comparatively, has been done and said on salmon-fishing in this country, and so much in Great Britain, that the American anglers are apt to turn to, and be guided by, English authorities. He will read of rods eighteen, nineteen, and twenty feet long. Well may he groan when he thinks of brandishing such a weaver's beam all the live-long day, and question whether he would not find sawing wood equally beneficial and far less laborious. In the matter of fishingrods I cannot but think that the mechanical common-sense of our English brethren is somewhat obscured by respect for tradition."

I lately lent my greenheart rod to a friend for a salmon-fishing foray in Perthshire. He assiduously flogged the water for a week, and came back without ever having had a rise, but assured me, nevertheless, that he had " enjoyed his fishing immensely." If this week's fishless casting had been done with a twenty instead of with a fourteen foot rod, it may be open to doubt whether the "enjoyment" would have been equally well marked.

These observations apply equally to fly-rods for Trout-fishing. I now seldom myself use a single-handled trout-rod much over ro feet, and I find that with a rod ro feet long I can generally command as much water as I wish. Indeed, for light streamfishing I often use one of the little spliced, so-called "Ladies rods," for the manufacture of which Mr. James Ogden, of Cheltenham, is famous. This rod has a length of only $8 \mathrm{ft} .6 \mathrm{in}$., and a total weight of 8 ounces. For whipping under boughs it will be found that a light handy rod of this description possesses great advantages. For those who like spliced rods, this same make of rod but a little longer-say ro feet-is a very perfect weapon, and will stand hard work, as I can avouch, having this season filled with one of them made by Ogden some 400 trout, occasionally up to nearly $2 \mathrm{lbs}$. in weight, and without ever calling the spare top into requisition. At the end of the campaign the 
rod showed hardly any traces of the work it had gone through, and though not taken to pieces, sometimes for a fortnight together, was straight enough to be pleasing to the eye, as well as to the hand. My rod was entirely of greenheart. Signor Abaurré who

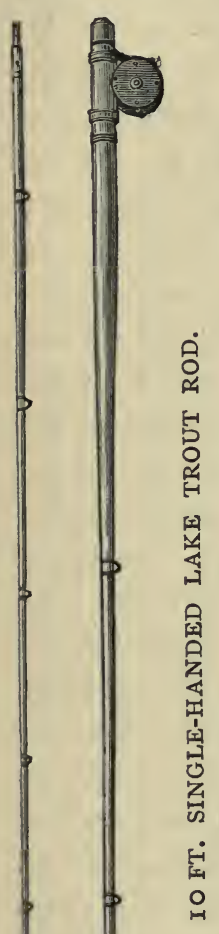
shared the campaign —and a keener sportsman does not live-had a rod the fellow to mine, but of blue mahoe, and his rod did not stand the hard work nearly so well. In fact, after a few weeks, it had, like Shakespeare's Witch, in the "Tempest," well-nigh " grown into a hoop."

I have had built by Farlow one of these ten foot greenheart rods made somewhat stouter throughout, and especially in the top, for extra heavy lake work. This rod, in which a little less 'swishyness' was desirable, is not nuade with a splice but in two ordinary joints, fitted with the "Fastener" (described at page 80) 'snake rings,' and the reel fittings I have elsewhere alluded to. For a lake trout rod, I think this makes a really perfect weapon, and it also serves excellently well the purpose [which a more 'limber' rod will not] of a stream minnow-spinning, and of a worm-fishing rod. Rods look very much alike in engravings, but possibly the illustration will help to eke out my description of the "New Chum." Its speciality is that it is powerful without being unpleasantly stiff. .

This reminds me to mention a "rule of the rod" of great importance to all fishermen, and pre-eminently to the fly-fisher. It is a rule, in fact, which knows of no exception, that the power-stoutness, stiffness, weight-of the rod, 
and more especially of the top joint, should be proportioned to the size of the fly or hook to be used. Thus, for small stream flies, a stout rod is not only unnecessary, but positively disadvantageous; frequently leading to the escape of hooked fish, or to the downright breaking of the hook or of the line. 'A delicate 'gossamer gut cast' and a spinner require, in order to do justice to their perfections, an equally delicate rod top, which yields instantly to the slightest strain, and keeps the rod bent and the line "taut," with a comparatively light pressure. Per contra, a large lake-fly hook-the barb of which takes three times the weight to bury itselfdemands theoretically three times as powerful a rod; and actually it will be found that a limp rod for a small fly, and a stouter, heavier one (N.B.-not necessarily a longer one) for a large fly, give the best results in practice. This principle I have carried out as well in the case of the $\mathrm{I} 4$ feet greenheart salmon-rod, before mentioned, as in that of my trout and trolling rods, the tops of which last are graduated to the size of the bait and hooks to be used. The green-heart rod, by the way, I had made entirely without varnish of any sort. A little reflection will, I think, induce my brother anglers to concur that all rods, and particularly fly-rods, should be made thus.* Mr. Wells' recent experiments have demonstrated that the higher an object is above the waterlevel the more readily is it perceptible to fish-vision, and as a consequence the elevated point of the rod, glittering as it sways backwards and forwards in the sun, becomes a sort of beacon light, warning the fish that there are, figuratively speaking, rocks ahead, or at any rate something abnormal in their vicinity. If it be objected that the varnish preserves the wood, and that the

* I am not prepared to say that in the case split cane rods, the varnish may not be an unavoidable necessity-though an unfortunate one. The sections of the cane are cemented together with some sort of glue, upon which, most likely, constant moisture would exercise a disintegrating effect, unless polished or varnished. 
unvarnished rod will last a much shorter time than the varnished one, my reply would be that it is of no consequence if it does not -of no consequence, that is, in comparison with its fulfilling the all important object of catching fish. . . But it has yet to be proved to my satisfaction that such is really the fact to an appreciable extent. I had until recently a two-jointed rod built by Messrs. Edmondson, now Mr. Henry Whitty, of Liverpool. This rod I became possessed of (I am afraid to think how many) years ago-but very shortly after leaving school-and one of the first things I did to it was to scrape both joints all over with a piece of glass; rather rough and ready, but quite effectual for the removal of every sign of black-stain, varnish, or polish. Yet that rod did me yeoman's service for something like a quarter of a century, and at the last was discarded, not because it became rotten, but because an enterprising car-driver, in want, I suppose, of a " $\tan$ dem-lasher," thoughtfully relieved me of the upper half. Nor is such a very easily noticed colour as black to be commended for rodstain. My taste may be vitiated, but I confess I know nothing more agreeable to the eye, or that looks more 'workmanlike,' than the plain, generally light brown, neutral tints of the natural woods.

\section{RINGS.}

In former essays I have pointed out the advantages of stiff, over loose rings, for all kinds of rods. The loose rings, besides often 'sticking'-pressing down flat on the rod and of course on the line-are very easily bent and broken off, leaving an hiatus in which the line bags or loops. But in any case for the getting out of line quickly the stiff or upright ring has a very decided advantage. I used to have my rods fitted with small straight upright rings of steel, but a form of ring has been lately introduced -or, if not lately introduced, has only lately come to my knowledge-which presents all the advantages of the upright ring whilst diminishing to a vanishing point some of its drawbacks- 
notably the tendency of the "free line" to get occasionally twisted round or "hitched' over. The form of ring alluded to is known as the "snake" ring. I was first attracted to it on theoretical grounds, but having had it applied to several rods and used it considerably with perfect success and satisfaction, I can now speak of its advantages with practical knowledge. The ring is made of "hard drawn German silver" if I remember correctly.

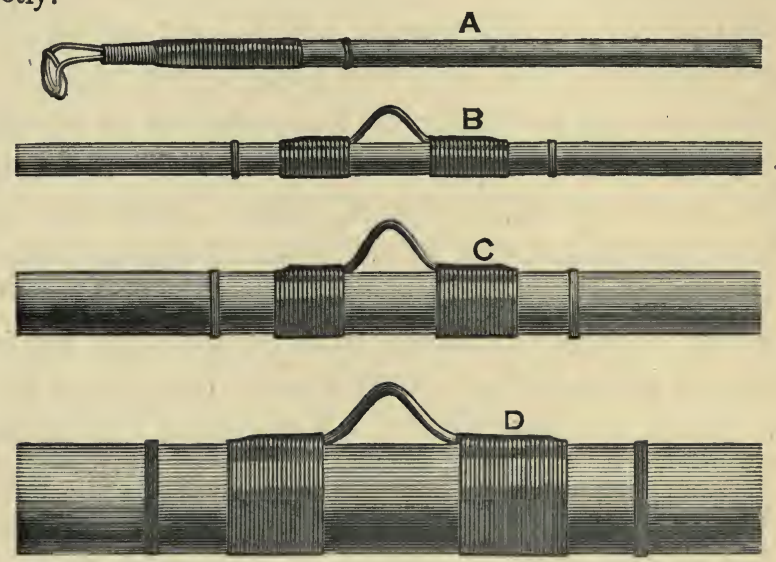

MODELS OF 'SNAKE' RINGS, AND TOP RING.

The cuts B, Cand D, are facsimiles of the rings-8in all-suitable for a io foot fly-rod, and taken from the bottom, middle and top. The first figure (A) also shows a form of ring, elaborated by the late Mr. Frank Buckland and myself, and which I can recommend as being the best shape $I$ am acquainted with for the top rings of every description of rod-fly, float and trolling. The "snake " ring, I may here observe, is admirably adapted for trolling rods, made of course proportionately larger.* Indeed, it was with a rod fitted with

* I am glad to find that so excellent an authority as the writer of "How and Where to Fish in Ireland "also advocates the snake ring. "There is," he observes, "a serpent ring used by trollers (not in fact a ring at all) which is excellent." 
this pattern of ring that Mr. Slater, the well-known tackle manufacturer of Newark, made his winning cast of 59 yards 8 inches at a recent anglers' " tournament."

\section{COMBINATION RODS.}

Of rods, the ostensible object of which is by a variety of butts and tops to fulfil half a dozen different rôles, a great many have from time to time been introduced, but, as a class, I have no very robust faith in them. Some, however, it must be admitted, display considerable ingenuity of arrangement. Of such I might instance a beautiful silver-mounted creation, with I do not know how many fascinatingly shaped tops, joints, and butts, the latter only a foot or a foot and a half long, and made of a wood altogether too lovely to run the risk of disfigurement by contact with the elements. This rod I prize highly, as it was "presented" to me many years ago through a London Banker, as an expression of sympathy, which I most cordially reciprocate, between anglers of the Old and New World. Mr. James Ogden, of Winchcombe Street, Cheltenham, has also brought to the birth a truly 'delicate monster' of this Protean family. He christens it the Neplus Ultra; and now we have a still younger candidate for 'piscatorial' honours in the form of a fly rod of many qualifications lately brought into being by that most enterprising of firms, Hardy Brothers, of Alnwick. The first difficulty in the case of these rods is to put them together; the second is to take them to pieces again, and stow their several component parts in the allotted "bags." Although Hardy's rod is only designed as a many sided fly rod, it boasts of no less than eight joints. There is also something a little awe-inspiring in the mere designation of this wooden Briareus-" Hardy's new combined II feet single hand and 13 feet double handed trout rod " -23 feet altogether ! . . But joking apart there are, I daresay, many fly-fishers to whom the combination of the two rods in one would be a convenience, 


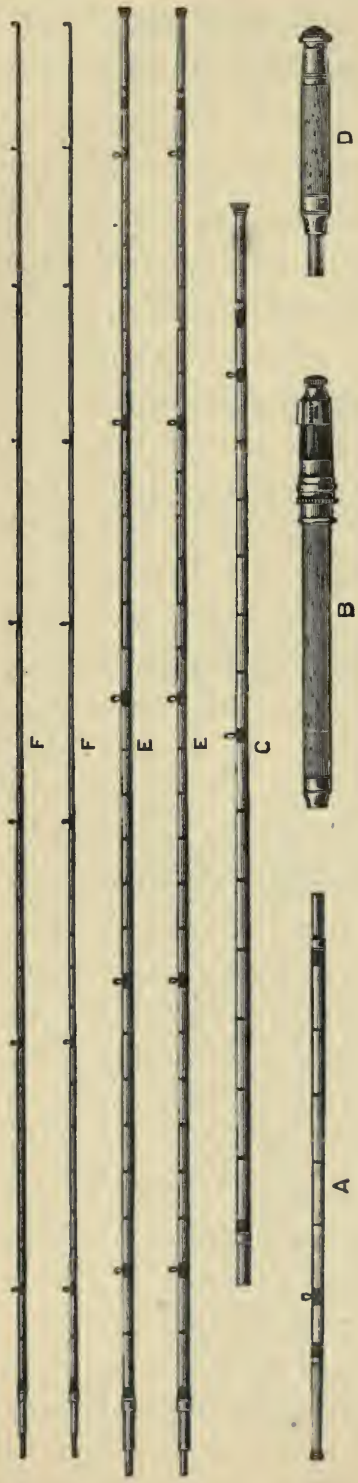

and Messrs. Hardy have too high a reputation to risk it by putting their name to anything which is not really sound and good. Moreover, this particular rod was shown to me and its merits explained at the Sportsman's Exhibition, and I must say it appeared to be a very serviceable weapon, and one which did great credit to the inventor's ingenuity. A diagram of the rod (or rods) with Messrs. Hardy's explanatory note is annexed.

"This is two complete rods in one. When intended as a single handed rod, the short butt, A, is used with the handle $B$, in conjunction with tops $\mathrm{E}$ and $\mathrm{F}$. For the $13 \mathrm{ft}$. the longer butt, C, is used instead of $\mathrm{A}$, and the short butt-piece, $\mathrm{D}$, fixes to end of butt $\mathrm{B}$, to give grip for one hand behind the reel. The short butt can also be used as single handed rod making II ft. 6 in. This rod is specially useful as a boat rod. If fishing in the bows, the $3 \mathrm{ft}$. length enables the angler to fish beyond the oars and angler in the stern. If fishing from the stern, unship butt $C$, and fix butt $D$, and you have the ordinary II ft. again. These rods we have only made in cane built with and without steel centre. We could make them to order, however, in wood if required."

ROD-JOINTS.

The old-fashioned ferrule and socket rod-joint, which, unless tied together, had a happy knack of coming apart when not wanted, and of obstinately 'sticking fast' and declining to come apart at all 
when 'earnestly desired' to do so, was, as a mechanical effort, about as faulty as it well could be, and the only wonder is that more scientific and convenient methods of fastening the rod together were not long ago devised. The 'Irish joint,' with which was fitted a rod I had by Messrs. Kelly, of Dublin, some fifteen years ago, was the first step, so far as I am aware, in the right direction. Here the ferrule was attached to the smaller instead of to the larger joint, over which it slipped, and was fixed in its place by a screw. This joint, besides never coming apart, possessed the merit of keeping the rain and rod-drippings out of the joint. It was, notwithstanding, very far from perfection. The mode of attachment making it almost impossible to obtain a close enough ' fit' of the overlapping ferrule to prevent a slight disagreeable sensation of "wabbling" at the point of junction. The ferrules of my rod also broke short across on one or two critical occasions, probably owing to the transverse rivet, and on the whole it could only be fairly described as a "modified success." Still I have an affection for the old rod, with which I killed more fish than I shall perhaps ever kill again. . . And at any rate it was a move in advance-all honour be to the inventor!

Since the Fisheries Exhibition, however, a number of vastly improved fastenings have been brought out-albeit entirely by fishing tackle makers, so far as I am aware-several of which fulfil all the required conditions in a very admirable degreeperhaps in as complete a degree as is mechanically possible. A few of the best of these I shall endeavour to present with illustrative diagrams, which will, I hope, make any lengthened verbal description superfluous, thus saving alike space and the reader's time.

Let me take first Farlow's new registered rod joint fastener.

This is an eminently simple, as well as perfectly effectual, "lockjoint"; and owing to its adding little or no weight to the rod is sure to take a high place in popular estimation. 
Fig. I shows the ferrule of the lower joint, upon which is fitted a movable ring (fig. 3 ); fig. 2 indicates the tongue and shoulderferrule of the small joint, with pin of fastening ; fig. 3 the formation of the ring; and fig. 4 the joint when united and ready for use. These joints are highly finished, and the best metal and workmanship are employed in their construction.

To fasten, put the joints together in the usual way, passing the pin on the shoulderferrule [just over fig. 2 , in the first cut] down through the slot of the long ferrule (fig. I), and then turning the small extra ring or ferrule (shown separate, fig. 3) as far as it will go to the left.

Of Hardy, Brothers, 'Lock-fast' joint, I have elsewhere spoken in terms of high praise, and I am glad to learn that its success has fully justified my encomiums. It is equally suited for salmon, trout and trolling rods.

The figures sufficiently explain the mechanism. Figure I 


$$
11
$$


represents the two parts of the joint before being brought together; and figure 2 the same when fitted together and 'locked.'

The locking is effected by the spiral wire, or 'worm,' brazed round the rim of the lower ferrule, and over which passes the projecting slot, seen in the upper figures, which jams or clamps the two parts of the joint together. An extra ferrule to which the projecting slot is attached gives extra strength, at a spot where it is critically necessary, and this strengthening has been further increased by what the inventors term their "unbreakable splint end ferrules." The ends, that is, of the ferrules are cut up into 6 "splints," which are bound down to the cane or solid wood, as the case may be, withsilk lapping. [Vide $\frac{1}{2}$ inch of shading above and below ferrules.]

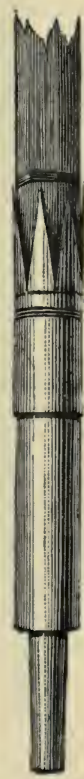

A

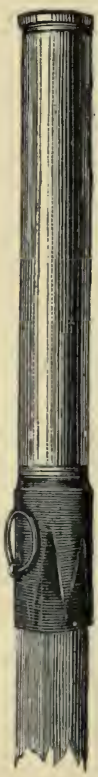

B

THE SERRATED FERRULE. 
The same plan, slightly varied as to the shape of the splints, is adopted by Mr. Frederick Malleson, of Brooklyn, U.S.A., in the manufacture of his 'Hexagonal split cane rods,' for which the wholesale agents in this country are Messrs. William Bartleet and Sons, Abbey Mills, Redditch, and 53, Gresham Street, E.C. (Henry Walker \& Co.)

The "serrated ferrule," as it is termed, ought to obviate all danger of the edge, or rim cutting through the bark or enamel of the cane.

' $A$ ' in the wood-cut shows the upper ferrule before being lapped over, and ' $\mathrm{B}$ ' the lower one after the process is complete. This joint, it is needless to say, is not a "lock-fast."

It will be noticed that in all the three patterns of joint illustrated in the preceding pages the larger ferrules of the upper joints, which slip into the ferrules of the lower joints, are made for their entire length perfectly parallel with the sockets into which they fit. The old form of ferrule, especially in inferior rods, used generally to be made more or less tapered downwards, which certainly effected a saving of time and attention on the part of the maker, but resulted in a gross mechanical imperfection, by which the strength of the joint was lessened, and the facilities for its ' coming apart' increased. If, as Mr. R. B. Marston observes, the object of a ferrule was to enable the fisher to cast his rodjoints instead of his line, nothing better could be designed to insure the result, 'the action of casting levers the joint out of place.'

When the joint is properly made, with a perfectly parallel socket fitting absolutely throughout, not only is the 'homogeneity' of the rod at the point of juncture increased, but also, owing to the joint holding by suction as well as by contact, the dangers of impromptu partings are greatly lessened. This is the true 'Philosophy of the ferrule '; as recently observed by the Editor of 
the Fishing Gazette, and it will be found most ably expounded and emphasised by Mr. H. P. Wells, in his "Fly Rods and Fly Tackle."

Several other tackle makers have patented rod joint fastenings, including Messrs. Anderson, of Edinburgh and Dunkeld ("Simplex Joint")*; Messrs. Watson and Hancock, of Holborn ("Waterproof Joint"), and Messrs. Williams, of Great Queen Street, Lincoln's Inn Fields ("Screw Cap Joint"). These inventions all propose to effect in different ways the same object, and it may be added, do effect it in a more or less complete degree. I have, however, only space left to notice in detail one other invention, the simplicity and economy of which entitle it to special mention. Moreover it is the only plan which, so far as I am aware, professes to be applicable to existing rod joints. Many fishermen hesitate to incur the expense of new rods or new joints ; whilst others again are so attached to the 'old wands' that have done them long and faithful service that they odiate the very idea of changing them. To such persons the 'spring clasp,' patented by Mr. Jas. Gregson, of Penny Street, Blackburn, which can be fitted to existing rod-joints at a merely nominal cost, may possibly prove acceptable. The action is sufficiently indicated in the engravings, of which ' $A$ ' is a section, and ' $\mathrm{B}$ ' the complete joint, showing together the position and action of the spring. This, when the joints are being put together, is lifted up by the finger nails at the small end, where

* I had occasion to speak very highly of this joint fastening in the ' $\mathrm{Bad}$ minton Library,' where also it is figured and explained. In my opinion, however, whatever may be its perfections otherwise, no sensible man would be willing to rely upon a rod which the smallest dent in one of the ferrules would render absolutely unserviceable, and I believe irreparably, so far as local 'doctoring' is concerned. The very perfection of the 'fit ' of the doubled, or exterior, ferrule, only aggravates the mischief. A "stopper" designed specially to fit this 'duplicated ' ferrule would, as I have pointed out, effectually remedy the danger, but Messrs. Anderson do not see their way to adopting the suggestion, and I regret that I cannot, therefore, conscientiously recommend any wandering angler-unless furnished with a spare rod-to adopt their otherwise very perfect and admirable "Simplex" joint. 
the turned-down point then enters into a corresponding hole drilled through both the outside and inside ferrules, and of course makes change of position of any kind impossible. A little use of

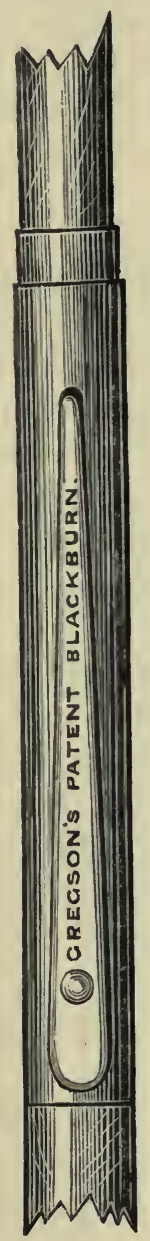

FIG. B.

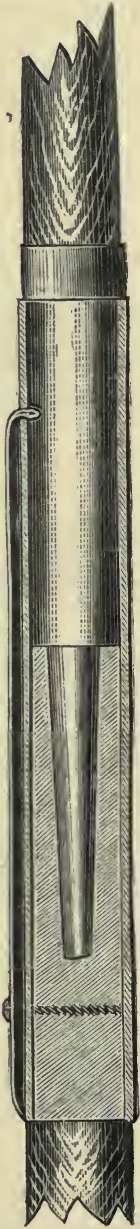

FIG. A. GREGSON'S PATENT SPRING-CLASP JOINT 
the file at a point on each side of the 'catch' would facilitate the process of lifting up with the finger nails.

It is fair to add that my favourable opinion of the spring-clasp joint is given only after examination in camera, and that I have not had an opportunity of putting it to the test of actual work. Mr. Gregson, however, has shown me a number of laudatory testimonials from fishermen who have done so.

\section{REELS.}

If Reels have not in the matter of 'improvement' quite kept pace with the improvements in Rods, they are yet prodigiously in advance of the unmechanical windlasses with which our forbears, in the not very distant past, were content to reel in the victims of their prowess. But I will not slay the slain twice over, or evoke, merely for the purpose of exorcising them, the ghosts of 'Pirns,' " multipliers," "winch-winders" and other similar lusus nature, which if not actually as extinct as the dodo, soon will be.

Of modernised improved reels or winches that which presents, perhaps, the greatest actual novelty is Slater's* "Combination Reel," so called because uniting the qualifications of a Nottingham reel and an ordinary plain or check reel. This it does without diminishing the efficiency of either. It is also vastly superior to the old-fashioned open Nottingham reel, in that-being confined to the barrel by transverse bars-the line cannot be perpetually ' winding off' - or I should say ' twisting off-the reel proprio motu when not wanted, and hitching its loose coils round the reel itself and everything else in its vicinity.

Nottingham fishing apart, however, the reel is applicable to all kinds of angling, and being exceptionally light, as well as simple in construction, presents advantages in many directions; but it is more especially to the Pike-spinner in the 'Thames style,' who

* Of Newark-on-Trent. 
walks down the river or lake side and casts with the line loose on the ground, that its qualifications most strongly commend themselves : whenever he has to wade, or the ground is 'scrubby,' and unfit for casting, he can in a moment unship the 'check' machinery and throw from the reel, a method of casting which, at any rate under these circumstances, possesses advantages that cannot be gainsaid.
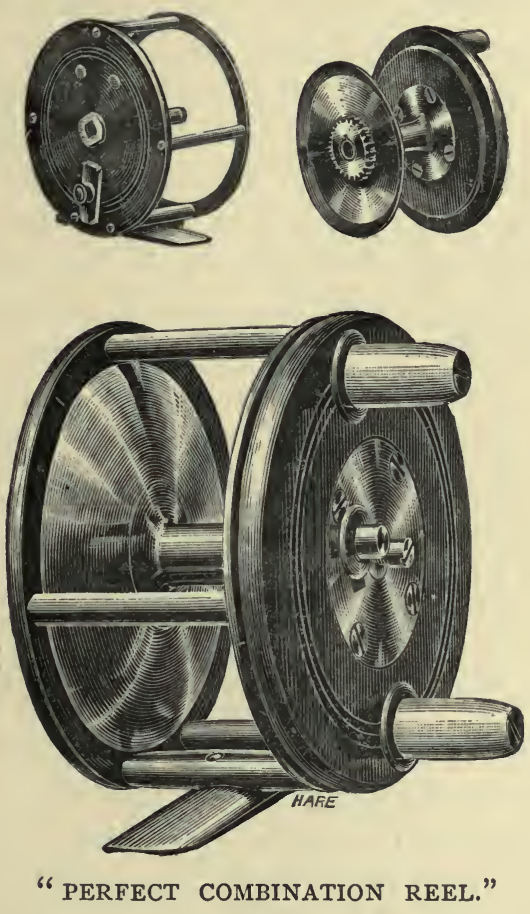

In order fully to adapt the Combination Reel to the requirements of the ordinary fly- and float-fisher, as well as to the troller; the winder or barrel, instead of being entirely of wood, as formerly-necessitating, of course, a large diameter-is now also 
made, in the form shown in the wood cuts, of wood and metal combined, by which the diameter of the axle is reduced, and the reel so far in all respects assimilated to the ordinary patterns of brass and bronze,-its speciality in regard to the Nottingham style of casting being of course retained. The insides of the barrel plates on both sides are, in this improved pattern, composed almost wholly of metal, rotating freely on a fixed steel pivot or centre-pin. Attached to the non-revolving (left hand) plate is a brass frame or cage supporting the horizontal bars, between which, of course, as in ordinary reels, the line passes, whilst this immovable framework is "recessed" into a groove in the revolving barrel. The object of the revolution of the whole right hand side-plate,-made exteriorly of wood-is to enable a 'drag' to be placed upon the running-out of the line, without whichas a means of regulating the length and direction of the castcasting from the reel in the Nottingham style would be practically impossible. The two portions of the reel readily come apart when it is desired to oil or clean them; and, it is when in this separated condition that the upper figures in the cut were taken, the lower figure showing the reel when put together. By simply shifting with the finger a button or 'catch' the action can be changed to a 'check.'

The diameter of the reel from which the engraving was made is $2 \frac{1}{2}$ inches; inside width between barrel plates, $1 \frac{1}{4}$ inch; weight $6 \mathrm{oz}$. This size is suited for float fishing generally, except where, from any cause, an extra light reel is an object.

Another comparatively recent introduction is $\mathrm{Mr}$. Rheuben Heaton's "Strike from the Winch" Reel, which has its advocates for Trout and even for Salmon fishing ; though, I confess, I should not be inclined to put any great faith in it-or rather in the principle it embodies-as applied to the latter purpose. The object of the reel is primarily to soften or relieve the 'jar' of the stroke by keeping the hand clear of the line and allowing the reel 
(the resistance of which can be made weaker or stronger) to do the work instead. It has no "check," in its technical sense, of any sort, and the graduated pressure is obtained by the application of a screw working over, and against, the end of the axle. It is important that the end of this regulator should be kept carefully oiled.

As I have observed, however, whatever advantages may or may not belong to this reel, I should feel no hesitation in limiting its application to Trout-fishing purposes.

For Salmon Reels we have, if not an embarras dechoix, at least several excellent varieties to select from.

First there is Farlow's "Lever Reel" - a solid brass (bronzed) reel, shown in two views in the engravings. It is made in all sizes, but it is distinctly as a Salmon reel that it finds its most natural place. Its speciality is the mechanism, explained by the upper diagram, in which the lozenge shaped light coloured piece represents a convex spring plate, which by means of a screw nut (shown in the lower figure) can be loosened or tightened at pleasure, so as to offer exactly the resistance to the running out of the line that may be desired. This takes the place of the ordinary check, which is, however, attached to a second variety of the reel for those who may prefer it. In this latter model the regulator-spring is transferred to the left hand, or opposite, plate, and replaced on the right hand plate by the check machinery.

There is also a little supplementary plate, which will be noticed covering the end of the axis, to admit of more readily lubricating the machinery.

Messrs. Chevalier, Bowness and Bowness, of 230, Strand, manufacture a very similar reel, in which the "pressure nut" is turned on and off by the fingers, instead of by a knife-blade or screw-driver.

These are both strong, handsome, and thoroughly serviceable reels; and for Salmon fishing especially, where it seems to be 


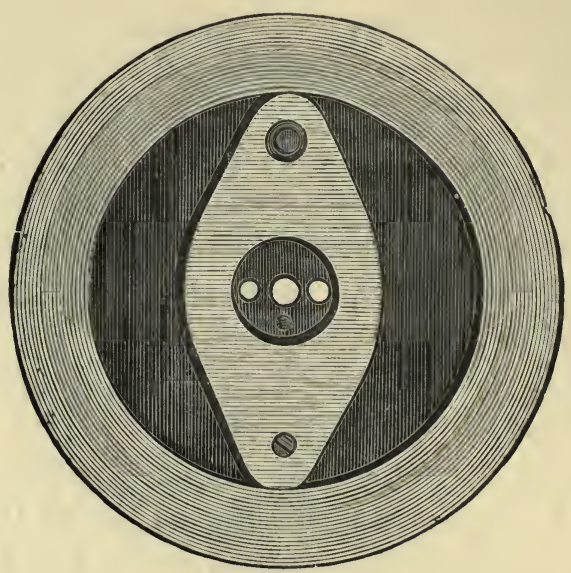

" LEVER REEL," FIG. I.

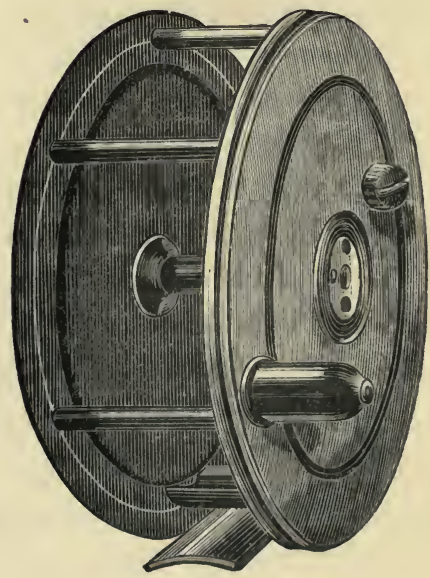

" LEVER REEL," FIG. 2.

the general theory-or, at any rate, practice-that weight is subsidiary to strength and durability, can be entirely relied on. 
Another capital winch-also more particularly suited for Salmon fishing-is Malloch's patent "Sun and Planet" Reel; which I have found excellent for all sorts of boat work. This is a Check Reel, and its peculiarity is that unless, and until, the

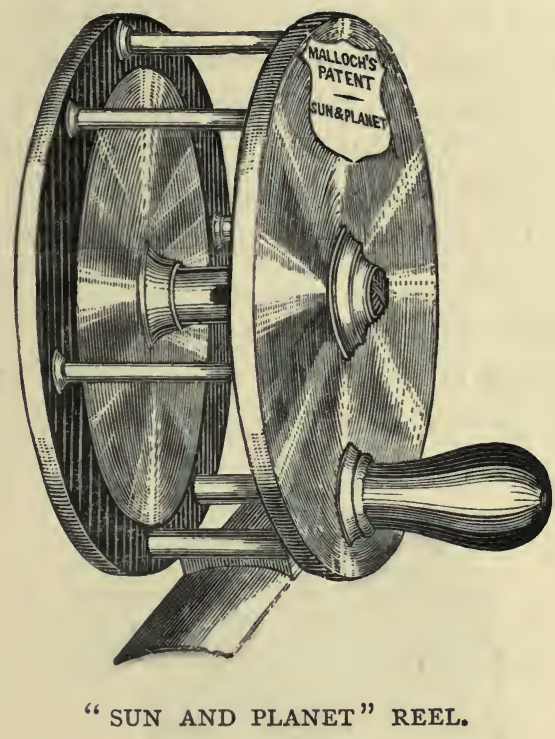

handle is taken hold of, the line runs out without any movement whatever of the side plate, so that, when trailing behind a boat, for instance, the rod can safely be left with the reel resting on the bottom, and in case of a "run" there is no danger of any contact between the reel-handle and boat-gear causing one of those sudden checks on the line which are apt to produce inopportune results. The same principle, though applied generally in a different way, has its very real significance for the salmon fisher, in whose case an accidental catching of the reelhandle in some part of his clothes often entails disaster. This accident has occurred to me scores of times, and especially 
in critical moments, whilst, say, following a running fish at top speed along a rocky river, when the entire attention has to be primarily directed to one's footing.

There is in Malloch's reel a very slight "multiplication"about one extra revolution of the winder for every four of the handle-an advantage, however, I must say, that appears to me doubtfully advantageous. Mr. Malloch also claims that his reel cannot "over-run," and that "by a slight pressure of the finger " and thumb on the handle whilst line is being taken out, the run " of the fish may be checked as much or as little as the angler " desires."

In the very handsome Salmon reel which I have of $\mathrm{Mr}$. Malloch's pattern the right hand plate is made of some white metal lightly bronzed, or rather "greyed," and the left hand plate of ebonite.

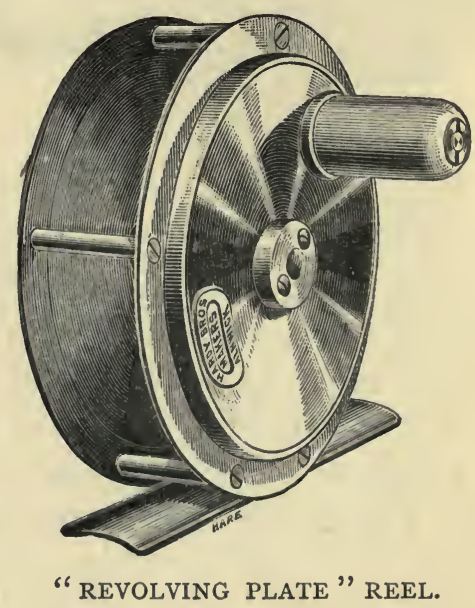

Mr. Anderson, of Prince's Street, Edinburgh, and Dunkeld, has brought out a reel-the "Excelsior" - on a very similar principle to the above, though in the actual work to which I have 
had occasion to put it the mechanism has not appeared to work quite so smoothly. The entire reel is of brass, slightly bronzed.

For those who, desiring light reels, have a preference for such as are made entirely of metal, Hardy Brothers' "Revolving Plate Reel" will commend itself.

The Inventors say :

"The object aimed at in introducing these reels was lightness combined with strength. The plates are made of fine German silver, hammered very hard. The reel is much contracted, and thus gives great winding power. Ratchet and bearings are of the best possible description. The reel is fully onethird lighter than the ordinary brass and other reels. Fishermen know how they suffer from having to carry heavy reels, and will, we believe, fully appreciate the great advantages these reels offer. We are at present only making in

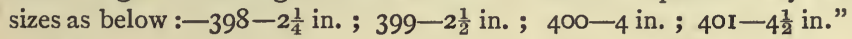

Messrs. F. T. Williams are the proprietors of another very pretty and serviceable light reel, the side plates of which are

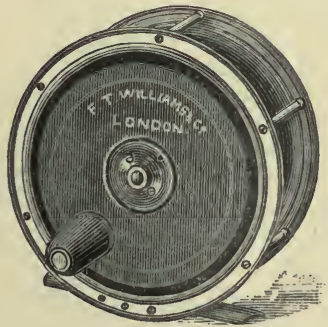

"SAFETY BOUND" EBONite Winch.

ebonite, and in order to prevent the breakages which not seldom occur when this otherwise delightful material is used, they secure the ebonite plates with rims of nickel silver, into which, instead of, as heretofore, into the ebonite itself, the rivetting bolts are screwed.

But I will let Messrs. Williams speak for themselves :-

"The ordinary ebonite winch," say the Inventors, "was always in fault, from the fact that if it received a blow it broke, and not only that, but the screws were continually coming out. Ebonite winches bound with the safety 
binding defy any blow, and the fact of the screws being let into the metalbinding removes all strain off the ebonite. This invention is considerably lighter than the ordinary brass winch. It is made in sizes both for trout and salmon."

The breakage of ebonite under adequate provocation is a fact which was sadly brought home to me this autumn by the fracture of the plate of my pet reel, through, I suppose, being let fall, or striking against a stone. The plate broke at one of the screw holes.

The very lightest reel in the world is probably that manufactured by Little and Co., Haymarket-entirely of aluminium. A reel of aluminium $2 \frac{1}{2}$ inches in diameter weighs less than $3 \mathrm{oz}$, but the price is a little alarming-four guineas.

The plate below represents the ordinary modern check solid brass reel (of the best manufacture), in which deep, narrow,

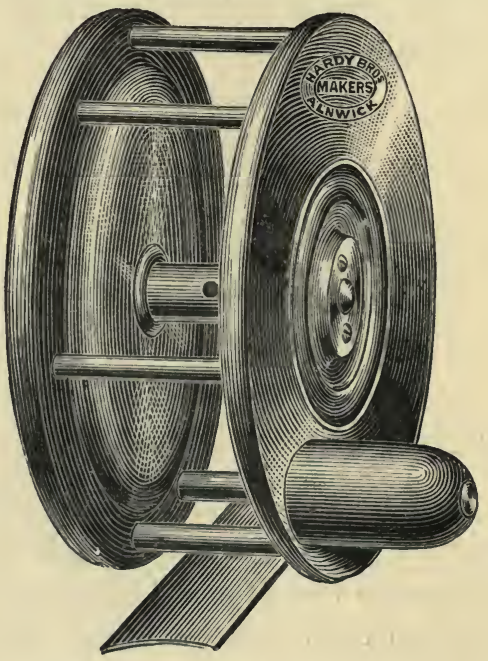

barrels, giving increased speed and power, have taken the place of the old shallow, broad-grooved monstrosities in vogue 15 years or so ago; whilst the handle is attached direct to the side plate, obviating to a considerable extent the constant 'hitchings' of the running line round the old-fashioned projecting crank handle. 
There is still, however, something left to be desired in this respect. The snake is 'scotched' not killed. Even with the handle attached to the side plate, the line still is left free to hitch round behind the back of the reel itself - a freedom of which, it is almost needless to say, it seems to have a provoking determination to avail itself to the utmost. It occurred to me, therefore, that a stop might be put, once for all, on this never-ending worry, by partly covering over the space at the back of the reel with a 'protector' or guard. The mechanical realisation of the idea was easy; the protector springs from the middle bar of the posterior curve, over which (bar) it ' clasps,'- - the exterior end pressing close on to and against the rod, whilst the 'interior' end is fixed to the metal support of the foot plate. I published an illustrated description of this reel-guard in the "Modern Practical Angler," Ist edition, r870, and other essays. It will be noticed, also, attached to the reels in the two drawings of my pattern of fly-rods, pp. 70, 73 . It can be attached to any existing reel.

Messrs. Bernard, of 5, Church Place, Piccadilly, have recently

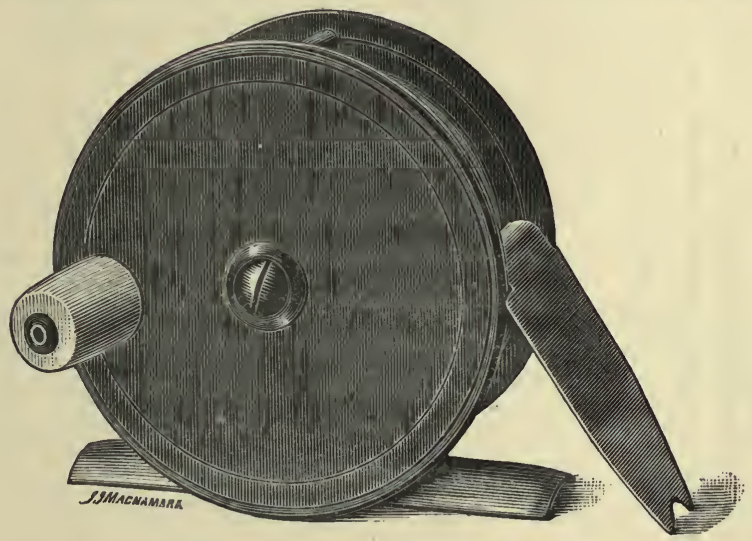

REEL WITH LINE PROTECTOR.

made a 'protector' on the same principle but differently applied; as it is attached—always, of course, by the middlebar-with a spring, 
forming an equally effectual prevention of ' linehitching. Indeed, in one respect, it is even more absolutely ' undefeatable' than my original device, as it occupies the whole width of the reel-barrel. A wood cut showing Mr. Bernard's modification as applied to one of his beautifully balanced silver-bronzed trout-reels is annexed.

To show how really serious an annoyance this hitching of the line round the reel is recognised to be, Messrs. Foster, of Ashborne, have actually gone to the trouble of constructing a reel in an enlargement of the rod-butt itself, which, it is needless to say, very thoroughly and effectually overcomes the difficulty. This reel Messrs. Foster have attached to some of their "steel centre fly rods."
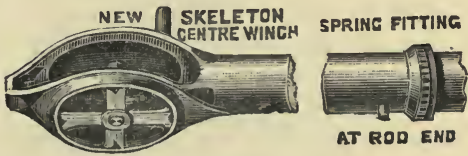

As a temporary expedient a very good plan is suggested by "Hi Regan," in "How and Where to Fish in Ireland," * by far the most recent and reliable guide to the fishing grounds of the sister Isle now extant.

The improvised 'Protector' "is a piece of light and tough leather (eelskin is the best), sewn round the back-bar of the reel, and bound behind, or taken in under and held by the fixed ring which secures the reel plate."

Some beautiful reels are now made in America, and I only regret that space does not admit of

* Sampson Low, Marston, Searle, and Rivington, 1886. 
my reproducing some specimens from the admirably illustrated cata logue of Mr. Chas. F. Orvis, of Manchester, Vermont, U.S.A. The "Orvis Reel " especially, with its narrow barrel, powerful lever, and side plates perforated throughout for lightness, makes one's mouth water.

\section{REEL FITTINGS.}

From the reel we naturally pass to the reel fittings, in which also several noteworthy improvements have been introduced. Messrs. Hardy have adopted 'Weeger's Wedge Fast' fitting, which practically takes a reel of any size, the lower end of the footplate jamming into a metal socket of diminished diameter, whilst a graduated depression in the wood above regulates the action of the upper ring.

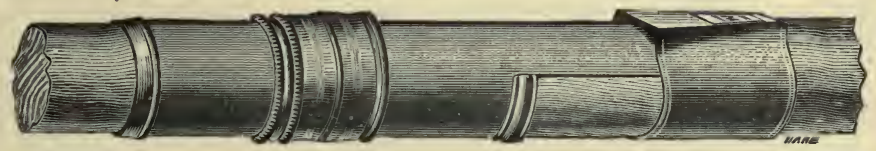

"WEEGER'S WEDGE-FAST" WINCH FITTING.

It is a very complete, indeed I might say, speaking as a mechanist, perfect invention, leaving absolutely nothing to be desired either on the score of efficiency or simplicity.

The same remarks apply in every respect to Farlow's new "Universal Winch Fitting," the jam, or wedge, being in this case obtained by a graduation in the socket underneath the lower ring.

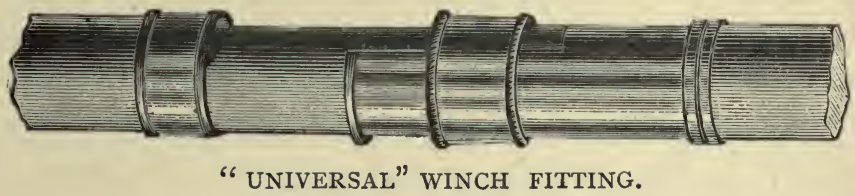

Having regard to the ever-recurring annoyance of "mis-fits" between reel and rod, of reels which slip about under the rings, or slip out of them, or refuse altogether to go into them, the reader will probably be of my opinion, that the advantage of a 
system adapting itself automatically and certainly to every size and shape of reel-plate can hardly be over estimated.

\section{REEL LINES.}

I think a very general agreement in theory will be found to exist, at any rate among salmon-fishers, as to the advantage, and in stormy weather I might say necessity, of a certain weight in the line to enable the fly to be thrown against and across the wind. The importance to the salmon-fisher of a line which will "cut its way like a knife through a fierce March squall" has been so well recognised that in order to give greater "cutting" power, linemakers have even gone to the extent of manufacturing reel-lines with wire centres, and Mr. Senior, the well-known author of many charming books on fishing, and now Angling Editor of the "Field," expresses himself as highly pleased with a line of this description made by Messrs. D. Foster of Ashbourne.

The principle of weight being a desideratum in salmon lines, is indeed, very generally admitted and acted on. That neither the theory, nor the practice based on it, would meet with an equally general acceptance by trout-fishers is certain. Indeed, the proof that it is so would no doubt be furnished by a cursory examination of the stock of trout fly-lines kept on sale by tackle-makers, amongst which undressed, and therefore relatively light, lines of silk, hemp, \&c., of silk and hair mixed, and even of hair by itself, will probably be found plentifully represented. Undressed salmon lines, on the contrary, will be met with comparatively rarely.

Then comes the question of double-handed trout rods, and what sort of line gives the greatest maximum of advantage in their case?

If simple strength and durability only were the problem to be solved, I should have no difficulty in giving an unhesitating vote for the hempen lines of the Manchester Twine Cotton Spinning 
Company. One or two of these, supplied to me originally direct from the company, have seen service from time to time for at least fourteen years, and they appear to be still as strong as ever-in fact, almost unbreakable. These lines were what is called, I believe, "cable laid." Bulk for bulk, in fact their strength and durability are unequalled by any lines I ever had of silk-dressed or undressed-of which latter, by the way, some very beautiful specimens, made of pure and undyed natural silk, are now obtainable. Of the plated hemp lines issued by the same company nothing favourable can with truth be said; and none of the dressings (tar, indiarubber, \&c.) that were forwarded to me for trial, either of plated or twisted lines, properly effected their object, or, if they did so temporarily, my experience is that they would not stand.

The silk line, on the other hand, is capable, as everyone knows, of taking a perfect and fairly durable varnish or oil dressing, and in addition to its quality of "weightiness," which-when regarded from the theoretical standpoint above referred to may be considered by many as of paramount importance-possesses, or ought to possess when properly prepared, a smoothness and polish diminishing notably the friction caused by passing through the rod-rings.

Supposing it to be assumed, then, for the sake of argument, that on a balance of advantages and disadvantages, the troutfisher as well as the salmon-fisher should give his support to silkdressed lines, which, after all, last quite long enough and can be made quite strong enough for all practical purposes, the next question-in regard to which, also, I have found considerable divergence of opinion-is : Shall the line be level or tapered ? I have met with some excellent fly-fishers, and men, too, who could give a "reason for the faith which was in them," who maintained exactly opposite opinions on the subject of 'level ' or ' taper,' and supported their respective views not only by strong argument, 
but by excellent practice. The result of my own practice and experiment is to lead me to give the preference to a tapered dressed silk line, for every kind of fly-fishing, both for salmon and trout. The experiments carried out by Mr. Henry P. Wells, on the subject generally of the comparative invisibility of lines in the water, conclusively show how vitally important is the question of the fineness of every part of the line-whether reel-line or casting-line-that comes anywhere near the flies or the fish. The tapered line is, of course, finer at the critical point in question than the untapered, and if only on the score of "fineness," should, therefore, be preferred. Apart from fine fishing, and regarded merely in relation to casting, the matter may not be one of very great moment on windless days and in calm weather; but in rough, stormy seasons, when the wind is blowing half a gale, perhaps right in the fly-fisher's teeth, the case is radically altered, and the man whose line is properly balanced and hard enough and heavy enough to cut through the air like a bit of wire will be able to go on casting with comparative efficiency, while his neighbour, less perfectly equipped, will find his flies "blown back into his face," as the saying is, at every other cast.

I had some reel-lines manufactured about a year ago with the design of still further developing the important principle here indicated, and I think the results obtained on actual trial with lines of different weight, and with both salmon rods and double and single-handed trout rods, were sufficiently successful to justify me in suggesting to fly-fishers, and salmon-fishers especially, to give them a trial. The principle is to "swell," or double taper, the casting-line-like the thong of a whip-at a point so near the "casting-end," that the whole of the "swelled part" shall usually be between the rod and the fy. The "swelled taper" may be made at both ends of the reel-line, so that when one end gets worn out it can be reversed and the other end used. In the experiments 
already mentioned, carried out with this and other lines, both level and taper, I found that there was little appreciable difference in calm weather, but that when casting across, or still more, against, a sharp wind, the "swelled" or whiplash line went out decidedly straighter and more easily.

These lines are made both with and without a wire centre by my agents, Messrs. D. Foster, of Ashbourne, Kent, whose steel centred "Acme" lines are so generally known and appreciated by

\section{PATENT "WHIP-LASH LINE."}

fly-fishers.* A rough sketch of about 30 yards of trout-line swelled at each end according to my patent, is appended.

As regards the colour of the reel-line, that which, according to Mr. Wells' experiments, appeared to be least conspicuous is described in the following passage :

"Nine varieties of enamelled waterproof line were tested, viz : Light peagreen ; Paris-green, with black spiral thread; light green, with a bronze spiral thread; translucent, with reddish-brown thread in close spirals; white and brown, in equal proportions; translucent, with green and red spiral thread; white, with black spirals; white, with black threads in diamond pattern ; and white, with brown threads in diamond pattern. All these were quite visible.

* " My experience of the Lines with fine gimp centre is confined to the 'Acme' of Messrs. D. and W. H. Foster, of Ashbourne. On receiving sample lengths, I put the ends under a strong magnifying-glass, and they looked so much like business that I ordered a line that would do for light salmon spinning (No. r), and another for trout fly-fishing (No. o). This was two seasons ago. I have used both lines hard ever since, and they appear to be quite good for the chances of 1886 . They are, in short, the best lines I ever had."-Wm. Senior, Angling Editor "Field."

"I I have used the Improved 'Acme' Line last season and this. The dressing wears perfectly smooth, and the metal never obtrudes. You have got hold of an AI line and an AI dressing for it. The "Acme' is a thoroughly reliable line for heavy jack."-R. B. Marston, Editor "Fishing Gazette." 
The least obtrusive was a line which seemed to have been braided from white silk with two black threads passing spirally around it in opposite directions, thus forming a black diamond-shaped pattern upon the white ground. The waterproofing had given to the white silk a translucent colour of a faint, dull greenish tint. The next in order of merit seemed to be the pea-green."

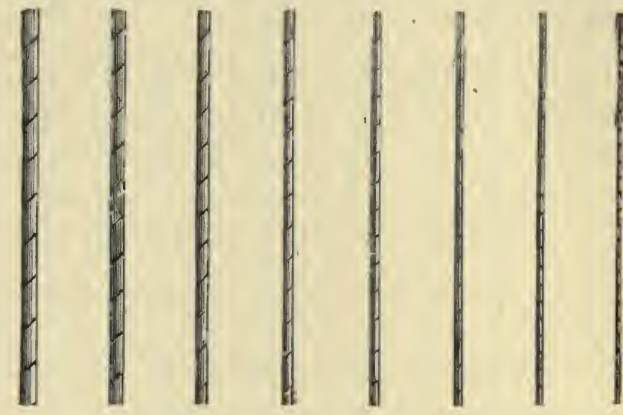

WATERPROOF BRAIDED SILK LINES.

Of the colors of casting lines ('gut collars') much has been written, and many and learned have been the disquisitions published by fly-fishers and gut stainers, whose dyes are as endless and varying as their individual fancies. I confess I found it very difficult myself to arrive at any original reliable conclusions, the experience of one day being apparently so often contradicted by that of another.

A few years ago, however, I tried some practical experiments with a glass box of water in which gut of the several stains could be immersed and looked at under varying conditions of light and position. The general result appeared to be that all stains were pretty much alike, and that in the case of perfectly sound clear gut no stain at all was necessary, - the negative color, or rather approximate colorlessness of the gut, seeming to harmonise on the whole very well with most sky-tints from whatever position regarded.

Since then Mr. H. P. Wells in his highly interesting book, "Fly-rods and Fly Tackle," has gone very fully into the subject, 
aided by a glass water-tank of large dimensions, specially constructed to facilitate the investigation; and having regard to the exhaustive nature of his experiments, so much more complete in every respect than my own, I cannot do better than, with $\mathrm{Mr}$. Wells' permission, give my readers in a condensed form the result of his investigation, leaving them to form their own judgment on his results and to test them in practice for themselves if disposed.

It would iseem, then, to result from Mr. Wells' experiments that the question of the color or stain of gut in its relation to light, and to fish-vision may, when rightly apprehended, prove to be both important, and the subject of laws which it would be greatly to the fly-fisher's advantage to study.

Mr. Wells primarily bases his experiments, and of course the deductions drawn from them, on the probable general similarity between fish vision and human vision.

"The eye, whether of fish or flesh, is but a lens refracting rays of light, and converging them to form a picture on a screen-the retina. In this respect, and as far as the mechanical principles of construction are concerned, it has its exact counterpart in the camera of the photographer."

"Light is light, and by its aid all animated beings see, and in its absence all alike are blind. The laws of nature operate equally and invariably both above and beneath the water; and until it is demonstrated to be otherwise I cannot think that trout see in any different manner, or by different means than do we. There is probably a difference in degree, but I cannot believe in kind."

The differences which do exist-as in regard to size, colour, sphericalness of form, and absence of the power of contraction and expansion-are indicated by Mr. Wells, and it is shown that they would naturally produce, under ordinary conditions, a less perfect vision than our own.*

* The rise of fish at flies after nightfall, and after the flies have long ceased to be visible to us, is explained by the difference of background against which they are looked at. 
The lens of the eye of a trout being without any power of contracting or expanding, the inference is that the fish is normally "near-sighted"; and this inference is verified by its habits.

"Is not the action of trout towards the artificial fly just what this nearsightedness would lead us to expect? Place the natural insect and its artificial copy side by side, and is the resemblance sufficiently close to deceive the human eye for a single moment? Though in colour they may be approximately similar - as to form, only the eye of charity can detect a resemblance. Colour, trout can undoubtedly distinguish at some distance, as well as that there is an object apparently edible trespassing on their domain, but it would seem that details of form are only perceptible at close quarters."

This view is in accord with my contention as to the "Exact Imitation theory" in the controversy that raged so fiercely some ten years ago. In that "free and gentle passage of arms," where I acted the part of general "challenger" (and which seems still as far from a final settlement as ever), I demonstrated by arguments, which appeared to me to be unanswerable, that "general colour, general form, and size "were all that the sight of fish enabled them to appreciate,- - to appreciate that is, when the fies are presented, not dry and floating passively in their natural position on the surface of the water, but wet and in unnatural movement under water. I gladly welcome the appearance of so redoubtable a champion on my side of the lists. In fact, whether we regard the question from the anatomical or from the analogical standpoint, Mr. Wells' contention is the only one that can be logically maintained. I am sorry that space does not admit of my quoting more at length from his conclusive and even "severely worked out" argument, which, however, all who desire to fish with their brains as well as with their hands will do well to read for themselves.

Having satisfied himself of the general similarity for practical purposes between human and fish sight, Mr. Wells constructed, as I have said, a large glass tank, in which gut casting-lines of various colors were successively and simultaneously immersed, and where they could be looked at from below, as from a trout point of view, at different hours of the day, in varying lights, and under 
altered conditions as to the state of the water,-every diversity from perfectly clear to dark porter tint being tried.

Nine different colours or stains of gut in all were experimented on by Mr. Wells-viz., "black, dirty olive-green, pea-green ; dark, medium, and light neutral tint (copperas and logwood); ink-dye, darker and lighter coffee-colored " and also the natural gut uncolored or stained in any way-with the following results :-

All casting-lines (Americanised "leaders") are visible when directly over the fish, and in a degree entirely irrespective of their color. Here diameter alone affects the result.

When viewed obliquely in clear water, all casting-lines are, except at twilight, visible through a stratum of two feet or less, but the color makes considerable difference in their obtrusiveness.

Whether the water is shaded or not effects these results but slightly, and the same may be said of a gloomy or lowering sky.

The underside of the surface of the water forms the background against which the line is viewed, and as the line contrasts or harmonises with the apparent color of this, so is it more or less conspicuous. On the surface of the water the bottom is reflected; and its colour modifies, in a degree diminishing as the depth increases, that received from the sky.

With clear water, the black stain was invariably the first to be seen, closely followed by dark olive-green and the dark neutral tint.

At any time of the day, and with any light, the black could always be seen through a stratum of water which utterly eclipsed the lighter tints; and this was equally true of the olive-green and dark neutral tint, except that in the twilight they appeared to less disadvantage.

When the rays of the sun fell perpendicularly, or nearly so, upon the water - say from ten to three o'clock-nothing gave a better general result than uncolored gut. True, occasionally it shone like silver, and then nothing could 
be plainer; but this did not take place in all positions, and except at such times it had a decided advantage over the others, and even at its worst it was at no great disadvantage. . . . [This, it will be observed, agrees so far with my own small experiments.]

The fact that the sun was obscured did not seem to destroy the advantage of the uncolored gut between the hours mentioned-[i.e., for the five middle hours of the day]; but, except with a rain sky, at other times uncolored gut was far inferior to all the others except the black; indeed, it was at times difficult to say which of the two was the most obtrusive, both being visible the entire length of the tank. The difference in the appearance of uncolored gut can be attributed to nothing but the direction in which the light falls on the water. When the sun is perpendicular, or approximately so, it seems to be at its best; while as the rays fall more and more obliquely on the water, it becomes more and more conspicuous.

A light coffee color (obtained by infusing the gut in a strong decoction made by boiling red onion-skins in water) almost equalled the uncolored gut at its best, while apparently far less dependent on the direction of the light. For general use at all times, particularly over a light-colored bottom, I incline, (says Mr. Wells) to think it one of the best of colors. If, however, leaders of but one color are to be used at all times, unquestionably that color should be a light shade of ink-dye-that given by " Arnold's Writing-fluid " diluted with an equal quantity of water. This always and at all times gave a good result, while it took the first place in merit oftener than any other one color. Over a neutral tint (copperas and logwood) of as nearly as possible the same shade, it had quite a decided advantage. It was at its worst in the middle of the day. A pea-green strand also gave an excellent average. Though it could at times be seen when some of the others could not, it was never obtrusive. I believe this would have given better results had it been a shade or two lighter in tint. For meadow-brook fishing it should be excellent-perhaps unequalled.

\section{The foregoing experiments, it will be observed, relate exclu-} sively to clear water; with "bog-water" the results were almost exactly reversed.

"All the lighter coloured leaders were here at a decided disadvantage, the uncoloured gut being the most visible, while the black was least so, and this irrespective of the time of day, and sun or shade. The dark olive and darker neutral tint gave almost, but not quite, as good results, and in the order named. No leader could be seen through more than three and a half feet of water. The uncoloured gut was invariably the first to appear, closely followed by both of the coffee-coloured. I had supposed," says Mr. Wells, "the latter would prove excellent in brown water, but such was by no means the case, since at all times, and under all circumstances, these were nearly as objectionable as the uncoloured, and far more so than the other light colours. The pea-green was the 
next to appear. The ink-dyed leader gave very fair results, but still inferior to darker shades. The fact that the uncoloured leader could be always seen at more than double the distance at which the black first began to be visible, illustrates the relative merits of the two."

For brown water was next substituted a mixture corresponding to the somewhat turbid condition of a stream on the subsidence of a freshet. In this medium no gut could be seen through more than eight inches of water even at noonday, and with an unclouded sky.

To generalise the results of Mr. Wells' experiments :

For ordinary clear water use uncoloured gut from about 10.30 to 3 or 4 o'clock; before and after these hours, light ink-dyed.

For meadow-brook fishing, or on water containing green floating matter, use light pea-green from first to last.

For brown or bog-water, a black stain-the darker the better.

If only one colour of casting-line is used throughout the day, in clear water, it should be of the light ink-dye stain.

As this is going to the printer's I have received from Mr. Wells samples of his light ink-stained gut. The stain is of a perfectly transparent greeny-bluish tint, and, as he says, is "not darker than that of an unclouded sky." It is obtained by soaking the gut in a mixture of one-half water and one-half " Arnold's Writing-fluid" (cold), which can be procured from Messrs. P. and T. Arnold, chemists, I35, Aldersgate Street, London.

"' 'Nothing,' says Mr. Wells, reviewing broadly the preceding varied experiments, 'surprised me more than the difference in obtrusiveness shown by different specimens, so nearly alike in shade and colour in the air as to require careful inspection to distinguish between them. This was marked in comparing the ink-dye and the lighter neutral tint (copperas and logwood). The intensity of colour in both was almost exactly equal, while the neutral tint was somewhat duller on the surface. The relative merits of the two can be judged from the fact that sometimes the neutral tint was visible through a foot more water than the other.'"

"For years events have been gradually forcing me towards the opinion that success in fly-fishing (particularly where the fish were educated to the angler's wiles) depended as much upon concealing the connection between the line and the fly as upon any other thing." " 
I cannot conclude these remarks without pointing the above moral, as it presents itself to my mind, and in its bearing on the question of the advantages of the eyed-hook system: If the colour and thickness of the link of gut next the fly are matters of such vital moment with a view to the concealment of the lure, of what paramount importance must it be to avoid the necessity, once for all, of attaching the flies by a separate strand of gut, always unsoaked, constantly of a different thickness and often of a varying colour? The "continuity" of the cast is broken at its most critical point. . . . I will not lengthen this already somewhat extended dissertation by recapitulating the other many and great advantages of the system of attaching the fly direct to the casting line by means of the turned-down eyed-hook and the jam-knot, but I can only say that the system has, to me, doubled the pleasure of fly-fishing; and that the more experience I have of it in practice, the more I find it fulfils the anticipations I originally formed of it on theory.

Before quitting the subject, however, I should like to add a few words on the subject of the 'exact imitation theory' and my 'typical flies,' already touched upon.

What I desire to say-if indeed I have not said it elsewhereis, that in suggesting the 3 typical flies, published in the "Modern Practical Angler," as illustrations of the theory that for wet flyfishing the immense numbers of patterns with which the fly-fisher crowds his book are really unnecessary and that a comparatively few patterns (and of those probably hackle flies best) were all that was really necessary, I did not assert, and never for a moment supposed, that my 3 flies possessed any special magical attractions over all others, and were the ultimate outcome of all possible excellence. I did not assert, and did not think, that they could not be improved upon-indeed, I have, from time to time, made several improvements in them myself, and I am by no means sure that the taste for particular patterns does not change 
from time to time, or that there is not a 'fashion' in such matters with fish as with fishers. I merely suggested the three patterns as a practical illustration of my theory, because with them I had found that I could kill fish in a great variety of streams and lakes. The flies were, in fact-as their name implies-designed merely as 'types' - and as such, of course, open to endless modification and extension. This is one reason, amongst others, why $\mathrm{I}$ have always refused to supply either tackle makers or individual anglers with patterns of them. Having suggested a few broad principles, I left others to accept, reject, or work upon them.

I am especially anxious not to let the present opportunity pass without these observations, because since my typical flies were submitted to the public, the practice of using floating flies, then confined to the comparatively few, has largely extended. Dry fly fishing has of late years become a generally recognised branch of the art, especially in England, and in so far as such practice is concerned my theories have no application. My hackle flies of 3 colours were only intended to be used wet, the then generally prevalent fashion. The moment we come to presenting the fly dry and passively floating, all the conditions are changed. A trout taking the floating (natural) fly lies quietly watching and waiting close to the surface of the water; and unless the insect passes right over his nose, or within a few inches to one side or the other, he will most commonly not trouble himself-even if he sees it at all (which is doubtful) - to move after it. Hence he ha ample opportunity for a careful scrutiny of the lure before making up his mind to take or reject it; and such being the case I am by no means prepared to fix, even in my own mind, a limit to the exactness of imitation of the fly on which the fish are feeding that may be possible or desirable.

A careful perusal of such books as Mr. F. M. Halford's "Floating Flies and How to Dress Them," and Mr. E. T. Pritt's "Flies of the North Country," and Mr. H.S. Hall's "Chalk Stream 
Fishing with the Dry Fly,"- the last named written at my request for the Badminton Library of Sport, - all full of illustration and information, will give an excellent practical initiation into the two systems of fly-fishing - 'wet and dry.' Both Mr. Halford and Mr. Hall are, it may be observed, on all points ardent advocates for dressing floating flies on eyed hooks : Mr. Pritt does not deal with the subject, but he advocates hackle flies for 'wet' fishing.

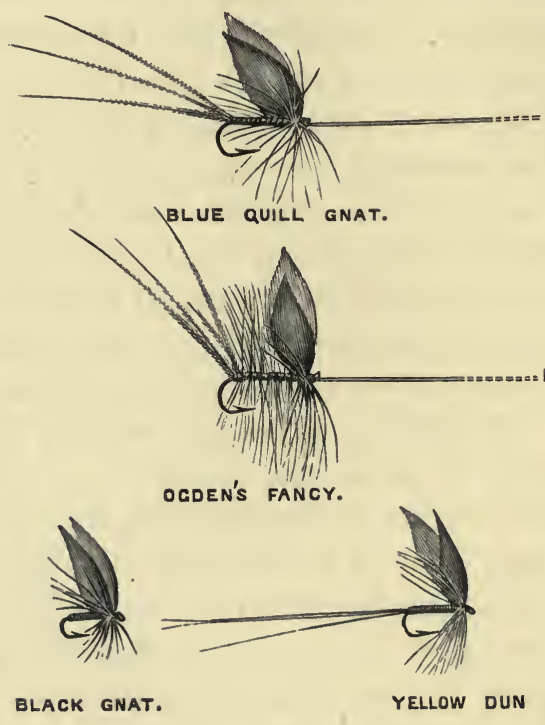

FLOATING FLIES.

In addition to the examples already illustrated some specimens of Mr. James Ogden's floating flies, tied on both descriptions of hook 'gut,' and eyed, are represented in the cut.

WADERS AND WADING BOOTS.

Many and great improvements have been introduced in these important items of the fly-fisher's outfit, since the time when the 
pitilessly hard, long, leather "jack-boot" was almost the only appliance in vogue. There is the leather-footed, leather-legged, india-rubber coated boot, delightful to wear and fascinating to handle, which never hardens-at any rate to the 'impossible' or 'agony' point-and is perfectly waterproof as long as 'foot and stocking' hold together. Then we have the 'wading stocking,' properly so-called, light and easily transportable, a shade less absolutely waterproof perhaps, but yet quite sufficiently impermeable for all practical purposes; and following after wading stockings, and as a sort of natural corollary, we come to wading 'trousers,' so commonly patronised by salmonfishers, and without which, indeed, many of the best casts on our rivers would be simply ' unfishable' unless under the penalty of a liberal importation of the element which is the prime object of waders to exclude; lastly we have Messrs. Cording, of 125 , Regent Street, inventing a 'life belt' wading-trouser, which fulfils not only the waterproof conditions, but also ensures the incautious wader a practical immunity from the chances of being drowned. The appearance and arrangement of these belted members of the Royal Humane Society are shown in the cut, which Messrs. Cording have had engraved at my suggestion, so that further verbal description is unnecessary.

Equipped with these I believe the inconvenient possibilities hinted at are reduced to a vanishing point, whilst the weight added by the air belt is inappreciable.

As all waterproof garments are liable to become more or less damp from repressed perspiration, they should invariably be dried after use, as well to prevent the linings, and, indeed, the rubber itself, becoming rotten, as for purposes of health and comfort. The best way of drying is to fill the legs and feet of the boots, stockings, or trousers, with warm bran, oats, or barley, which should be shaken out as soon as it begins to cool [if this pre- 


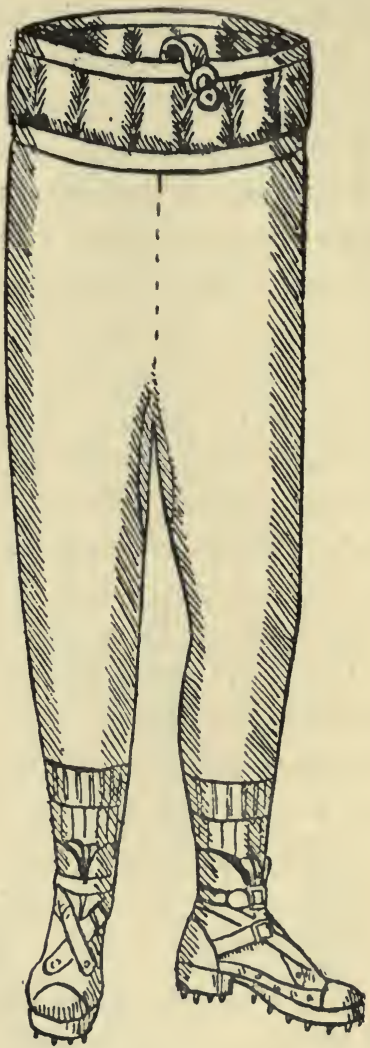

CORDING'S LIFE-BELT WADING TROUSERS.

caution is not attended to the moisture which has been absorbed begins at once to re-evaporate]. When the waders have been emptied of their drying contents they should be turned inside out and hung up, foot upwards. In the case of the combined rubber and leather boots noticed, this (of course) cannot be accomplished, and many fishermen keep the 'feet-part' always filled with care- 
fully dried grain or sawdust, or on boot-trees, with the object of swelling or keeping them in shape, and to avoid shrinking.

I cannot better conclude these few remarks on waders than by quoting in extenso a letter on the subject (published since the above was written) by Henry Downes, Esq., M.D. Dr. Downes's letter is full of interesting and suggestive matter :-

SIR,-Anglers are often perplexed in coming to a decision as to what description of waders they should provide themselves with. Now, it may be said with truth of waders, as well as of rods, lines, and flies, that one description will not prove adapted for all purposes or parts of the fishing season.

In Devonshire, and in some other countries in England, this begins early in February, when the water is very cold and easterly winds prevail. While such a state of things exists many fishermen refrain altogether from wading, contenting themselves with fishing from the bank; but there are those who have sufficient confidence in the strength of their constitutions to wish to doso.

For such waders must meet these requirements : To keep out the water, to exclude the cold, and to retain the heat emanating from the human body. The Messrs. Cording, I25, Regent Street, provide fishing boots which admirably meet all the above. They are made complete, in the first instance, in the same way as fishing stockings, soles with nails being afterwards added. Water is thus effectually excluded, and, as the material of which they are composed is a thick leather water-proofed outside, they both exclude cold and retain heat.

The objection often made to these boots is that they cannot be turned inside out, so as to be easily dried when the insides have become moist from condensed perspiration. But when we consider the season of the year for which they are recommended, it will be found that as the insensible perspiration emanating from the human body is then very slight, this will hardly be perceptible; and if the boots are made sufficiently light and easy, the greater part of it will escape in the form of vapour between the boots and stockings, and not become in any degree condensed on the stockings worn under them. A pair of flannel bags filled with sawdust is supplied with these boots, and if put into the oven for a few hours and then placed within them, the boots will soon become perfectly dry on the inside. The boots should afterwards be put on boot-trees, so as to keep them of full size, as otherwise they shrink, and become tight and troublesome to put on.

Being made of a stiff and somewhat unyielding material, it will be found that they are apt to run into holes on the inside of the knees by the friction of one surface of leather against the other, if much walked in.

This is easily remedied by having a pair of covers made for them of woven flax cloth, extending from the tops of the boots to a few inches below the knee, with a small loop for the strap of the fishing boots to pass through and keep them in their places. 
They will thus be completely protected from all injury, and last many seasons. The great ease with which these boots are put on and taken off is alone a great recommendation : instead of having to put on fishing stockings, and then socks over them, and afterwards brogues. Two pair obviate all objection to them, as while one pair is being dried the other pair can be used.

As the weather becomes milder, a lighter description of waders becomes desirable, and the Messrs. Cording have met this want in the shape of wading stockings made of stout black felt waterproofed outside. These will be found warm and comfortable, possessing the great advantage that they can easily be turned inside out to be dried.

This kind of fishing stockings is especially recommended because they are composed of soft and pliable material, and if accidentally injured, the waterproofing being on the outside, the damaged spot can be immediately discovered and repaired with a piece of waterproof material attached to the outside. Ordinary fishing stockings consist of double-cotton fabric with a thin layer of waterproof between ; and as this is a solution of india-rubber in mineral naphtha, which is very volatile, the latter soon evaporates, and when long exposed to the air, its waterproof qualities disappear, and the stockings let in water in many places, the attempts to remedy this soon making them resemble patchwork; when this happens, the sooner they are discarded the better. Thus, while one pair of the thick felt fishing stockings, waterproofed outside with due care, will last several seasons, those generally purchased on account of their low prices will seldom last one season, and often not so long.

When the hot weather of summer arrives, a still lighter description of waders would be found advantageous, but they should be made of black waterproof material. White is as improper for this purpose as is any other article comprised in the equipment of the angler, owing to its presenting when in the water a glaring and conspicuous appearance.

The two latter descriptions of waders are to be worn with brogues with worsted stockings over them to protect them from friction.

As to fishing trousers for wading when trout-fishing, it would be well if every fishing association, having the power to do so, strictly forbid their use in every trout stream of moderate size in England. They certainly give those who wear them considerable advantages over those only provided with fishing stockings ; but fishermen who come behind one of these amphibious sportsmen have very little chance of success for several hours afterwards, the fish having been thoroughly disturbed in their most secure retreats.

While objecting to wading trousers for trout-fishing in trout streams of moderate size, it must be added that they are quite indispensable when fishing for salmon in wide and deep rivers, in order to enable the fisherman to reach the haunts of salmon, often inaccessible by any other means.

It must not be forgotten that grease of any description has a great affinity for india-rubber, immediately combining with it; grease of any description must not therefore be used to soften either fishing boots or fishing stockings. Now 
it will probably be said that these suggestions with regard to waders for fishing are all very well ; but that the expense of providing three descriptions for the season would prevent many persons from adopting them.

For those who are of this opinion, the intermediate felt fishing stockings, water-proofed outside, will be the best to purchase for use for the whole season; but for those able and willing to incur the outlay, the three pairs of the different kinds recommended will prove advantageous.

The most expensive outfit we can possibly procure for trout-fishing will not amount to a ruinous amount; and cheap fishing-tackle being a delusion and a snare, those who obtain everything of the very best quality will never regret having made such an investment.

$$
\text { I am, \&c., }
$$

The Editor of the Fishing Gazette.

Henry Downes, M.D.

Of ' Brogues,' to wear over leggings or trousers (of course with a thick worsted sock between) several improved forms have also been introduced, such as the "Test Brogue," manufactured by Messrs. Anderson and Co., of 37, Queen Victoria Street, E.C., in which the nails are clinched into a solid leather sole, built up with specially prepared felt ; or the "Invincible Brogue and Sole," of Messrs. Hardy Brothers, Alnwick, in which square-headed nails are fastened right through the sole and rivetted into copper ' washers,' as shown in the cut, before the sole is sewn to the brogue. The brogue itself is russet-coloured, made of oak-bark

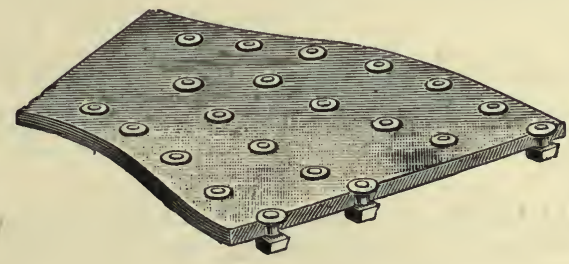

tanned hide. Needless to point out the advantages of having nails which cannot slip out, or, by piercing the sole, injure the waders inside. Some waders prefer brogues with corrugated india-rubber, or felt soles, as rendering them less likely to slip, 
but having never tried experiments with these I can say nothing about them. If brogues become uncomfortably stiff through drying, a good plan is to soak them for a short time in (cold) water previous to use.

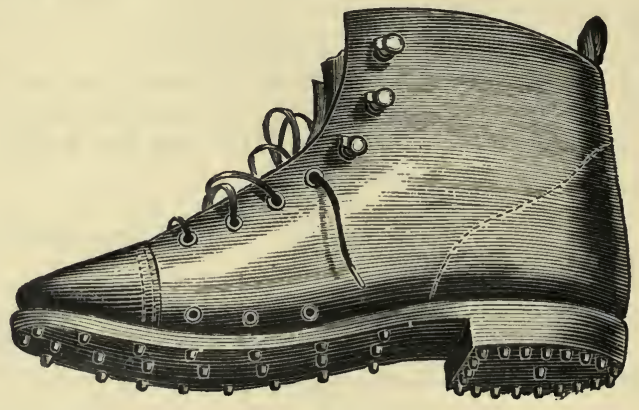

I may here mention some stockings with the knee-cap bent into the form of the joint, which were shown at the last Sportsman's Exhibition. I have an idea that the makers were Messrs. Brown and Co., 66, Chancery Lane, but though I took the name and direction, I cannot be quite sure if the address card I have by me is the correct one. Certainly these stockings would be much less likely to slip down than stockings with 'legs' of the ordinary cylindrical pattern, and therefore should prove a boon to waders.

For those who wish to attach felt soles to their wading boots the following recipe given by Mr. J. Gregson, of Blackburn, may prove useful :-

"In reply to 'Acme' for a cement to attach felt to rubber soles, if he will procure some rubber varnish from any mackintosh manufacturer and apply in the following way, he will have no difficulty in making a neat and good job of his boots.

"First, cut two pieces of felt a trifle larger than the soles of his boots (see that the felt is perfectly dry); then, with a small stiff brush, rub the varnish well into the surface of the felt ; now let the varnish dry for 12 hours, then give another coat and let it dry as before. 
"The boots (which must be perfectly dry) must be well rubbed with coarse sand-paper all over the bottoms where the soles have to be attached, and two coats of varnish given them in the same manner as the felt, allowing each coat to dry before applying the second. When the second coat is dry, press the felt soles well on the boots. It will not hurt them if he hammers them, so as to get the varnish well pressed together. Now pare round the edges, and he will have a neat and serviceable job. I should like to hear how he succeeds.

"J. Gregson, Blackburn.

"N.B.-The above instructions hold good for repairing all kinds of fishing stockings and trousers."

\section{DRESS.}

The importance, as well to the wader, as to the fly-fisher, float-fisher and troller alike, of wearing pure woollen material, not only next the skin, but in every part of their clothing, can hardly be exaggerated from a hygienic stand-point, to say nothing of the additional comfort which their use gives. Of all such garments the best in my judgment is, by far, the all-wool clothing manufactured by "Dr. Jaëger's Sanitary Clothing Company," which I have long adopted, not only for sporting but for every-day wear. I know of none so perfectly suitable to the requirements of the sportsman, whether with horse, rod or gun, or which so admirably adapts itself to all changes of climate and temperature. Cool in hot weather, warm in cold weather, the effect of the sanitary wool clothing is to maintain a regular and even temperature of the body, with an agreeable and healthy moisture of the skin. The importance of these conditions, having regard to the constant weather-vicissitudes to which the fisher necessarily exposes himself, cannot be over-rated. They apply equally to the robust and to the weakly - and indeed as much (if not more) to women than to men, whilst to those who suffer from lumbago-the wader's enemy-I speak from experience when I say that the effect is almost magical. In cases of rheumatism, also, I hear on all sides glowing accounts of the benefits derived from Dr. Jaëger's system. Only last night $I$ sat by a well-known sportsman at 
dinner, who told me that some months ago, when nearly crippled, he was advised by Dr. Ringer, the celebrated medical writer, who makes the treatment of rheumatism a special study, to adopt the all-wool clothing, and that in 48 hours he was half cured, the cure having been completed since. I owed my own adoption of the system to the advice of another eminent London physician whom I consulted for lumbago-a legacy of youthful indiscretions in the wading line-and having experienced so much benefit myself I am glad to have the opportunity of recommending it to my fellow sportsmen. In an article in the "Spectator" of 13 Nov., I886, on a recent book of mine, "The Sporting Fish of Great Britain,' in which I advocate wool clothing, the reviewer concludes :-

"As we are writing for the benefit of anglers we will add our testimony to that of Mr. Cholmondeley-Pennell in favour of the woollen clothing supplied by the "Jaëger Sanitary Clothing Company." We have tested it on Mr. Pennell's recommendation, and we are well satisfied with the result."

Another sportsman writes to the Fishing Gazette (4 Dec., I886) :-

"In my fishing suit I follow out Dr. Jaëger's sanitary woollen system, and have nothing but woollen clothing, and no linings or other portions of my garments are either cotton or linen. The result is a uniform temperature, one neither getting oppressively hot nor miserably cold ; and having, in addition, the cloth waterproofed to begin with, I can be out for a day without ill effects."

The most charming of under garments for comfort is the Jaëger combined drawers and under-waistcoat in one, which entirely does a way with all tightening in, tying, or buttoning round the waist, and also with the necessity for wearing shirts of any kind. I also find their patent combination outer garment-Norfolk jacket and knickerbockers in one (a natural complement to the first)-a great luxury for all sporting purposes. The "combination" part of the business of course gets rid entirely of braces-those most unmechanical of trouser-suspenders and inconvenient of appendagesthe absence of which, and consequent complete freedom of shoulderplay, I find to be a great advantage in shooting; and as I have been 
in my time a winner of probably more shooting prizes than any other Englishman living, including half the grands prix of Europe, and the last "Universal championship" at Monaco, my experience in matters relating to the gun is, at least, tolerably practical. The disposition of this dress in connection with " Jaëger's Combination Under Garment" is such as to facilitate the discharge of the natural functions, in which respect, N.B., it would present great advantages as applied to the campaigning uniform of our soldiers. Exteriorily, no one would notice any difference between the combination dress and an ordinary Norfolk Jacket and knickerbockers. Its general appearance may be seen in the frontispiece, taken from a photograph.

Now that the fair sex are taking seriously to sport (I was much interested, by the way, in reading that Her Royal Highness the Princess of Wales is an enthusiastic pike-fisher) it would be very ungallant, to say the least of it, to omit any notice of their especial requirements, of which an appropriate costume forms an important feature. To enjoy completely any kind of open air sport it is a sine quâ non that the sportsman, or sports-woman, should be properly equipped for it ; and assuredly of that which is comprised in the term 'equipment,' the clothes one wears are not the least important item.

All my remarks on wool-clothing apply equally to the shooting and fishing dress of ladies. A fair sportswoman who has had large practical experience both with rod and gun, favoured me with her ideas on ladies' sporting dress, when I published the Fishing Volumes in the Badminton Library of Sport, extracts from which I append :-

"Short skirt of linsey wolsey made as simply as possible-in fact, a kind of ' housemaid's dress.' Norfolk jacket made of all wool material. A comfortable toque (the close-fitting toque does not catch the wind). It is best to have the costume of one colour, say a nice heather mixture or whitish grey. 
"Now for the most important item-boots. They should fit perfectly, and be made of porpoise-hide, with honest broad soles and plenty of room for the toes, and flat heels-in their proper place, not under the arch of the instep. The boots should lace in the same way that men's shooting boots do, and be made to come well up the leg (so that gaiters can be dispensed with). Length of skirt an inch or so above the ankle. [I say 5 or 6 inches. H.C.-P.]

"This dress is suitable for either fishing or shooting. If worn for the latter over a 'clayey' country, a few inches of light waterproof on the bottom of the skirt are advisable. Some ladies wear gaiters, but I think if the boots are made high enough they are not necessary. 'All-wool ' under-garments should be worn, from stockings upwards."

This dress, with the Norfolk Jacket and Skirt made in a single piece (all-wool cloth), is also manufactured by the Jaëger Clothing Company.

The Sanitary Clothing Company have two principal depôts in London, No. 3, Prince's Street, Cavendish Square (close to Oxford Circus), and 4I, Fore Street, Moorgate Street, E.C. I always get my 'kit' from the Princes Street Depôt, as being for me the most accessible, but no doubt exactly the same things are to be obtained at both establishments, as well as at their retail depôt at No. 85, Cheapside, E.C., and 59, East Street, Brighton. Other depôts, I82, Wabash Avenue, Chicago, and 827, Broadway, New York.

Whilst on the subject of the Sportsman's outfit, I may call attention to the Sans Bouton gaiters, a "notion," as our American cousins would call it, introduced by me a year or two ago, and which was registered by Messrs. Nicholls \& Co., of No. 18, Piccadilly, W.

In explanation of this little innovation on the orthodox pattern, I may perhaps quote one or two extracts from the press notices of the Sportsman's Exhibition.

" Mr. Cholmondeley-Pennell is fertile in inventions for the sportsman's personal comfort. His last 'notion' is the 'sans bouton gaiters' (registered), which are intended to remedy the fault inherent in all gaiters with 
buttoned or spring sides, namely, that in heavy wet, or soaking turnips, the water at last gets in between the interstices. In Mr. Pennell's gaiter there are no buttons or springs, and consequently no interstices, their place being occupied by a waterproof seam. The modus operandi-by which, incidentally, all the bother of buttoning and unbuttoning is got rid of-is simply a reversing of the ordinary sequence : the gaiter is put on first and the boot afterwards. The absence of buttons should commend itself to anglers, especially trollers. The price is the same as ordinary leggings."-Bell's Life, 3oth April, I884.

"This legging is made on a very good and very simple principle. . . There are no buttons or springs to fasten up. . . You have only to pull it on and tighten a strap at top and bottom. For either fishing or shooting it will be found to save time and trouble and give much comfort."-Fishing Gazette, 22nd March, I884.

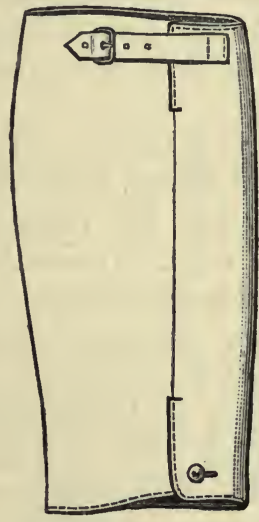

\section{"SANS BOUTON" SHOOTING AND FISHING LEGGINGS.}

"The 'Pennell Sans Bouton Shooting and Fishing Leggings' (registered), an invention of Mr. Cholmondeley-Pennell, are amongst the novelties attracting notice at the Sportsman's Exhibition. By this very simple and practical invention the labour of putting on and off of leggings is reduced to a minimum, there being only one button at the bottom and one strap at the top to fasten. The sides of the leggings are represented by a waterproof seam, so that the sportsman walking in wet turnips or long grass will keep his legs and feet dry instead of getting them wet through between the interstices of the buttons and button holes, as in the case of the ordinary leggings. We commend this very simple and useful invention to the notice of our readers." - Land and Water, 22nd March, 1884 .

The leggings are made either in leather, flax or canvas. 


\section{ROD-BOXES.}

Speaking of 'leather,' reminds me I have omitted to mention the subject of 'Rod' boxes, which, however, are probably now-adays made more often of wood. Still the old-fashioned cylindrical solid leather rod-case, with the 'unpickable' lock, which, as a boy, caused me, I fear, to break the roth commandment, had a special 'character' of its own-a free and easy, 'knockabout' sort of devil-may-care look, making one quite comfortable in one's mind even when watching it subject to the gentle attentions of the railway guard or porter. Mr. B. R. Bambridge, of Eton-on-Thames, makes a speciality of these solid leather rodboxes, both cylindrical and 'square'; as well as of boxes in oak and Japanned tin, all of which can be relied upon as thoroughly sound and serviceable.

Another 'box' of peculiar interest to those who tie their own flies, is manufactured by Messrs. Williams, of Great Queen Street. Their "Vade Mecum for Fly Dressers" is really a marvel of ingenuity and compactness. It contains compartments-some 20 in all, I should judge-for stowage of hooks, feathers, silks, wax, gut, and the amateur fly-dresser's hundred and one trifling, but practically indispensable, implements; and all in the modest compass of a box about to inches high by 3 or 4 wide, and the same in depth (of side). The way the various boxes 'dovetail' one into another, and each in his proper and accessible place, is like one of those puzzles we delighted in as boys-except that the 'puzzle' in this case is only of a few moments' duration.

Some further matters of interest to fly-fishers will be found further on under the head of "Miscellanea."

\section{GUT.}

I am sorry to say that I have nothing in the way of "improvement" to chronicle in regard to this prime necessary for fishermen. On the contrary, my impression is that every year the gut gets shorter and less perfect. Messrs. M. Carswell, the well-known gut makers, of Glasgow, claim to have invented an improved instrument for 'drawing' gut ; but drawn gut is, even when a necessity, a necessity to which I only submit 
on " compulsion," as it soon gets 'woolly' or 'pulpy,' and wears out rapidly when exposed to moisture or friction. The gut when first made has an outer yellow skin, and the 'dissolving off' of this-probably by some sort of alkali-produces a whitening or bleaching effect, which makes the gut semi-opaque. Mr. R. B. Marston writes on this subject: "That ordinary unstained " bleached gut is semi-opaque may be easily proved by placing it " over black writing on white paper. Mr. S. Allcock informed " me some time ago that there was no difficulty in getting gut like "glass, but that the dealers would not buy it unless it was " bleached-a process which impairs its strength-and he sent " me some strands from which the thin yellow skin had been " merely peeled off, instead of being removed by chemicals. The "gut was as transparent as the purest glass. I should like to ask " him if he cannot put some of this really transparent unbleached "gut on the market, and also what prevents „undrazon gut being "manufactured as fine as drawn gut ?"

Dr. Henry Downes, who wields a graceful and prolific pen in matters piscatorial, has touched upon this same question of gutbleaching in a letter to the editor of the Fishing Gazette :-

MANUFACTURE OF GUT IN SPAIN.

SiR,-Many years ago an officer in the 42nd Highlanders gave me a hank of gut which he had brought from Gibraltar, having purchased it when stationed there. It was in long strands, and had a distinct orange-coloured coating.

It was the best gut I have ever seen, the strands being much longer and stronger than any we can purchase in this country.

If, by soaking in water, the orange coating could be easily removed, as stated in your footnote to the interesting letter in the Fishing Gazette of the Ist inst., I have no doubt it would prove most perfect gut, far superior to any that can be had at any fishing-tackle shop in England.

It is a great pity that gut of this kind is not imported, as the various processes through which it is put before being offered for sale no doubt materially affect both its strength and transparency. $-\mathrm{I}$ am, \&c.,

Tiverton, Devon, May 3, 1885.

Henry Downes, M.D.

Here then is a department of fishing-tackle making in which improvement appears to be not only most desirable but in all pro- 
bability feasible. I commend the subject to the practical consideration of our great gut importers, such as Messrs. Carswell, of Glasgow, and Ramsbottom, of Manchester.

The best gut is the longest and roundest, the evenest in substance, and most absolutely transparent-transparent (to borrow Mr. Marston's words) "as glass."

I conclude these brief observations with a diagram and description of the "Buffer" Knot, for single gut salmon casting lines, and gut spinning traces. The effect of it is to diminish greatly the size and unsightliness of the knot, whilst at the same time making it the strongest instead of the weakest part of the cast. But as no man's witness in favour of his own invention is free from suspicion of bias, I will quote in preference the frank testimony of Major John P. Traherne, whose excellent chapter on salmon fishing in the Badminton Library of Sports has been so widely read and so highly appreciated :-

"Not long ago I fondly imagined I had invented a plan for "uniting the links of a casting line without knots, and was on "my way to the Fishing Gazette office to unfold my secret. My "friend, Mr. Cholmondeley-Pennell, happened to accompany me "on a different business, and on my letting him know what mine "was turned round and said, "My dear fellow, I am very sorry "for you, but I brought that out years ago in the Modern Practical "Angler, and as we were passing Farlow's shop at the time he "took me in and soon convinced me that he was right and that " his principle and mine are the same, although differently carried " out. Therefore, although I can lay no claim to be the inventor " of the 'buffer knot,' I can honestly say that I had never seen or " heard of it before.

"It is impossible to invent a better method of fastening gut "together than that which makes the fastening the strongest 'instead of the weakest part of the casting line, and it is surprising "to me that this method has not been adopted." 
The figures numbered $\mathrm{I}, 2,3,4$ in the wood-cut, represent the four different stages in the process of tying the Buffer Knot, of which figs. I, 2 and 3 show its initiatory, and fig. 4 its ultimate appearance.

\section{THE 'BUFFER' KNOT.}

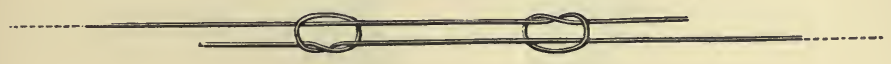

1

2

3

a

The final stage, it will be observed, consists in lapping between the "buffers" or separate halves of the knot. This may be done either with waxed silk (the lighter the color the better) or with very fine gut, previously thoroughly well soaked.

The knot is called the 'Buffer,' because, literally, the two half-knots, with their intervening lapping, act as buffers to receive and distribute any sudden jerk or strain on the line. To the salmon fisher, or pike spinner who uses single gut traces, this knot means in all probability the saving of the loss of several fish -and those generally the best-every season.

\section{MINNOW-SPINNING TACKLE.}

The cut shows a tackle which will be found equally suited for spinning the natural minnow (or a small loach) either for salmon or trout, and whether in running or still water. Who was the inventor I do not know, but it was shown and explained to me some years ago, more particularly in regard to its use for salmon 
spinning, by Mr. Augustus Grimble, whose capital book on deer stalking has lately been given to the public. I have described very fully all that relates to this Tackle and the method of employing it in the Badminton Library; and I will therefore

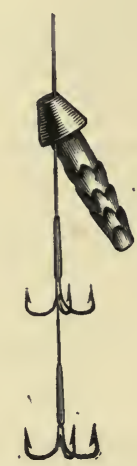

FIG. I.

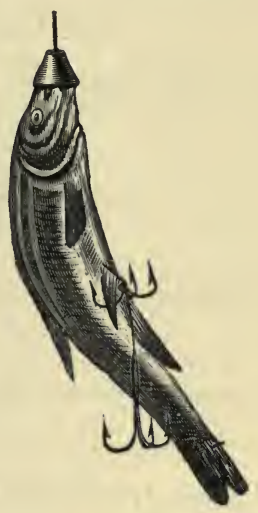

FIG. 2 .

\section{SALMON AND TROUT MINNOW-TACKLE.}

only here give a brief formula for baiting it. Having detached the lead from the trace-or the trace from the flight of hooks (shown before detaching in fig. I) - pass the gut through the bait by means of a baiting needle, introducing it at the vent of the bait and bringing it out at its mouth; then slip the lead down the gut and push it down into the bait's throat and belly, drawing up the hooks until the bait is curved in the position shown in fig. 2. The bait is now ready for use. For salmon, and also for lake spinning for trout, a larger minnow than that shown in the illustration is desirable.

The only drawback to this excellent tackle is that, in order to bait it, the trace must be detached from the running line-or the gut-flight from the trace. A tackle of my own, especially designed to meet this difficulty, is appended. 

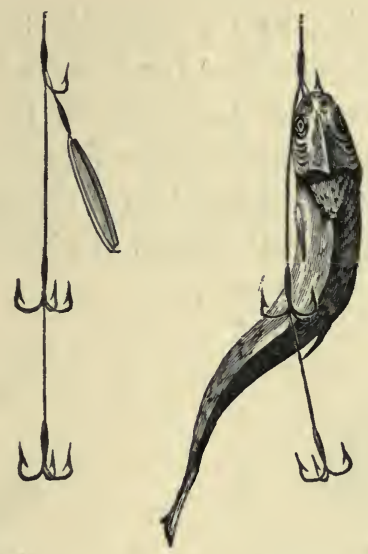

FIG. I.

FIG. 2 .

PENNELL STREAM MINNOW-SPINNING FLIGHT,

To bait it all that is needed is to push the lead quite down into the bait's belly, ${ }^{*}$ closing the lips with the lip-hook. The upper triangle is then inserted through the bait's back behind the dorsal fin, so as to crook or bend it into the position shown in the cut, or until a brilliant spin is obtained.

I notice that since this tackle was first brought out it has been included in several of the Tackle-Makers' catalogues, so that I presume they have found it more or less approved of. Messrs. Farlow make a speciality of this, and of the preceding flight.

Of Artificial Minnows a bare catalogue would occupy many pages. Of these the major part are of brass or silvered and gilded metal-and some half golden, and half silver, plain or painted. They are for the most part variations of the well known Devon Minnow, which in my experience still takes a good deal of beating. There can be no doubt, however, that the two flying-triangles

* To facilitate this the short link to which the lead is attached should be stiff-the gut-loop being lapped over with waxed silk, right up to the lead. 
with which these minnows are 'rigged'-though in themselves very good for hooking fish-have an inconvenient habit of getting entangled with each other and with the line, and accordingly many inventions have from time to time been brought out to obviate the annoyance. Illustrations of three of the most recent are appended. They are all of brass or white metal.

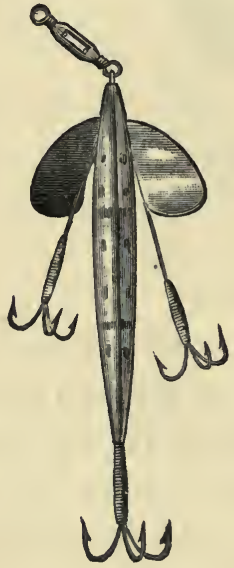

"EXCELSIOR SPINNER."

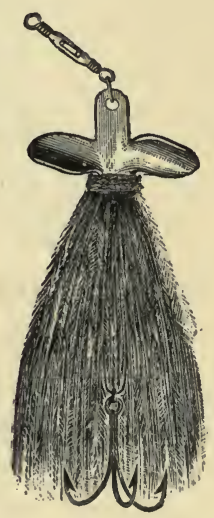

"HALCYON" SPINNER.

The Excelsior Spinner, by Messrs. Hardy Brothers, is similar to the quill minnow, which Messrs. Cummins, of Bishop Auckland, manufacture. It differs from it, however, in that it is made of metal instead of quill-thus both lasting longer and being more suitable for fishing heavy streams. The quill minnow I have known, however, very successful in light water. It is precisely of the same pattern as the above, merely substituting painted quill for brass, or white metal.

The Halcyon Spinner, made by the same firm, is based on the model-or more correctly, perhaps, on the idea-of the wellknown Alexandra fly. It is made either of Nickel Silver, or brass 


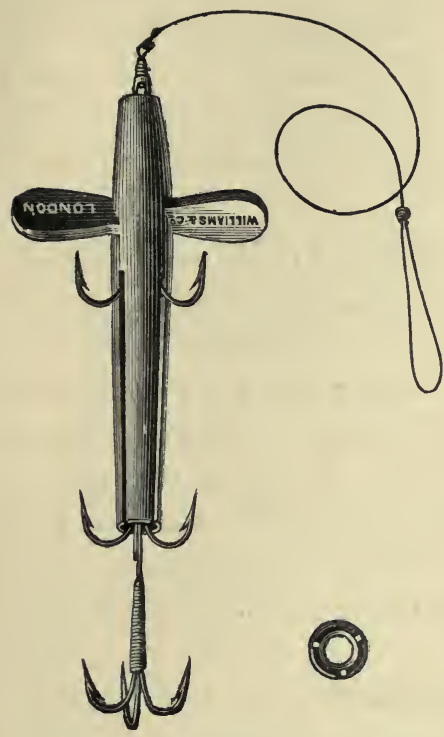

plated, having two small "fans," or wings, at the head, and is dressed with the same feathers as the Alexandra fly. I have not used it, but Messrs. Hardy describe it as having been very successful both with the salmon and trout.

This metal Minnow instead of having 2 slots at the side, like the Devon Minnow, has 3 ; thus allowing the triangles to pass right up the bait as far as the wings, and dispensing altogether with flying triangles. It is the invention of Messrs. F. T.

"IMPROVED" DEVON MINNOW. Williams.

Another metal minnow, in which a different 'rig' again is

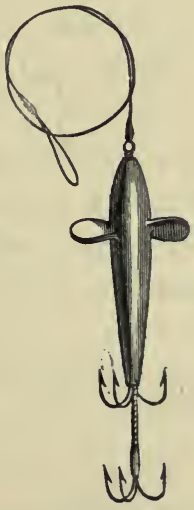

NEW BRASS MINNOW.

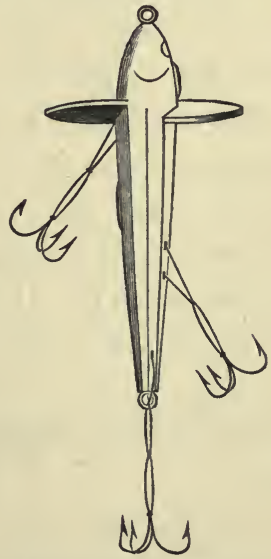

HEXAGONAL MINNOW. 
adopted, is Farlow's new brass pattern, and if the 'theory' that trout generally take the minnow by the tail be correct, it ought to be an excellent one. In this case, as well as in that of the "Excelsior Spinner," the bait does not, of course, run up the line when a fish is hooked.

I designed the "Hexagonal Minnow" (solid metal) originally to meet some of the inconveniences indicated as belonging to the arming or 'rig' of the ordinary 2-slotted Devon minnow. Any entanglement of the triangles is, it will be seen, almost impossible in the "Hexagonal Minnow." The object of making it severalsided-hexagonal or octagonal-was, of course, to produce a more glittering effect, which, especially when water is at all clouded or very dark, would naturally be advantageous.

This minnow does not run up the line on hooking a fish.

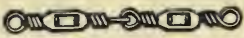

DOUBLE SWIVEL.

In the trace for stream minnow-spinning at least one double swivel (another little dodge of my own) should be employedclose to the junction of the trace and reel-line-in addition to the swivel (if any) at the lips of the bait. This is necessary to prevent kinking.

As the bait is of itself heavy and only for a short time in the water in stream fishing-usually a sort of 'in and out process'no fixed lead on the trace is either necessary or permissible.

For lake spinning, where a lead is most commonly used, an

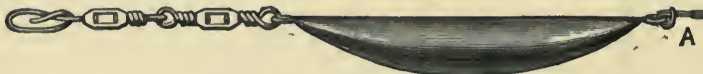

SPINNING LEAD AND DOUBLE SWIVEL.

(' $A$ ' upper end of lead.) 
excellent pattern, figured in the engraving, will be found more fully described under the head of "Pike Spinning Tackle." It often happens, however, in shallow lake trout fishing that no lead whatever, for the purpose, that is, of weighting the trace, is desirable; and in this case, in trailing the minnow behind a boat, the line is very apt to kink, no matter how many or how perfect the swivels. So situated I have found the plan illustrated below effective and convenient. It consists of a piece ot

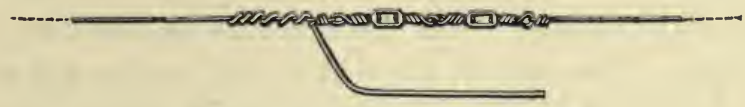

\section{LEAD-WIRE 'SWIVEL COMPELLER.'}

lead-wire twisted round the trace just above the uppermost swivel, with the end bent down in the form shown. Thiswithout practically adding to the weight of the trace-offers sufficient resistance to its twisting tendency to compel the swivels to perform their proper function. For temporarily adding weight it is also a good plan to twist stout lead wire round the trace, above the swivels, in the manner described under the head of Pike Tackle.

In traces for lake spinning there should always be at least 4 feet of fine clear picked gut between the lead and the bait. I have not infrequently used a 3 yard fly-cast for the purpose, cutting the trace and tying in the swivel, \&c., near about the middle. Good sport may often be obtained amongst the lake trout on 'an impossibly calm' day by thus trailing a brass minnow-simply substituting the minnow for the fly. The plan stood me in good stead this year, I remember, when fishing Loch Urigill, Sutherland A dead calm set in, and being unprovided with ordinary trolling tackle (even had such been applicable to that lake, which it was not) we might have sat on the shore and smoked away the midges at considerable leisure if we had not adopted the plan described. 
My friend and I rigged up our extemporary trolling gear, and, whilst "whistling for a wind," managed to have some capital sport amongst the denizens of that teeming though somewhat weedy sheet of water, all unaccustomed to the sight of a spinning bait of any kind.

\section{PRAWN TACKLE.}

Though not exactly a sequitur to what precedes, I may here perhaps describe a tackle for fishing the prawn for salmon, which is highly recommended by my friend, Major Traherne. It consists of two double hooks and a needle, as shown in the lefthand figure. The needle, attached to the line by a free loop, passes in at the bait's tail and out at its breast, where the protruding point is pressed as far as it will go through the small loop, shown on the lowermost pair of hooks. A few turns of cotton or silk-red for choice-round the tail prevent the latter slipping; or the binding may be continued up the body and back again to the tail.

When baited the appearance of the prawn and hooks is as shown in the right-hand figure, represented, as well as the bare tackle, about half actual size.
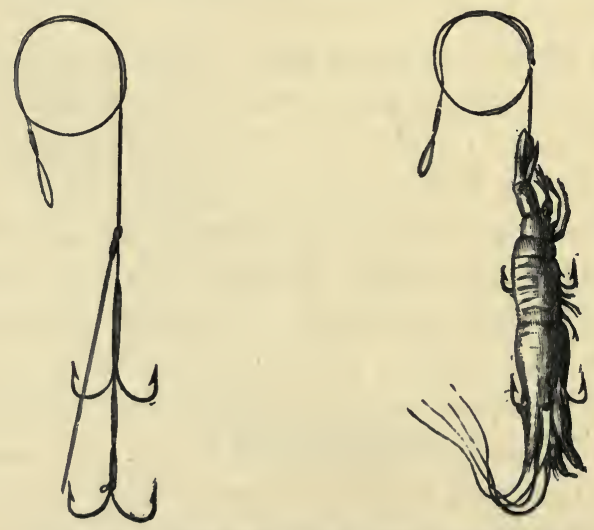

PRAWN TACKLF BAITED AND UNBAITED. 


\section{PIKE TACKLE.}

I must not eviscerate my "Book of the Pike," * by reproducing here all the little matters in which, from time to time, I have endeavoured to improve the various descriptions of tackle used in spinning, trolling, and live baiting - the more so as most of these are well known and have been already for some time before the public; but as, since the last edition of the "Book of the Pike" was published, I have made one or two considerable further improvements in spinning flights, I may perhaps not inappropriately briefly notice these. The most generally important, as it appeals

PENNELL "STRAIGHT REVERSE AND TAIL HOOKS,"

AS ATTACHED TO FLIGHT.

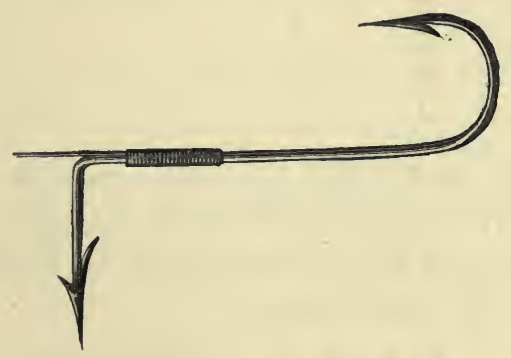

SIZE FOR MEDIUM FLIGHT.

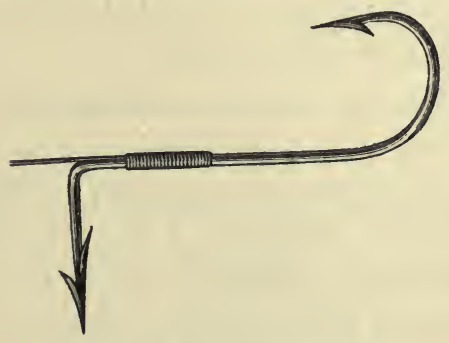

SIZE FOR SMALL FLIGHT.

* 4 th Edition : Routledge and Sons, Broadway, Ludgate. 
to all classes of Pike spinners-novice and ' past master' alikeis the "straight reverse" hook for crooking, and keeping crooked, the tail of the spinning bait.

The diagrams represent the most commonly used sizes, bare and lapped on, of the "straight reverse" hook. This hook is both easier to adjust than my original curved reverse STRAIGHT REVERSE AND TAIL-HOOK, BARE.

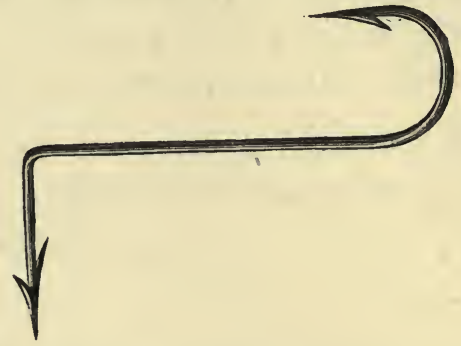

hook, and also makes the bait last much longer and spin more brilliantly. The second barb was the ingenious addition of Messrs. Farlow, who keep all these flights-as well as the tracesin stock, made from my patterns.

Of Flights all sizes may of course be made to suit special requirements or individual taste, but those shown in the engravings, and particularly No. 2, are applicable to the greatest number of ordinary waters and ordinary baits.

No. x.-This flight is suitable for a small-sized gudgeon, dace, bleak, chub, or trout, $4 \frac{1}{2}$ to 5 inches long. It is adapted particularly for very fine pike-spinning or spinning for Thames trout.

The small figure to the right at the top represents the appearance of the bait when attached to the flight.

No. 2.-This flight is what may be termed a medium size, though I rarely use any larger myself. It is suited for a largish gudgeon, or for a small dace, \&c., $5 \frac{1}{2}$ to 6 inches long. 


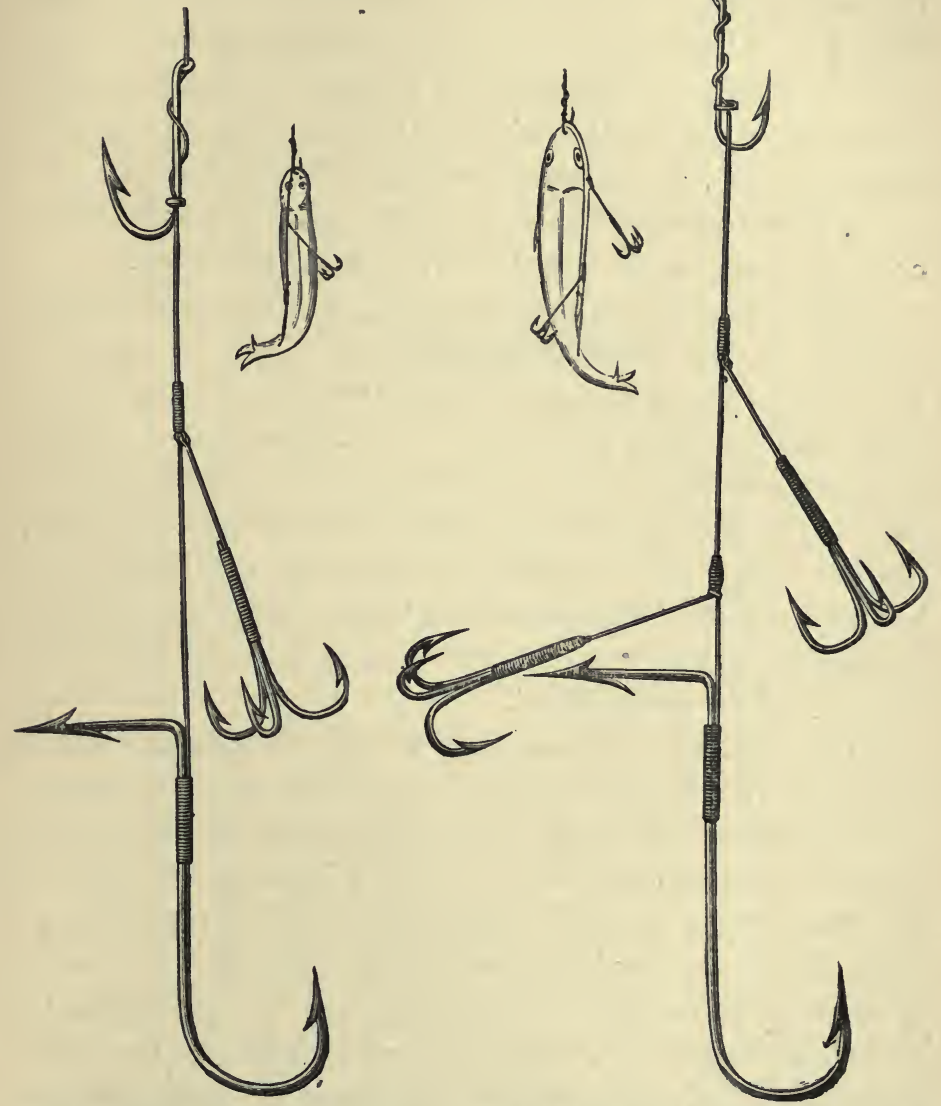

SMALL-SIZED SPINNING FLIGHT. LARGER-SIZED SPINNING FLIGHT.

There is also a still larger size made-No.3-not figured here, adapted to a heavier bait, say a dace of $6 \frac{3}{4}$ to $7 \frac{1}{4}$ inches long.

PIKE SPINNING TRACES.

Many years ago I published in the Field the diagram of a lead intended to obviate the spinner's bette noive, "kinking." Kinking is 
solely the result of the non-acting of the swivels, thus allowing the twisting motion of the bait, instead of being confined to the lower part of the trace, to extend upwards to the reel-line.

To remedy this, I changed the position of the lead, so that instead of being evenly balanced, by the trace passing through a hole up the middle, the centre of gravity was shifted to a point below, thus creating a 'block on the line,' above which the 'twist' could not pass, and obliging the swivels to do their work.

This notion was at once taken up, and numerous were the patterns of lead designed to perfect the idea, the journal in which my letter was published leading the way with the "Field" lead, which has again been varied over and over again. I myself made more variations than anybody, but still could never feel sure that the possible limit of perfection had been reached, having regard to the numerous points that had to be considered-such as 'weed catching,' conspicuousness in the water,-and above all that the paramount essential of a genuine and effective ' block' should be thoroughly fulfilled.

One point soon became plain to me, viz., that in order to give the system fair play the correct position for the swivels was close below the lead; just at the point, that is, where the vis inertice of the lead was likely to exert its influence upon them in the most direct manner. Then, after further experiments, I found that two swivels joined into one had, for some reason, a much more certain and reliable effect than the same two swivels separate; and, finally, in order to secure the utmost economy of time and convenience in changing flights, baits, \&c., I designed a 'hook-swivel' - now the property of Messrs. Farlow-
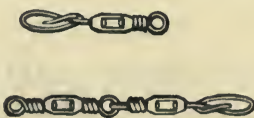

PENNELL 'HOOK-SWIVEL.' 
which I believe combines in the simplest possible form the essentials of such an appliance : i.e., small and sightly; instantaneously attachable to, and detachable from, the line when wanted; impossible to become detached from it, under any circumstances when not wanted. It is hardly necessary to point out to those who have tried them, that none of the other existing hook-swivels fulfil the whole of these conditions; whilst several can hardly be said to fulfil any one of them.

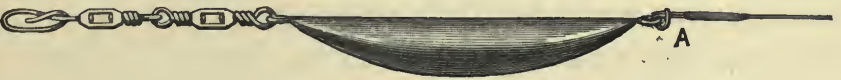

NON-KINKING LEAD, AND HOOK DOUBLE-SWIVEL.

The engraving-repeated from p. I30, to save the reader the trouble of referring back-shows the form of lead, with hookswivels attached, which appears to me on the whole to possess the greatest number of advantages with the fewest-or, as I might rather say, without any-disadvantages. It is neat, cannot catch in the weeds, and by being made with wire loops in one piece and the swivels joined on, is not only calculated to outlast a score of leads and swivels attached in the old fashioned manner, but also saves a great deal of time to the Tackle Maker, both amateur and professional.

Attached to the line as I shall presently describe, it is, I have no doubt, the best form of the under-hanging lead that has ever been elaborated-this I say my own special pattern notwithstanding. The lead figured is the outcome of patient consideration on the part of Messrs. Farlow, working on my previous models and on the pattern already referred to as the "Field" lead-the "Field" lead having been again modified in various points by $\mathrm{Mr}$. H. S. Thomas, in his clever book "The Rod in India."

In order, however, to do full justice to this lead, it is important that the upper part of the trace-whether of gut or gimp-should be looped to the wire at the top end of the lead exactly in the 
manner shown in the cut (marked A). By the gut or gimp loop being thus attached the plane of the horizontal line is thrown slightly higher (in other words, the centre of gravity is further lowered), very greatly increasing the efficiency and twist-resisting power of the lead, whilst offering no projection to disturb the water-or catch in weeds.

Let me urge upon any of my readers who intend trying this lead to insist absolutely upon attention being paid to this apparently most trivial, but really most important, point.

If extra weight be required, it can be very conveniently and expeditiously gained by the addition, above the fixed lead, of a temporary coil of lead wire. To apply this I found the best plan was to twist it first round a hair-pin, or a fine baiting-needle, laid on the trace (and, of course, including the trace itself); then, drawing out the pin, the lead wire can be tightened in easily in regular coils by twisting with the finger and thumb.

As regards the material of the trace itself, I generally use below the lead 3 or 4 feet of salmon gut, and then a few inches of fine gimp between that and the flight-the actual flight itself, except under special circumstances, being also dressed on fine gimp. The gut links should be knotted together by the Buffer Knot described at page 125 . This is most important, as with a stiff rod and the sudden sharp stroke necessary in spinning, the gut, if tied in any other manner, is very likely to break.

Several attempts have lately been made to adapt fine twisted wire, specially annealed, to the purposes of spinning traces. I can conceive that they might prove very successful for the portion of the trace above the leads, but since, some years ago, I gave up experimenting myself in this direction with twisted copper wire, I have not had any practical experience on the subject, so that I can offer no opinion worth having one way or the other.

It must be said, however, that their appearance is all in their favour. I have before me a spinning trace in thickness equal to 
the finest gimp, composed entirely of " Dr. Collis' patent steel wire," for which Messrs. Little and Co., Haymarket, London, are the agents. The steel, which in its manufactured form is of agrey color, is tempered in hot sand before twisting, and it takes a good deal of 'scientifically applied' effort to succeed in effecting a fracture. Dr. Collis' wire ought to be especially suitable for Mahseer fishing.

The same remark applies to Messrs. Farlow's "Annealed twisted wire," of which the editor of the Fishing Gazette says :

"We feel perfectly certain that this annealed twisted wire will be found to meet a great want, viz., a material of great strength, fineness and hardness to resist teeth of pike and eels. Wire has been used before now, but in single strands ; this twisted wire is a great improvement."

In dismissing this subject of spinning flights and traces, a few quotations from the independent opinions of the Press and of individual pike-fishers on the qualifications of the tackle I advocate may not be amiss. The tackle itself will be found figured more or less accurately (or inaccurately) in most of the angling books and catalogues published during the last decade.

\section{(From letters published in the Field.) \\ "MR, PENNELL'S SPINNING TACKLE.}

"As I observe that a discussion has lately appeared in your columns between Mr. Cholmondeley-Pennell, 'the apostle of fine fishing,' and the advocates of the status quo, I beg to bear my testimony to the success of the former gentleman's theories, so far as I have had an opportunity of testing them. During the last fortnight $I$ have been using a set of the spinningtackle recommended by Mr. Pennell, and nothing could be more admirable than its working; ' kinking,' an old enemy of mine, did not once make its appearance, and of the six fish run on the last day, not one failed to find its way safely to the bag."-ONE wHO IS NOT TOO OLD TO LEARN.

"Allow me to add my testimony to that of your correspondent, "One Who is Not Too Old to Learn,' as to the merits of the spinning-tackle explained in your columns by Mr. Pennell, the 'apostle of fine fishing.' I dressed a trace, flight, \&c., according to his plan, and I must say that I never had better sport (for the water) than since I have used it. I lost comparatively few fish, and besides basketed several perch, which I had not previously done over the same ground, probably owing to the coarser tackle then employed. The 
greatest boon, however, for which spinners are indebted to Mr. Pennell, is the complete cure of ' kinking,' accomplished by his mode of fastening the lead."JACK KETCH.

"A friend of mine, Colonel Villiers, is in raptures with the killing tendencies of your pike tackle, and tells me he has discarded all others. From my limited experience, I fully endorse his opinion; it is deadly indeed, proving fatal in about five times out of six, or perhaps rather more."-From W. PEARD, Author of "A Year of Liberty," "Fish-farming," \&c.

"The remedy proposed to obviate kinking, pleases me very much, the said kinking having been invariably my bugbear. I have discarded line after line all to no purpose, but I feel satisfied that you have found a remedy for this hitherto bête noire of anglers. The perusal of the 'Book of the Pike' has completely revolutionised my faith in my own tackle."-RICHARD B. AUSTIN.

"I gave this tackle a severe trial a short time since; I tried it with a bleak. Now a bleak is always a difficult bait to make spin well, it is very apt indeed to get out of spinning and is so soft that the slightest touch dislodges the hooks and throws it out, so that it often will not spin properly; and this reluctance with the aggravation natural in spinning baits, somehow always occurs just at the very moment when you want your bait to spin its best. The bleak I had, too, came from a spot where some hot water is discharged, and this always makes them much softer than their fellows. Added to this they were in spawning condition, and in even a worse state still than ordinary. Nevertheless, in spite of all these adverse circumstances, I spun a bleak with Mr. Pennell's tackle for more than two hours. I was fishing long cast, and two or three times it fouled the bottom and took hold of twigs and rubbish, yet it never once got out of spinning for an instant, but spun on to the last as well as it did when I put it on. With the ordinary three-triangle tackle, the bait would have been out of spinning and the centre triangle loose in ten minutes, and in ten minutes more the bait would have been useless."-ANGLING EdiTor, Field.

"Mr. Pennell's plan of hanging the lead is glorious for pike-fishing."H.B.

"Mr. Pennell's new and improved style of fixing the lead on a spinning trace to prevent the line from twisting will prove the best thing that ever happened to pike-fishers who fish from a reel. He is quite right, it is a perfect cure for all kinking. The gentlemen whom I have supplied with the tackle are much pleased with it, and tell their friends it is the best idea ever inventedand I think so too. I have frequently been perfectly stuck fast from the line twisting, and have been obliged to take it all off the reel and draw it behind me through a field before I could start again ; but, thanks to Mr. Pennell, that sort of work is now all over."-WM. BAILy, Nottingham.

"Spinning for pike is an accomplishment so very widely practised by modern anglers, and the means hitherto adopted are, from a variety of circum- 
stances, so unsatisfactory that we are glad to welcome any attempt to improve the apparatus in general use, or to render those sudden partings between individuals connected by the fine line or strong gimp sympathy, which are so distressing to one of the parties concerned, less common than they unfortunately are. It is notorious among spinners for pike that no tackle has ever yet been invented from which a very large proportion of fish hooked do not manage by some inscrutable means to effect their escape. We have ourselves noticed this fact, and many of Mr. Pennell's views upon this head, as well as others connected with the art, certainly meet our warm approbation. His remarks regarding kinking, for example, are excellent, and the means he takes to avoid it are apparently all that is needed. His plan of employing flying triangles is, to us, original. . . ." - Field. Review of "Book of the Pike."

\section{From the Fishing Gazette.}

"'Has your correspondent, the 'Bostorn Bittern,' in his search for an efficient flight for spinning the natural bait, never heard of or seen the 'Pennell' flight? If not, let me advise him to give it a trial next season, as I am confident, after trying various others, that there are none to approach it. I have used it now for three seasons, and as to missing 50 per cent. of fish, as he complains of, I will engage that if mounted and used in the manner recommended by its inventor (and it can be so procured at several of the London tackle-makers) he will not miss Io per cent. of the fish with it. It is as superior to the old-fashioned three-triangle flight as sunshine to a rushlight. It gives a most brilliant spin, and I have taken fish with it when all other methods have failed. I get mine from Mr. A. Young, of Oxford Street, and find them well and properly made by him."-Rotans, Bury St. Edmunds.

\section{LIP-HOOKS.}

To save myself trouble, and to ensure regularity and durability in lip-hooks, I had some made with two loops of metal brazed on to, and forming part of, the hooks. These answered very well, and are now generally used.
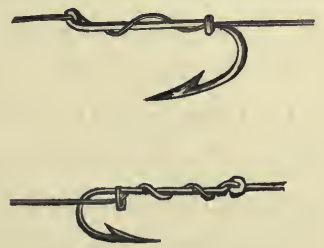

LIP-HOOKS WITH METAL LOOPS. 
In regard to these lip-hooks, Mr. A. N. Cheney, in an article in the "American Angler" says :

"I wrote an article upon 'Hooks for Trolling Gangs' (spinning flights), which was published in The Angler, Feb. I4th, 1885, with an illustration of lip hooks. Since then Mr. H. Cholmondeley-Pennell has described in one of his books that form a part of the 'Badminton Library,' a lip hook of his own designing, that seems to leave nothing to be desired in a lip hook. It has two loops.or rings, one at the end of shank and one at the side, and gut or gimp has no opportunity to slip when this movable lip hook is used."

To save myself still further trouble, however, whilst at the same time "refining" to the utmost this conspicuous part of the flight, I recently hit upon a plan by which the lip-hookitself could be altogether dispensed with; instead, in fact, of keeping the flight in its place by means of a lip-hook I produce the same result-only much more securely, and in a more workmanlike manner-by tying the gimp itself in a half knot through and round the lips of the bait. To effect this, of course it is necessary to detach the trace below the hooks-(here the hook-swivel comes into play) —and it is also necessary-or at any rate convenient-that if a gut-trace be used, the gimp bottom should be very neatly spliced on to it, so as to admit of the whole thing passing readily through the bait's lips when tying the knot.

To make this attachment is easy when the knack is once acquired. I daresay it will appear complicated in verbal description, but I will try to make it as clear as possible. Having detached the trace below the lead, insert the tail-hook of the flight in the bait's tail, and the straight-reverse hook also, right through its side, so as to crook the tail nearly but not quite to a right angle; now pass the end of the gut or gimp under the bait's gillcover (dotted line B, in cut) and out at its mouth, and then transversely through bothlips. Finally make a sort of half knot (C) by passing the trace through itself under the loop formed at the mouth, and having drawn it tight re-attach the loop of the trace (A) to the hook-swivel. 


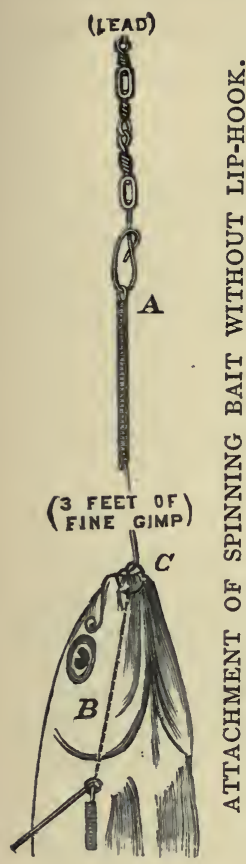

The detachable loop of the trace, whether of gut or gimp, must be lapped close up to the end, in the manner shown in the cut at A; this will not only make it stiff enough to be passed through the bait's nose and lips-thus dispensing with a baiting needle-but also forms a better and neater fastening as regards the hook-swivel. If any difficulty should occur in making the pointed loop penetrate the bait's nose, prick a hole in the latter first with the point of the large tail-hook.

The flight-barring the omission of the lip-hook-is in all respects identical with that already figured p. I35. The above method adds greatly to the durability of the bait, as well as to the general "fineness" of the tackle at a critical point. (It may be observed, parenthetically, that so far as any purposes of hooking are concerned the lip-hook is practically useless-no one can call it sightly.)

STAINING GIMP.

Yellow or silver gimp in its natural bright state fresh from the tackle shops is sadly unsuited to "fine fishing," and, therefore, to heavy baskets. To obviate this I tried various "stains," but gave them up because I fancied they had a tendency to weaken if not actually to rot the gimp, and of late years I use-for the lead as well as for the gimp-simply a light coating of "Brunswick Black" (to be obtained at any Ironmonger's) which can be put on at the river-side, or five minutes before starting, for it is readily renewed when it wears off, and tends to preserve rather than to destroy the gimp. I carry in my trolling case a minute phial of Brunswick Black, stopped with a cork holding a bit of feather. This supply is ample for a week's campaign. 
Here are two or three recipes for staining, which are, I should think, likely to be reliable, and which are stated to produce no bad effects on the strength of the gimp:

"Put your gimp into a little box of card paper, or what not; cover it with some flowers of sulphur, put it aside, and in a day or two it will be as black as you can desire. If you cannot waita day or two, but must have it at once, get a little. sulphur in the soluble state, viz., sulphide of ammonium-formerly hydrosulphuret of ammonia. Put a few drops of this into water, and immerse your gimp. A few hours will make it black enough, without in the slightest degree injuring the silk within.

"You had better conduct the process out of doors, as the odour of sulphuretted hydrogen is not agreeable to everybody."-[Mr. Hearder, in the Field.]

\section{Captain Robinson writes :}

"In your 'Book of the Pike,' which I have lately read, bichlorate of platinum is recommended for staining brass gimp. This I failed to obtain in a county town, but being convinced of the importance of staining gimp, I thought of trying sulphide of potassium. As I find this gives a permanent stain to both silver and brass gimp, I take the liberty of mentioning it to you. Sulphide of potassium may be made by dissolving a little lapis infernalis in water, mixing flowers of sulphur with it, and heating in a Florence flask. I believe quicklime in boiling water will also dissolve sulphur."

Mr. W. N. Locking, in a recent communication, sends me two recipes, tested, he says, by his own experience. I give both, though the second has nothing to do with staining gimp, because it may prove of use to some of my readers :

"' 'Spratt's mange lotion for dogs' is the handiest, quickest and most reliable stain for gimp of all kinds that I have met with. I merely wet a small piece of flannel with it, run the gimp through it once and leave it. In about an hour it is well stained. I have not found it to rot the gimp. . . . Washing with some kind of coal tar soap will usually keep off flies and mosquitos, and is pleasanter than the turpentine unguent."

RODS.

The general observations already offered in regard to fly rods apply, mutatis mutandis, to all sorts of rods used in Pike-fishing, and especially to spinning. For no kind of Pike-fishing should I recommend a rod of over $\mathrm{I}_{3}$ feet in length, whilst for any non- 
muscular troller a I2, or even a Io or II foot rod, would be preferable. My own 'pet rod' is $\mathbf{2}$ feet long. The two middle joints are of bamboo, the butt ash, and the tops-of which I have half a dozen-of greenheart. By having a number of tops the rod can be made to do extra duty when required. For instance, with a fineish top it makes a capital rod for paternostering, Thames-trout spinning, legering for barbel, or for worm-fishing, prawn-fishing, and minnow-spinning for salmon. With a somewhat heavier top, it is perfect for light Pike-spinning; and with the shortest and heaviest top is in its element where heavier spinning baits are employed, as well as for gorge-bait fishing and livebaiting.

The heavier the bait and the larger the hooks the stouter should be the top used. This, as before pointed out a propos of fly-rods, is a general rule to which I know of no exception.

For observations on the best form of Reel I refer the reader to the same chapter, p. 86, and as regards Reel-lines, I shouldNottingham fishing apart-unhesitatingly recommend an untapered dressed-silk line (and that not too stout) for all the objects enumerated in the preceding paragraph.

Next to great strength-which should be tested practically by the hand when purchasing the line-the all-important point is that it should be perfectly smooth. A rough line, whether owing its roughness to bad dressing or bad plaiting, is a constant source of annoyance, wherever, as in the cases alluded to, a free and easy "running" is of the utmost moment. No matter what may be its other qualifications, unhesitatingly reject any line that is not perfectly smooth.

For casting from the reel, Nottingham fishers commonly use a line of the finest white undressed silk, the strength of which, having regard to its bulk and weight, is something extraordinary. Mr. Slater makes these lines double, by some new process of manufacture, thus still further adding to their strength whilst 
adding scarcely anything perceptible to the bulk. A line of this sort, however, is quite unsuited to the ordinary Thamesstyle of casting, and to any other mode of fishing in which the line is intended to any considerable extent to hang free of the reel, whether it be held in the hand or coiled on the bottom of a punt or on the ground.

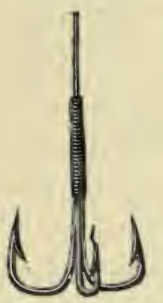

The observations previously offered (p. 76 ) on rod rings, joint fastenings and reel fittings apply equally to trolling and spinning rods. A few notes on a conveniently portable form of pike-gaff will be found at p. 53 .

All triangles used in spinning - flights ought to be brazed together in one solid piece, and TRIANGLE OF' 'PENNELL SNECK" ноокs. should be of the "sneck-head" pattern (without twisted points) or (better) my variation of it. They should not be too short in the shank. The difference as regards its penetrating power between the worst and best forms of hook when employed in triangles is not less than roo per cent.

\section{ARTIFICIAL SPINNING BAITS.}

Of artificial pike baits-of which the name is simply legionmy experience has been, I must say, uniformly unsatisfactory. Moreover pike taste in such matters appears changeable. What will kill, perhaps, fairly well on a particular river or lake one season will hardly secure a run the next, and even the timehonoured 'spoon' seems of late years on many waters to have entirely fallen into disuse.

More recently composite baits-half spoon, half red wool or feather-have found advocates, who, we may presume, have had cause to be satisfied with their performances. One of the latest forms of these is the "Fluted Spoon bait," made by Messrs. G. M. 


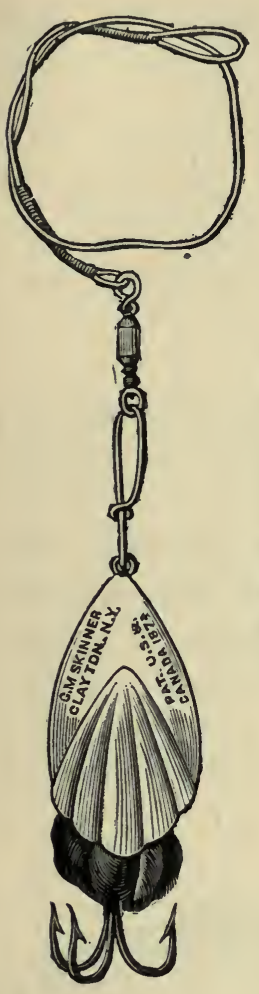

Skinner, of New York, and for which Messrs. Hancock and Watson, of 308 , High Holborn, are the London Agents. It is made in several patterns, of which one is shown in the engraving.

Speaking of "Composite baits," I am tempted to describe a plan that I have on ". more than one occasion found successful, when natural baits of the proper size or species were not obtainable. It consists of half of a roach (say) cut off $\mathrm{V}$ shaped above the vent, and dove-tailed into a tin head, to which the not inappropriate name of the 'Extinguisher' has been given.

The Extinguisher, slightly compressed at the sides to fit the flattened shape of the bait's body, is fitted with tin 'wings' to make it spin; whilst what represents the back of the head is given a coat of Brunswick Black to increase its fishlikeness. The trace is first passed upwards through a hole in the apex, and then the decapitated bait is sewn securely into it with holland thread, for which purpose there are holes drilled in the sides of the 'Extinguisher.' As I say, I know that this spinning bait will kill pike-and sometimes kill right well-but my experience of it has not been sufficiently extended to enable me to express anything but a tentative opinion of its general capabilities.

The 'Extinguisher' part is represented in the engraving.

Some trouble and nicety are necessary to put it together properly, but when small baits are a sine quâ non and none are 


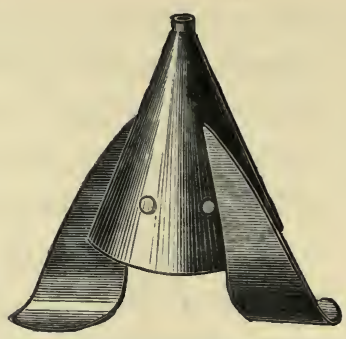

THE 'EXTINGUISHER.'

forthcoming the spinner must not grumble if he has to take extra pains to provide a feasible substitute. Any tin-smith could knock up a few extinguisher heads in ten minutes.

Another bantling of my own, to which I am able to give a still less reliable 'character,' was intended to be a facsimile of a bleak; the two sides of the little 'flat fish' 'were represented by two slabs of mother of pearl, carefully engraved with scales, gill-covers, \&c., and the eyes by the brass rivet which fixed them on to a centra plate of metal. The hooks furnish a sort of rough resemblance to the dorsal and anal fins.

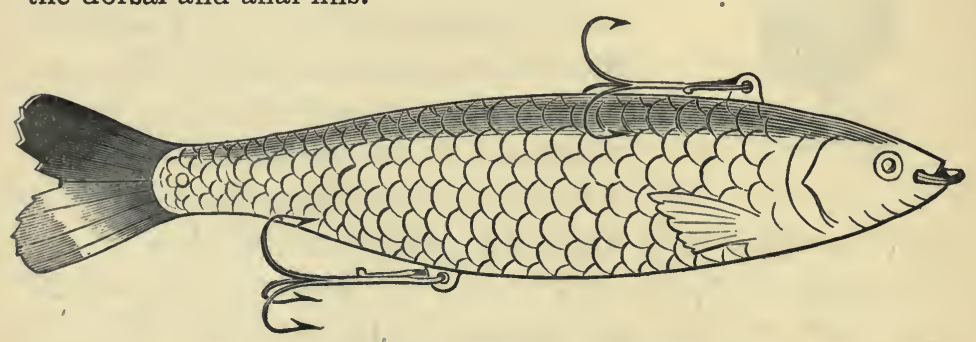

MOTHER OF PEARL BLEAK.

The 'spin,' it will be observed, is obtained from the tail, where the uncovered metal is left for the purpose.

My experience of this bait is, I say, still smaller than with the extinguisher, having been confined, in fact, to a single cast! On arriving at the river-side I saw a good fish feeding, I cast my new 
nacre bait over him, and he took it at once, the next moment breaking me in a stout weed-bed, where, for aught I know, the bait is lying to this day. This was my first and last cast. Still, as I have never seen another artificial bait equally accurate in its resemblance to the fish it was intended to represent, this solitary experience with a bait designed on the "exact imitation theory," may not be altogether unsuggestive or without interest.

\section{BAIT CANS.}

The carrying of all baits alive, wherever possible, is of importance even to the spinner and troller, and to the "live-bait" fisher it is hardly necessary to say it is a matter of some importance. Not many years ago an ordinary tin pot, or kettle, smaller at the top than at the bottom, was the best article our tackle makers could produce for this purpose; then we had zinc receptacles of an oblong shape,-thus,

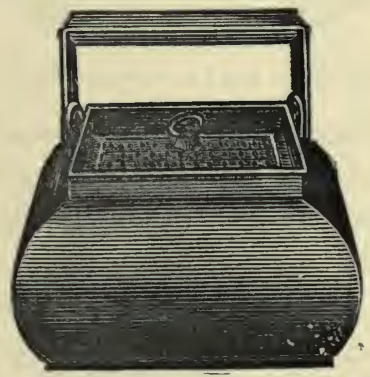

which, at least, gave the inmates more room "for life to gasp ;" and later some ingenious person hit upon a can with removable perforated inside, by which means trouble and time were saved to the fisher, and unnecessary poking and prodding about to the baits.

This was a step in the right direction, but something was yet lacking. Fish cannot 'breathe' in water which has become de- 


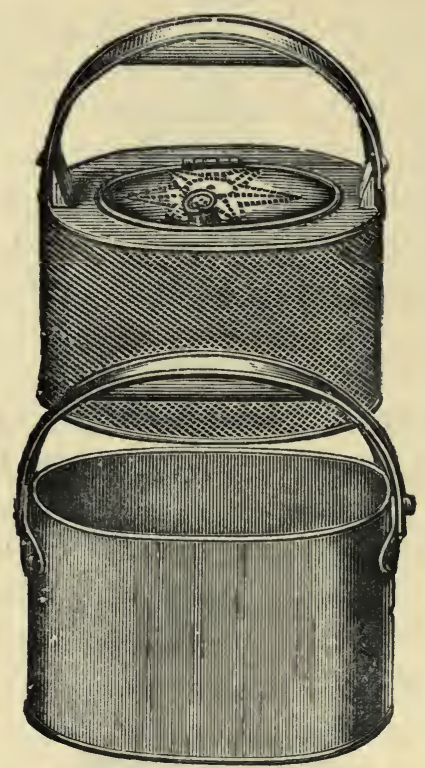

MESSRS. WHITTY'S (LATE EDMONTON'S) BAIT CAN.

oxigenated ; and hence, when the many pairs of gill-leaves (fishlungs) had separated from the water in the can all the oxigen it originally contained, they first 'turned up,' as the expression is, and then died. Various dodges have been invented to meet this. I used to employ a sort of hand-bellows, consisting of an india-rubber 'squash-ball,' fitted to a piece of tubing, with which I could, with considerable trouble-and always supposing that I did not forget it-from time to time convey some bubbles of fresh life to the baits. But by Mr. Basil Field's aerating can all these more or less rudimentary contrivances were superseded, and an idea, valuable both from a utilitarian and from a humanitarian point of view, received its complete and legitimate development. By pressure upon the little knob shown in the handle of figure 2, which can be readily applied whilst 


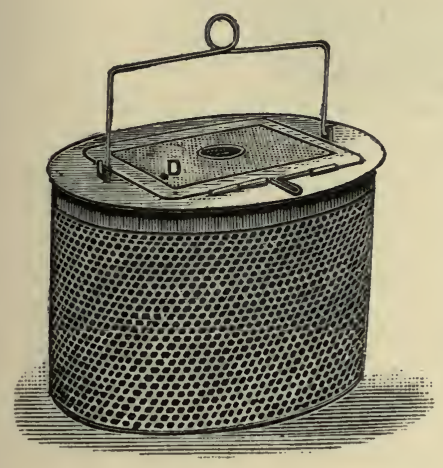

FIG I.

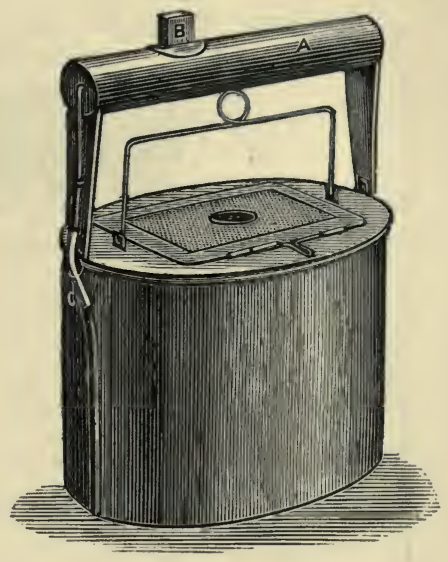

FIG. 2 .

FIELD'S AERATING BAIT CAN.

carrying the can, a sort of bellows is set to work, that effectually, aerates the water and will enable baits to be kept alive and vigorous for infinitely longer periods than heretofore, and with infinitely less trouble. The can, it will be seen, also possesses the other improvement alluded to of an inner, or removable, perforated cage, figure $\mathrm{r}$, which lifts out to admit of a selection from the baits.

Mr. Field's excellent invention is manufactured and sold by Mr. Henry Bawcome, of 2, Victoria Road, Holloway. It is made in two sizes-I gallon and $\mathbf{I} \frac{1}{2}$ gallon.

In quitting this subject, I ought not to omit to mention another ingenious invention, which it seems odd no one should have thought of before, so obvious is its adaptability to the needs of the itinerant pike and minnow fisher. The following account of "Aspray's Folding Bait Can" is taken from the Fishing Gazette. 


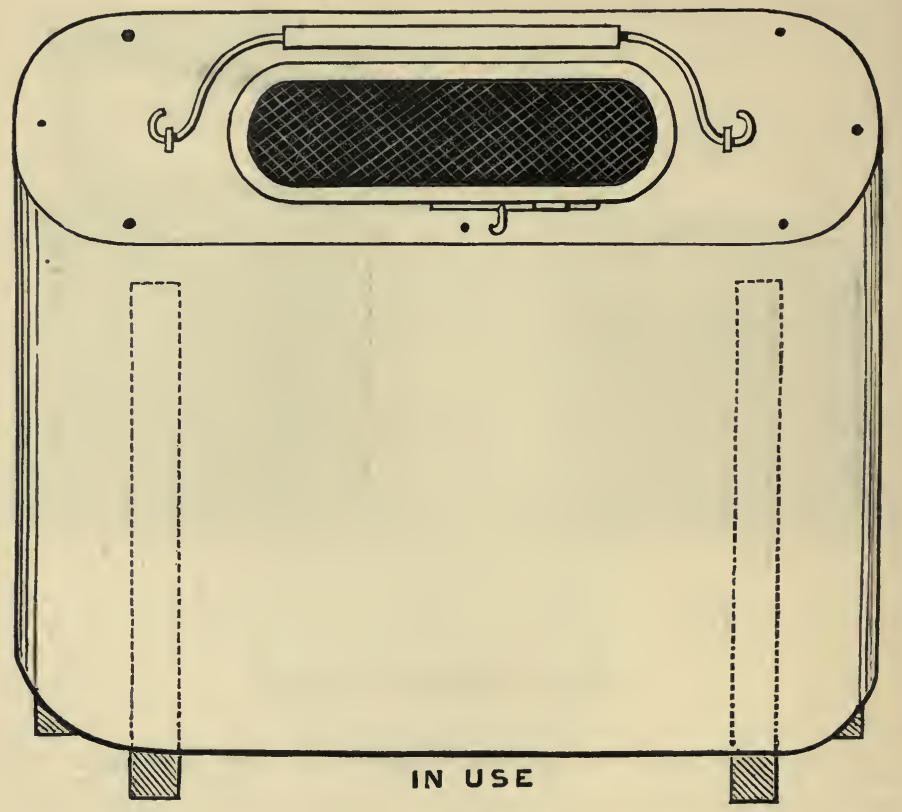

FOLDING LIVE BAIT CAN.

" Every angler who uses a live-bait can must often have considered it a great nuisance to carry when empty. Mr. Aspray has got over this difficulty in a very simple manner. He has patented a receptacle for live-bait made on the principle of the collapsible opera hat. Fancy the convenience of a bait can which you can fold up and put in your pocket when you do not want it for carrying bait. . .

"The affair is made of waterproof material-similar to that used for wading stockings-with a zinc top, fitted with a perforated lid as in the ordinary bait can; there are four thin pieces of wood fitting in spaces in the side, and extending about an inch below the bottom; these keep it rigid, and

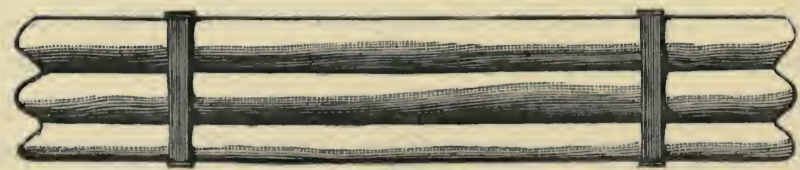

EOLLDED. 
also form four legs, so as to keep the can off the ground, and when not in use are carried inside. When the can is folded, and fastened with two elastic bands, it occupies a very small space, and can be carried in the pocket or basket. Mr. N. Aspray, Surgeon-Dentist, 22, Eastbourne-terrace, Hyde-park, is the inventor."

The "Troller's Knife" can hardly, I think, be strictly called a "Modern Improvement" seeing it has been before the Angling public for some fifteen or twenty years, but as I find there is still a steady "demand" I may perhaps be allowed to allude to it. The idea occurred to me in consequence of the difficulty I experienced in collecting-and, indeed, in recollecting-before starting for the river, the several little appliances necessary to comfort and efficiency,-pocket knife, baiting-needle, disgorger, \&c. ; and it struck me that a 'Trolling Knife' which would contain them all would be a saving of trouble. I, therefore, had a knife made containing as far as possible what was likely to be really wanted, whilst eliminating unnecessary articles, and the knife figured in the cut was the outcome.

The only part of it which was, I believe, really new was the "disgorger blade," as it has been somewhat inaccurately termed, and this has since figured in most so-called fishing knives. It is a really powerful, serviceable weapon, and the extra length obtained by the attachment to the knife-handle has saved me many a cut finger. The knife is manufactured and sold only by Messrs. Watson and Hancock, 308, High Holborn.

In quitting the subject of Pike Tackle improvements, more or less novel, I have reserved one of the best until the last, as a runner keeps his strength for a final spurt. Mr. Alfred Jardine's remarkable success amongst leviathan pike is well known, and the beautiful and life-like casts of some of them are familiar to many besides Trollers, who visited the late Fisheries Exhibition. The tackle with which his execution was principally done is described in the Fishing Gazette as the "Pike 'Leger' and 'Jardine 
THE TROLLER'S KNIFE.

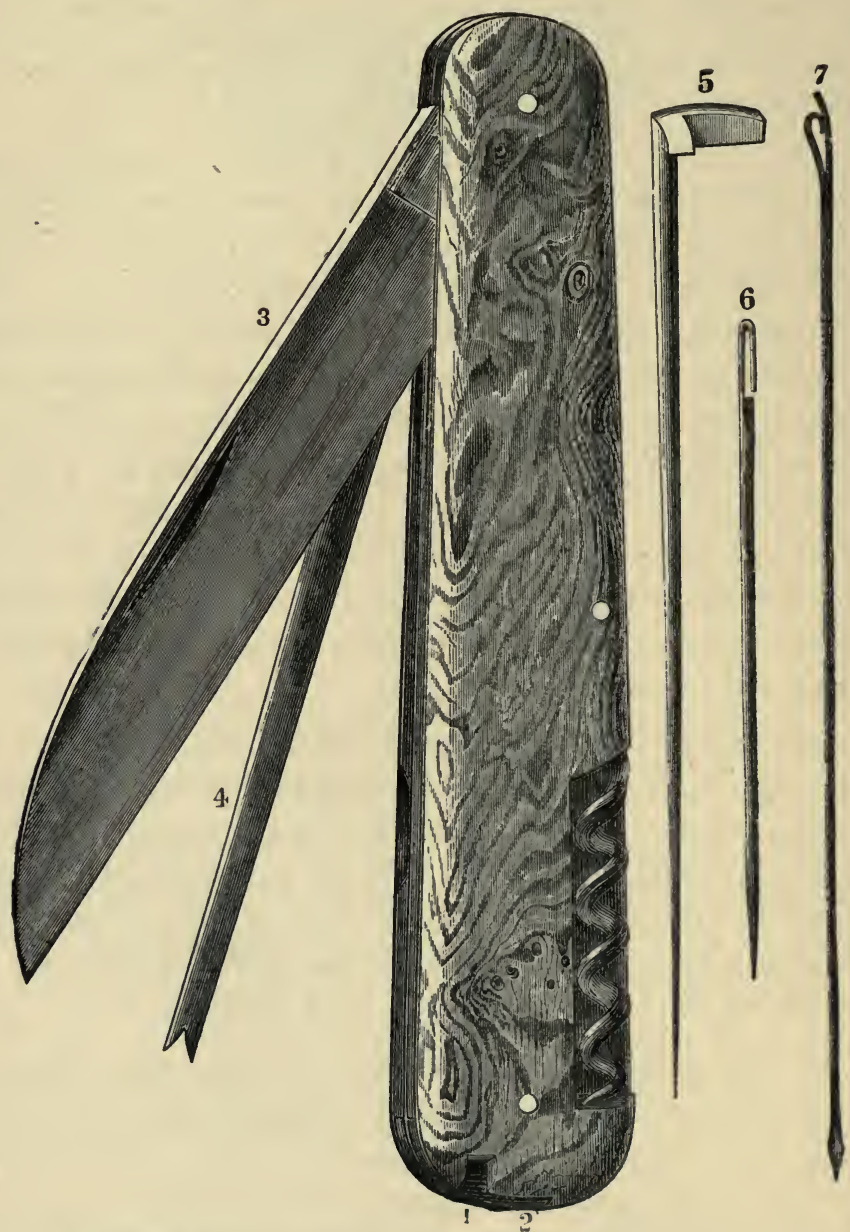

I. Box containing minnow-needle and baiting-needle.

2. Hole for pricker (marked 5 ).

3. Blade for crimping or other purposes.

Snap '" ; and as I have given the cut I cannot do better than'give also Mr. Jardine's own description of his tackle :-
4. Disgorger-blade.

5. Pricker, for loosening knots, separating feathers, \&c.

6. Minnow-needle. 7. Baiting-needle. 
"When rivers are 'in flood,' and in thick water especially, a capital plan is to 'leger' for pike with tackle consisting of $I \frac{1}{2}$ yard of stained salmon-gut, on which is placed a half-ounce perforated bullet, with a swan-shot and swivel $20 \mathrm{in}$. above the 'snap-tackle,' to prevent the bullet slipping down too near the bait which should be a dace 5 or 6 in. long.

" On getting 'a run,' wait for four or five seconds before tightening up the line and striking the fish. Quiet eddies and backwaters, where roach and dace congregate in floods, are the best places in which to 'leger,' for in such places pike also retire, to shelter and rest themselves from the impetuosity of the streams; and for the purpose of being near their 'commissariat.' Under such circumstances they may frequently be caught when the chances are apparently all against the angler filling his fish bag, so that 'never despair' is a maxim well worth a pike-fisher's adoption.

"In 'leger-fishing' there is no reasonable limit to the depth. Even 30 or $40 \mathrm{ft}$. can be readily fished, and in the Scotch or Irish lakes Ioo ft. for the matter of that-if desirable-without difficulty.

"Supposing you threw 30 or more yards from where you are; when the 'leger-bait' drops in the water, immediately pay out more line (say six or eight yards), according to the depth you are fishing, until the bait rests on the bottom, then gather up the 'slack' until you have a tight line. If after a few minutes no 'tug' occurs, lift the point of your rod and draw the bait to another place, where let it again remain for a short time and pirouette about. By pursuing this method you can fish and search every portion of the bed of the river or lake round about you, and should any pike near get a 'kick' or ' knock on the head ' by the bait, it is pretty sure to be immediately seized-for pike are certain to be hungry and on the 'look-out' for food which it is difficult for them to find in floods and thick water." 


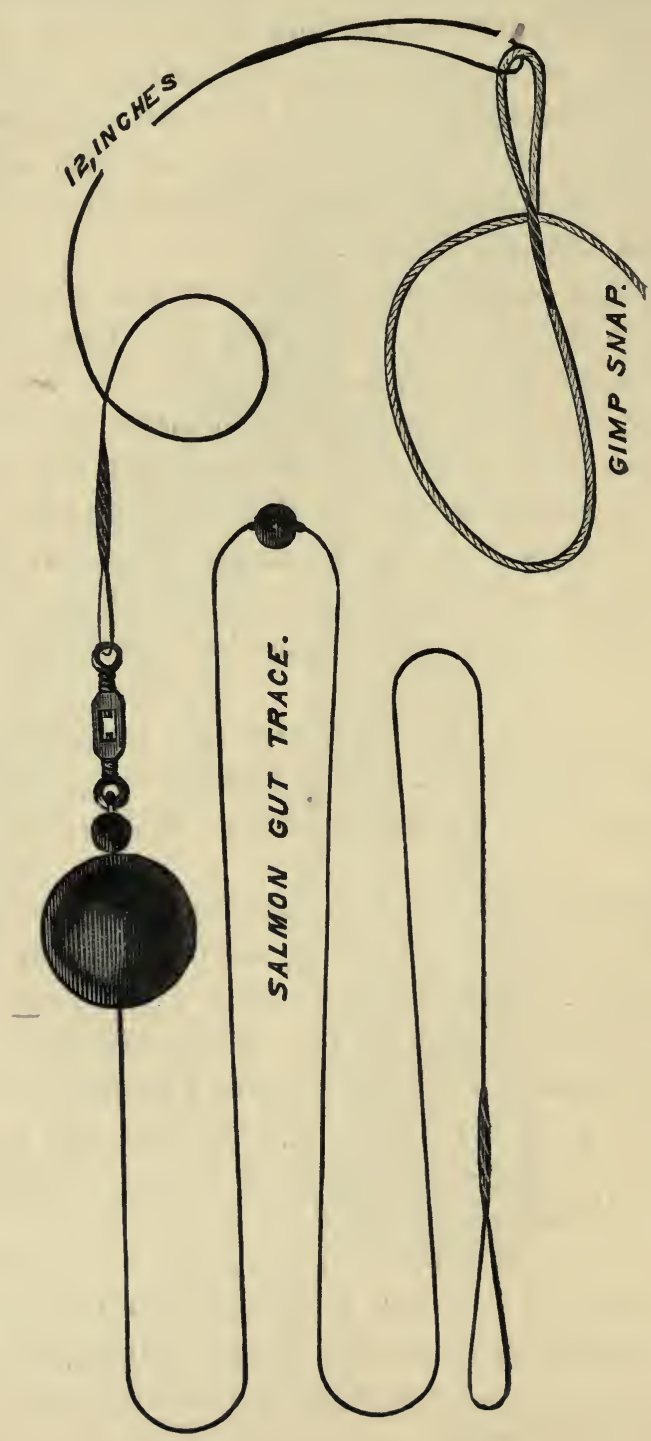



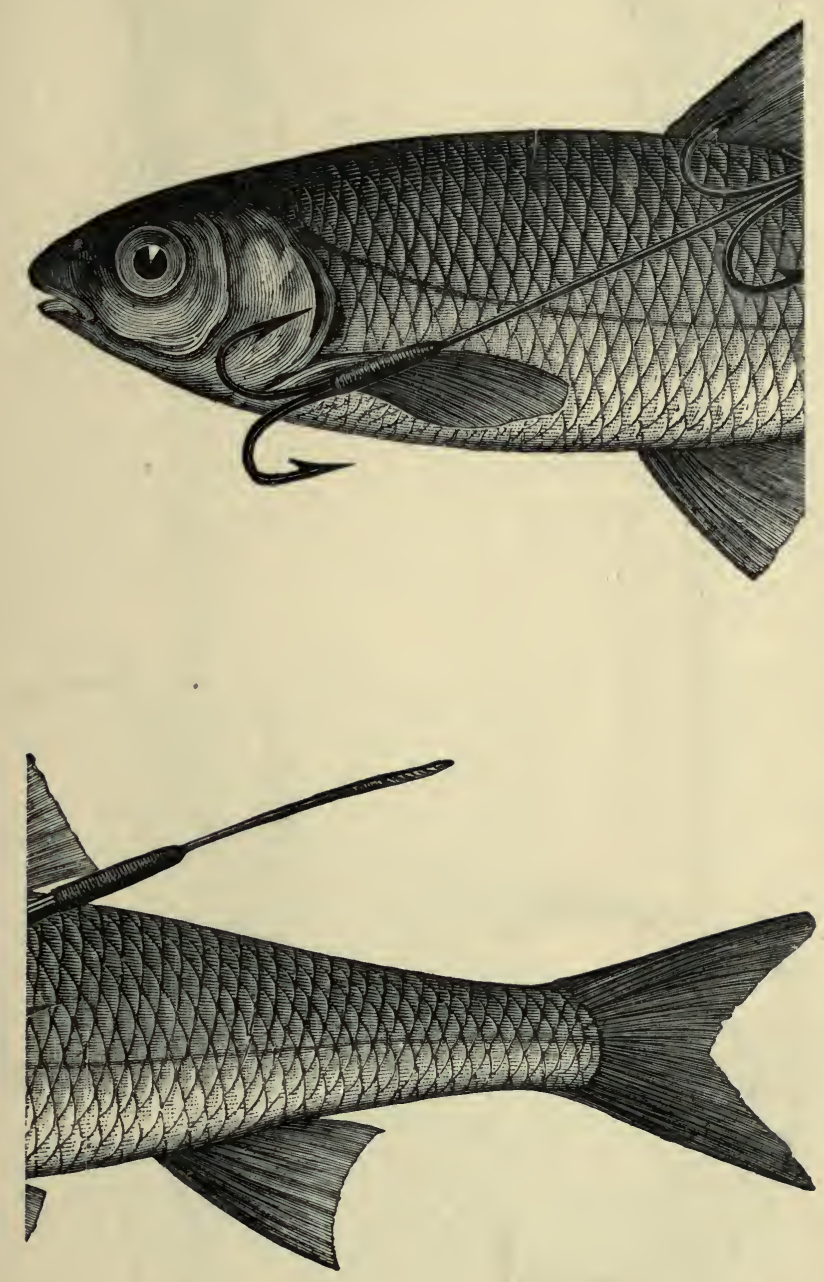

PIKE "LEGER" AND "JARDINE SNAP-TACKLE" BAITED. 

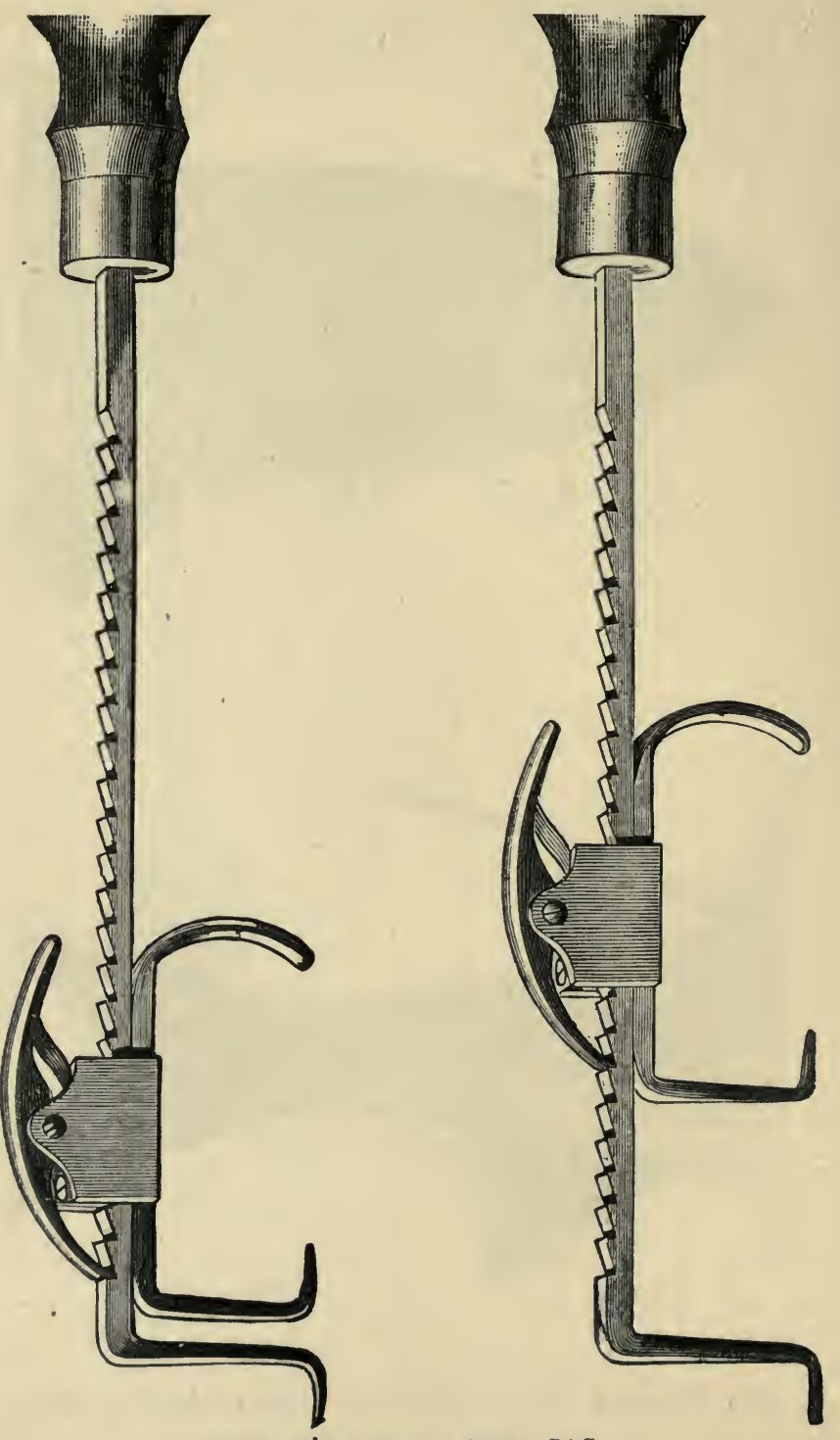

JARDINE'S PATENT PIKE GAG. 
Another useful invention of Mr. Jardine's is the "Pike Gag," for forcing and fixing open the jaws of the fish whilst extracting the hook. This will often save the troller being "let blood in the fingers," as an old author puts it. About an inch of the handle-nob has had to be cut off in the engraving-otherwise a facsimile, $\frac{1}{2}$ real size-on account of the exigencies of space. It still, however, remains a 'majestic torso,' and has a sort of thumbscrew, torture-chamber aspect, calculated to strike terror into the bosom of the biggest Essox that ever swam.

The left hand figure shows the gag closed, in which position the two prongs are inserted between the jaws. The prongs and the jaws are then extended to any length or width desired by pulling up the "spring-rachet," as seen in the figure on the right. The hooks may then be disengaged "comfortably"-i.e., to the troller.

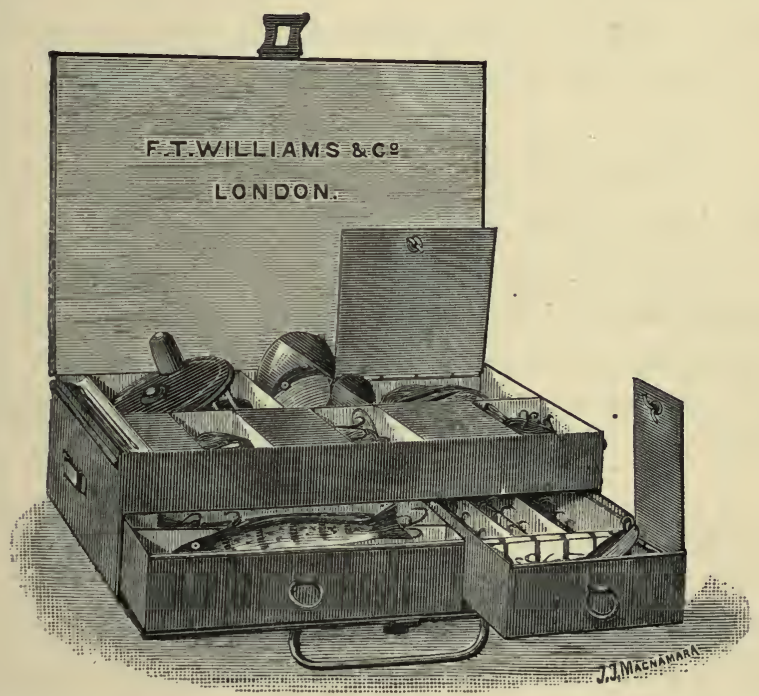

The Cut represents a useful Pike-tackle case, for artificial baits, traces, floats, minnows, \&c. 
Messrs. Williams' box is intended to carry a complete Jackfisher's outfit, including reel; and has several separate divisions for hooks and flights-it is certainly very compact considering how much it holds. Measurement, II inches long, $7 \frac{3}{4}$ wide, and $3 \frac{1}{2}$ deep.

Another excellent "General Tackle box," in japanned tin, is made by Messrs. Chevalier, Bowness and Bowness, 230, Strand. To the angler travelling, or living abroad in hotels and fishing quarters, I should especially commend this box, as containing the requisite space and variety of drawers, compartments, \&c., to enable him to stow the whole of his tackle impedementa-whether for fly, float, or pike-fishing-in one case. The box is made in four or five different sizes.

Mr. B. R. Bambridge, of Eton-on-Thames, makes also an excellent general tackle box for travelling or home purposes, with plate for name or initials, address, \&c. The box material is either of japanned tin, mahogany, or oak.

\section{FLOAT FISHING AND MISCELLANEA.}

The improvements in actual float-fishing gear that I can enumerate are very few. Indeed, beyond the most important one of the application of eyed-hooks to all kinds of float-fishing and bottom-fishing generally-for which the reader is referred to preceding chapters-there is really hardly anything noteworthy to chronicle.

\section{TIIE TRAVELLING FLOAT.}

The gradual spread of the Nottingham style of fishing-with float both fixed and 'travelling'-in most branches of river fishing and in some branches of pond fishing, though in many respects presenting great advantages over the old style, hardly comes within the scope of this essay, having been now for a great many years before the angling public, the modus operandi being also very 


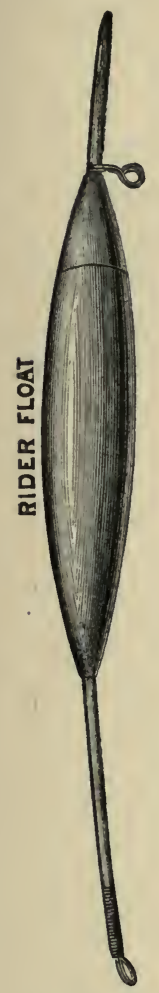

generally understood; and when I have noticed, more as a curiosity than with utilitarian intention, another float, "the glowworm," which is supposed to shine, like its prototype, in the dark, and thus enable the enthusiastic angler to pursue his sport after night-fall, I have said pretty much all that is to be said on the subject.

The above brace of floats are the manufacture of Messrs. Foster, as also is an improved form of clearing hook, which may be useful at a pinch, when tackle has to be liberated or lost.

I should not, by the way, omit to notice another good modification of an old invention in the same direction-Williams' "Cumberland Clearing Ring." The first object, of course, of all clearing rings is, by being slipped down over it, to clear the line that has got fast on the bottom, or received an unwelcome

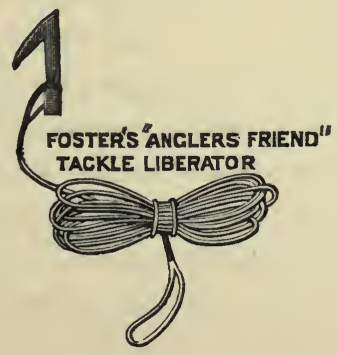


'retainer,' from stump or weed. The novelty in the Cumberland Ring is that, when this process fails, the major part, at any rate, of the line or trace may be rescued, commonly with the loss of hooks only, by 'cutting away below.' Experimentalists will, however, no doubt see the point of the advice given by the patentees to use caution in passing the ring, with knife blade set, down the rod and line. The ring is named after Mr. Cumberland, the inventor. In the illustration, $\mathrm{A}$ is the ring, $\mathrm{B}$ the spring that acts on the knife, $\mathrm{C}$ the knife when 'set' or open, and D the same when closed.

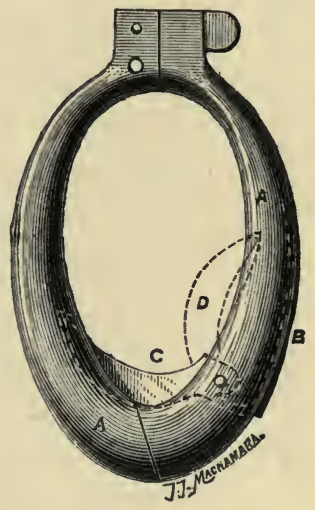

THE CUMBERLAND CLEARING RING.

Nor must I 'forget to recollect' a clearing apparatus, the ingenious invention of the Rev. Eardley C. Holt, and especially applicable to Fly-fishing; as, in addition to a prong or fork for detaching the fly from super or sub-aqueous obstacles, it is fitted with a strong, sharp blade which operates on the bough or twig (always just beyond our reach !) in which we are 'hung up.' In the diagram-half the actual size-the cutter is shown in its position when 'set.' The whole thing screws into the top of the net handle or gaff-handle. The manufacturers are Messrs. Farlow. 


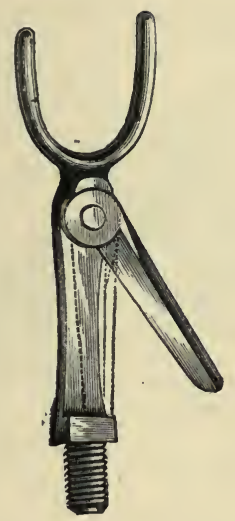

MR. EARDLEY HOLT'S CLEARING KNIFE.

Let us pass on from modern improvements more especially connected with float-fishing, to the mention of a few of what may be called general angling miscellanea. And as I am warned by the publishers that though 'Art is long life is short,'-which I read as a delicate hint to finish-I will condense as much as possible even the few things I had it in my mind to say about them, and, so to speak, introduce them without an introduction, or with the briefest of explanatory or descriptive notes.

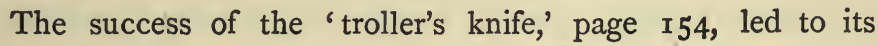
giving birth (though in other hands than my own) to a somewhat smaller-sized offspring, suited for trout-fishing, and fishing generally, except for pike. This was brought out some years ago by Messrs. Hancock and Watson, tackle makers, of No. 308, High Holborn, and how they can make and sell it at the price they do $(6 \mathrm{~s} .6 \mathrm{~d}$.$) , is one of those mysteries into which I do not$ pretend to penetrate. Not unnaturally, it has had, I understand, a very successful career. The scissors and disgorger blades are excellent, both in design and workmanship, and as every fisher, 


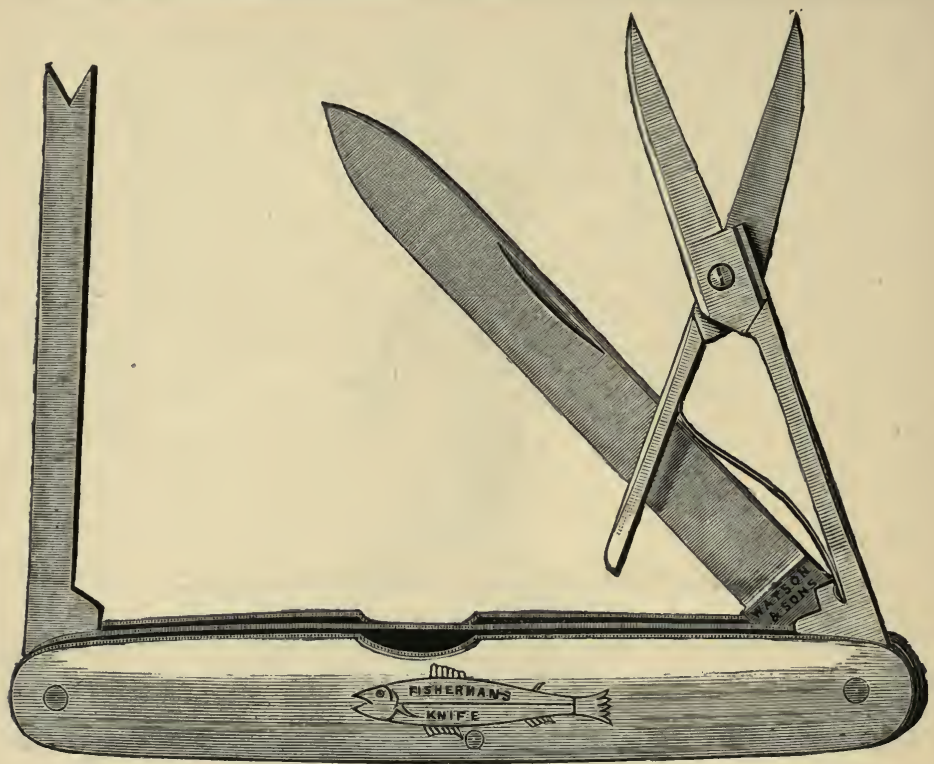

THE FLY-FISHER'S KNIFE.

whether with fly or float, must carry some sort of knife or cutting implement with him, he cannot, perhaps, do better than give Messrs. Watson's knife a trial. Another, though somewhat more elaborate and expensive knife, manufactured by the same firm, is also figured in the cut opposite. It contains in addition to knife, scissors, and disgorger, a saw, corkscrew, two prickers, and a pair of tweezers.

A pair of "disgorger scissors," invented by Messrs. Foster, and intended thus to combine two implements in one, shown in the annexed diagram :-

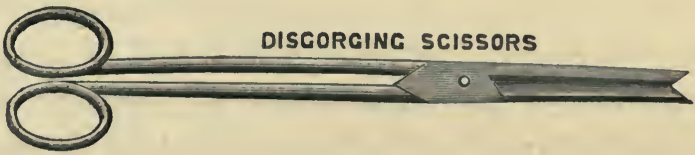




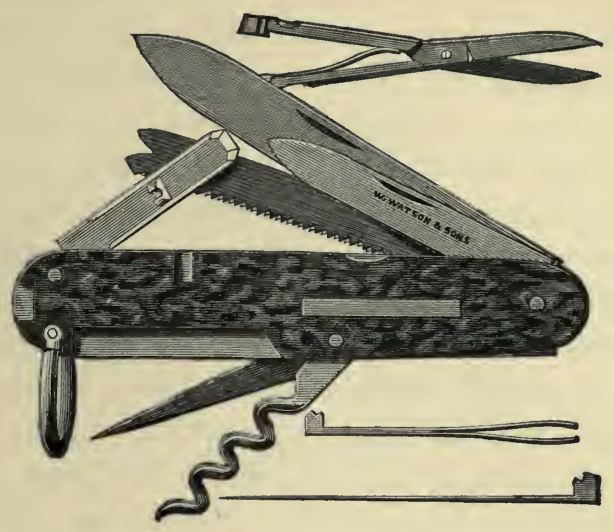

The "Marston Fishing Pliers," designed by Mr. R. B. Marston, Editor of the Fishing Gazette will be found extremely useful to all classes of fishermen, as they combine, to quote from the circular of the manufacturers, Messrs. Wilson and

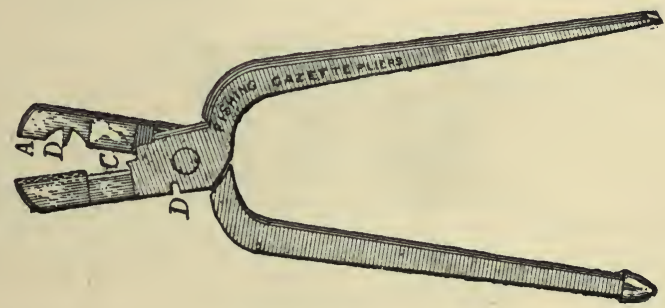

THE MARSTON FISHING PLIERS (HALF ACTUAL SIZE).

Son, 7, King William Street, Strand, "six useful tools in one:""A. Strong round-nosed pliers, for every purpose of a pliers. D. Knife for splitting shot, large or small. C. Fine wire cutter. D. Strong wire cutter. Screwdriver. Rimer for making holes in wood, leather, \&c., or clearing out a ferrule when the top or other joint is snapped off short in it." 
After pinchers naturally come vices. Here is Mr. James Ogden's "Improved Fly Vice," which very thoroughly and satisfactorily fulfils the necessary conditions; the first being that it should really hold the hook so that it will not move when manipulating the $f y$. This vice will hold, and hold fast, too, any hook from No. 000 to a salmon hook. Another great advantage it possesses is that the vice holding the hook can in one half second be almost instantaneously raised or depressed a complete foot, at pleasure; or, equally instantaneously, turned round and fixed again so as to bring the fly into the desired position. Lastly, it is thoroughly strong, mechanically simple in operation, and will effectually clamp on to any table not more than $2 \frac{1}{2}$ inches in thickness.

Hardy's leather Drinking Cups are another little condescension to the weakness of the flesh which have found a good many encomiasts. A cup and its case figure in the cut.
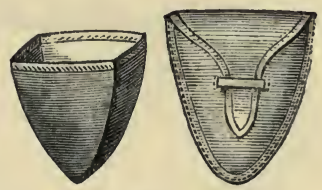

LEATHER DRINKING CUP.

Another convenient ' notion'-an arrangement manufactured by the same firm-is Colonel Johnson's Rod Rack,which appears to hold everything from a pipe to a salmon gaff; but how they are all'kept upright in their respective resting places is not quite so evident from a superficial examination of the engraving. No doubt, however, they fulfil their intended object or Messrs. Hardy would not sell them. 


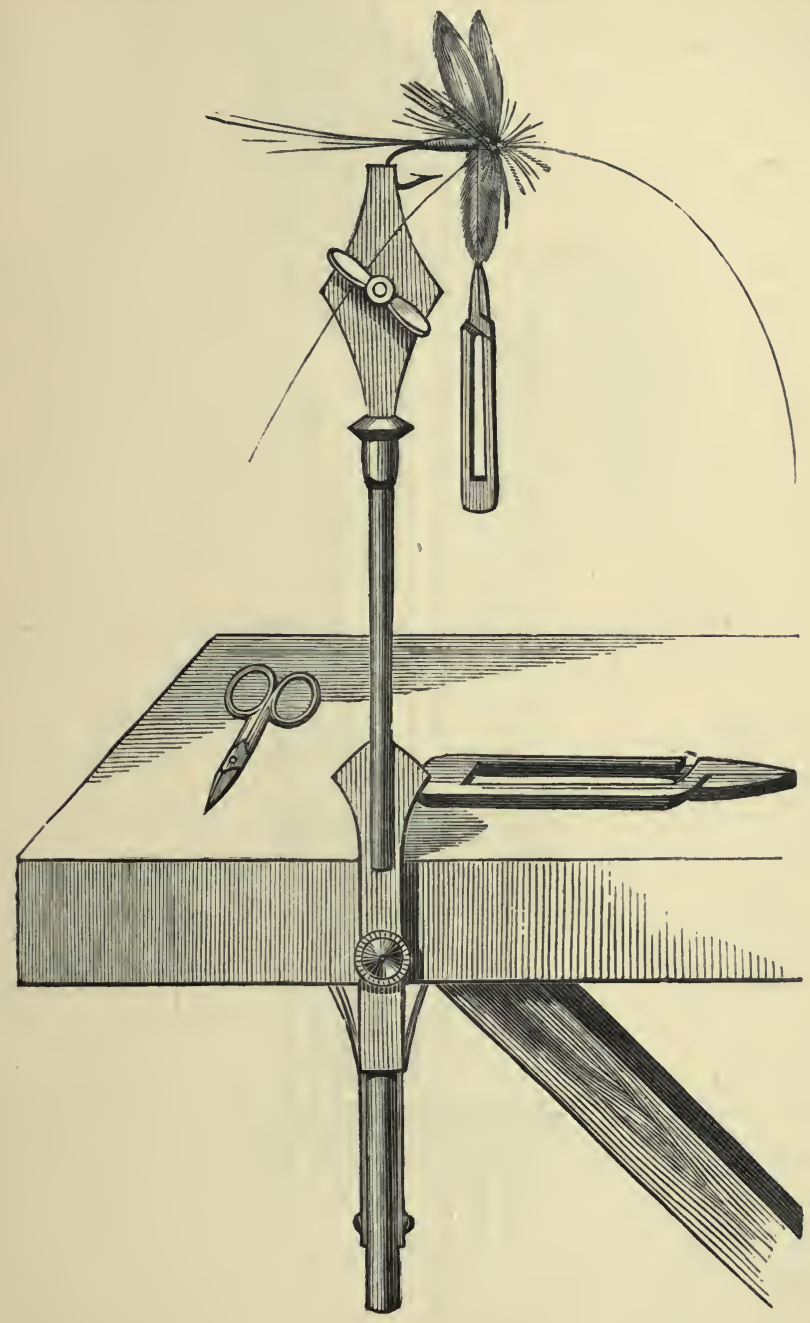

OGDEN'S IMPROVED FLY VICE. 


\section{8}

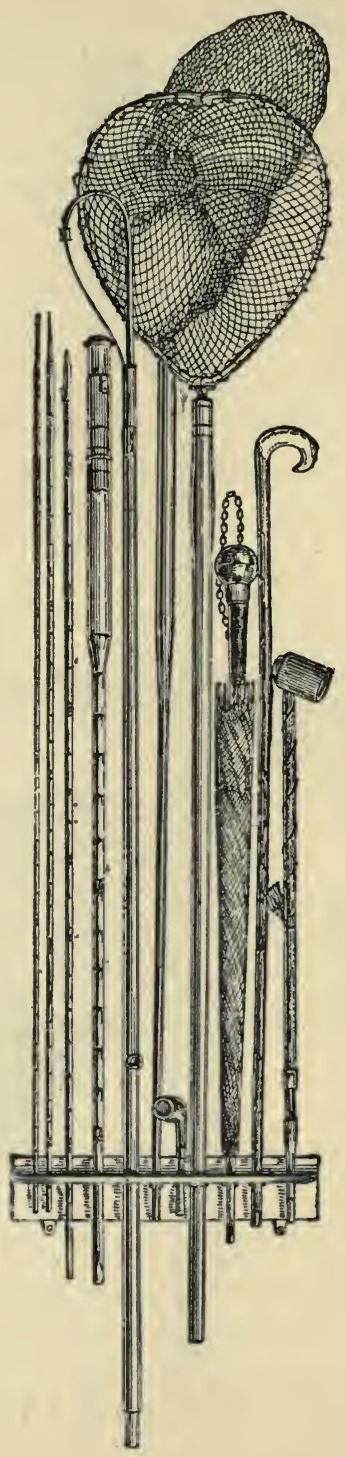


Let me also commend to the notice especially of trollers and fly-fishers a clever invention by Messrs. Farlow for winding off and drying lines. It quite deserves the panegyric bestowed upon it by its inventor.

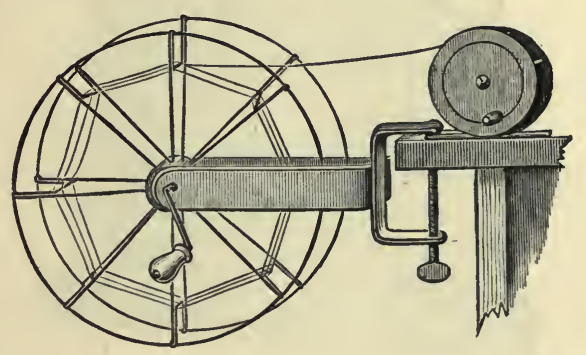

FARLOW'S “ SKELETON" LINE DRIER (REGISTERED).

"A machine for effectually drying lines when wet, made so that the air passes freely through to every portion of the line, and so dries and preserves it. Each winder is fitted with a screw clamp, so that it may be screwed on any table. This clamp, also, is made to secure the winch, thereby rendering the running on and off the winder a very easy matter.

"The great advantage gained in using this winder is, that it entirely prevents the kinking of the line, as is usually the case in the old method of winding the line round the backs of chairs, \&c."

Lastly (ah! pleasant and yet half sad word to the author to write), bottom fishers will welcome Mr. Jas. Ogden's "Seat Basket," figured below-together with his "Spring-folding Landing Net," and "strapped-on" mackintosh; whilst a further addition to their bodily comfort may be extracted from the use of Messrs. C. L. Mathews and Co.'s 'Adjustable Rod Rest,' which is claimed by the inventor to be equally applicable to river, pond and punt-side. 
The well-known response of the bank fisher when asked if he had had a bite-“"No, I only came here last Saturday "- suggests the practical convenience of the foregoing appliances.

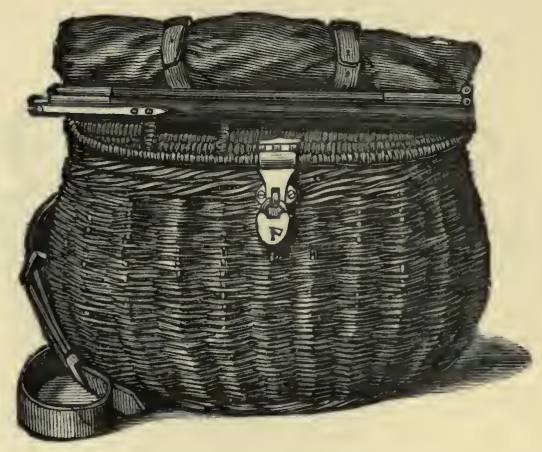

This may sound "kinder sarcastic," as Artemus Ward calls it, but nothing is further from my thoughts. Indeed my heart goes out to these bank-side fishers-these patient sitters by the waterwho for hours together will watch with ever abiding perseverance the top of their 'quivering quill.' I plead guilty to a positive affection for the little ragged urchins, who, with their sticks and pin-hooks, and a soda water bottle to hold their spoils, cluster as thick as bees in clover along the dusty towing-path of the Regent's Canal, and I wish I could distribute amongst them the catching of some of those creels, full of glorious trout, for which in the wild wilderness of moor and loch I have been, alas! so often able to find no better destination than the farmer's pig-trough. Depend upon it the gentle spirit of the mighty master and prototype of our craft lingers lovingly amongst these waifs and strays along life's footway,-perhaps his truest, because least exacting, disciples; and if I had no other cause to be a votary of the angle, the million sons of toil to whom in the intervals of their weary round of 
existence it offers a healthful and consoling recreation, would have been reason enough to make me so. . .

Dear brothers-children, boys, grown men, all you who have taken the pledge in this our freemasonry-let us shake hands together in spirit, at least, if we may not in the flesh.

\section{FINIS.}

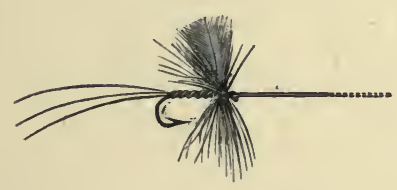





\section{APPENDIX.}

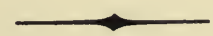

SOME ADDITIONAL EVIDENCE IN FAVOUR OF EYED-HOOKS FOR TROUT, SALMON AND FLOAT FISHING.

As it is obviously impracticable to quote the full text of all the communications from which the following extracts are taken, it has been necessary to omit a good deal of criticism on my own hooks, and those of others, both encomiastic and the reverse. The dates of the letters, \&c., quoted, are, however, given, so as to facilitate reference to the full text if desired. The letters appeared in the Fishing Gazette where not otherwise stated. 



\section{APPENDIX.}

\section{[AS}

What a blessing eyed-hooks are in places remote from tackle shops ! Not long ago we were trout-fishing, and only one fly in our book would the trout look at. Of that fly we had but a solitary specimen tied on an eyed-hook; had it been on gut the neck would probably have broken in a couple of hours, for we were casting up stream against the wind-a most trying operation for the necks of flies. However, we husbanded that fly capitally. Each time the gut appeared a little worn we broke the fly off and re-affixed the gut, and by that means used it all day, and had the satisfaction of bringing home twelve brace of plump little trout. How thankful we were to the inventor of eyedhooks !-Editor, Fishing Gazette, 15 th May, 1886.

\section{"Mr. Cholmondeley-Pennell's Turn-Down Eyed Trout Hooks.}

"Having," the writer states, "made a thorough trial of flies dressed on these hooks, against flies dressed on ordinary hooks with gut lappings," he thus sums up :-

"The result of the Week's Fishing, during which my worst day was Four Brace, and my best Nine Brace, is, on every point, favourable to the flies tied on turn-down eyed hooks. I may summarise these points as follows :

"I. The flies never 'flick' off.

"2. They can be changed-attached and detached-in less than half the time.

" 3 . They are stronger; because whenever the gut gets at all frayed at the head it can be at once shifted (re-knotted on) whereas with flies lapped on gut the weakening at the head commences very soon, and any change involves sacrificing the fly; consequently the fly is, in many cases, used long after it has become weak. But beyond this there is, I think, an actual extra strength imparted by the form of knotting to the eyed-hooks (Mr. Pennell's 'jam knot') as compared with the ordinary lapping.

"4. The Turn-down Eyed Hooks appear to me to hook more fish in proportion to rises, and to lose fewer fish after being hooked.

"I have never met with an instance of the knot slipping.-BLUE UPRIGHT.

6th June, 1885 . 


\section{SUCCESS WITH MR. PENNELL'S TURN-DOWN EYED HOOK AND JAM KNOT.}

[EXTRACT.]

You will be pleased, Sir, to hear that I can now record myself another " convert" to the eyed-hook system. It has taken me a year or two to change, but I think now the transformation is complete. I came here provided with Mr. H. R. Francis's patterns dressed by Farlow on Mr. Pennell's turned-down eyed-hooks, and, am pleased to say, have found them very effective, particularly the Hare's Ear and Olive Dun. . . .

I should say that if the gut is properly moistened, a slip is next to impossible.

\section{J. Asbridge Hall}

(Member of the Fly Fishers' Club, Kilnsey Club, and Yorkshire

I7th April, I886.

Anglers' Association).

Sir,-Allow me to add my testimony to that of Mr. Asbridge Hall as to the excellence of Mr. Cholmondeley-Pennell's Turn-Down Eyed-Hook system with the Jam Knot. I have been using nothing else constantly for the last month, and cannot say too much in their, and its, praise. The ease and simplicity with which the flies are attached, even in the most boisterous weather, the saving of both time and trouble by the quickness of the Jam Knot, and the escaping of all need of soaking and tying on flies, really leave nothing to be desired ; and though I must admit I started with modest expectations of success, or I might even say with almost a prejudice against "them new-fangled notions," as my keeper expressed it, I confess practical trial has converted me entirely to Mr. Pennell's system, and I shall never use any other in future.

With regard to the special bends of hook-and I have used both the "Pennell Sneck" and the "Pennell Limerick"-these are, of course, matters quite separate and apart from the system itself, and I rather incline to think that some, at any rate, of the hooks I have used of the "Limerick" bend turn rather too much inwards, and that a slightly "ranker" point-side would be surer of hooking, especially when fish are rising shy. This, however, is a matter of detail, and may very probably be the result of imperfection in the manufacture, as I do not find it in all the hooks. I enclose my card.-I am, \&c.,

Devon Minnow.

P.S.-The attaching of the flies to separate gut strands "tied on short lengths of gut at one's leisure instead of at the river side " would at once rob the system of half its attractions and advantages. I have not had a single instance of the Jam Knot slipping, even when using the very finest drawn gut.

Ist May, 1886. 
A Scotch correspondent writes:- "Dear Sir,-Fishing from Aultnagillagach Inn, Sutherland, on Tuesday last, my father and I caught with fly in Loch Urigaill 2 II trout, weighing $48 \mathrm{lb}$. The best previous take appears to have been 180 trout, $391 \mathrm{lb}$., in $1874 . "$

The size of wire I find best here is No. 8 Pennell sneck, unlessthere is almost a total absence of wind. I inclose pattern and fly, which I dress for my own use, which I have never seen used by anyone but myself, although I daresay it is not new. I find it a capital fly."

The fly our correspondent sends is dressed on one of Mr. CholmondeleyPennell's new turned-dowll eye hooks, and is made thus : Body, scarlet wool, ribbed with five turns of flat silver tinsel; the wings are set on upright, and are made from hen pheasant wing - a delicate feather, by the way, which might be much oftener used in trout fles than it is; a black-red cock's hackle at shoulder. It is a good pattern evidently. We should be glad if our correspondent would give us his opinion of Mr. Pennell's new hook. . . [EDITor, Fishing Gazette.] 5 th June, 1886.

\section{MR. PENNELL'S TURNED-DOWN EYED-HOOKS.}

SiR,-I have much pleasure in complying with your request that I should give my experience of Mr. Pennell's turned-down eyed-hooks. : . . . I bought a packet of No. 6 Pennell snecks (eyed) at the beginning of the season in order to test the eyed system. I have since ordered all the larger sizes, which I think will be useful for this district, but I only received them a few days since.

So far as my experience has gone, I have everything to say in favour of the eyed hooks, and think their chief advantages are :-

(I) After the gut has once been thoroughly soaked, the flies can be changed five or six times as quickly as those dressed on the old wires, and the bob fly can be changed as easily as the tail fly.

For using the old wires, unless they are fastened on in the old fashion with a loop, the bob flies, after once having been taken off the cast, are useless; besides, half the gut is wasted in fastening on the bobs.

(2) As Mr. Pennell says, in your issue of 24th April, "If the colour and thickness of the link of gut next the fly are matters of such vital moment, with a view to the concealment of the lure, of what paramount importance must it be to avoid the necessity, once and for all, of attaching the flies by a separate strand of gut, always unsoaked, constantly of a different thickness, and often of a varying colour? The continuity of the cast is broken at its most critical point."

I have often experienced myself the inconvenience of having all my flies of a certain pattern dressed on the same thickness of gut, which one often has to put up with when buying flies in a hurry. 
(3) The flies last much longer when dressed on the eyed-hooks; as, of course, the gut can always be changed when it becomes worn, which is often a very great boon when one is fishing with one's last fly on a pattern that is killing well. I do not find that if the gut is properly attached to the wire it wears out sooner, if as soon, as it does with the ordinary wires. I have fished five or six hours against a strong head wind without re-attaching the fly.

(4) They are much more easily carried about, and there is, of course, no gut on them to deteriorate with keeping. . . . TRUTTA.- [Extract.]

I7th June, 1886.

[As regards the hooking powers of eyed-hooks turned-up or turned-down, our experience is that they are the same, and Mr. F. M. Halford confirms this. Mr. Halford informs us that he finds the jam-knot perfectly secure when used with Mr. Pennell's 'fine-eye' hooks, but that it is not safe with the ordinary eyed-hook of commerce.-EDIToR, Fishing Gazette.]

\section{HOOKING POWER OF EYED-HOOKS.}

SIR,-As I observe you ask the opinions of fly-fishers who have practically tested the hooking power of eyed trout-hooks, I have no hesitation in assuring you that, in my experience, they both " hook" and " hold" at least as well (if not better than) any of the old-fashioned hooks lapped on to gut. Repeated trials of one against the other leave no doubt whatever in my mind on this point.

Their other advantages have been well summarised by your correspondent "Trutta," whose favourable judgment I cordially endorse.

As in your correspondent's case, however, my remarks apply solely to Mr. Cholmondeley-Pennell's hooks with turned-down eyes, bought from Farlow's.

I have no faith in any of what you iustly call the " ordinary eyed-hooks of commerce," the eyes of which are for the most part turned up-a principle to which I have the utmost objection-and so large as to be both unsightly and incapable of attachment by the Jam Knot.

I inclose my card.-I am, \&c.,

July 3 rd, 1886.

Blue UPRight.

\section{Testimony in favour of strength of jam knot, \&c.-[Extract.]}

It has been advanced in favour of the eyed-hook that it is more economical, that the flies are not so liable to flick off when casting, and that the jam knot is a more secure fastening than the gut attached to the hook in the old system. With the last of these assertions I fully concur. I fished two days with a Greenwell's Glory without requiring to retie the jam knot. And at the end of that time, before the drawn gut broke at the eye, the steel yard I was testing it with registered within an ounce or two of three pounds.

3rd July, 1886.

H.H. 


\section{EYED-HOOKS.}

SIR,-With regard to this question, there is one thing which I think every fly-fisher will acknowledge-viz., that we all have noticed that a run of luck or the reverse continually happens in hooking or losing fish. I have lost fish after fish on some days with the old-fashioned hook on gut, and have fished week after week with hardly a loss.

This year on the Anton (where, by-the-bye, we have had a wretched season from the scarcity of fly), I have, using always the eyed-hook, hardly lost a fish that I have once hooked, till about a week since, when, with a large evening Sedge Fly, in a mill pool, I hooked five fish in about a quarter of an hour, and lost four of them. This, however, I entirely attributed to this cause - that I always endeavour now to avoid striking at a rise, feeling convinced that with a small hook more fish are lost than caught by the act of striking. On this occasion I was, as I have said, using a large hook, which I had not done for a long time, and I have no doubt that something in the shape of a strike was required to make the comparatively coarse point take a proper hold. By striking, I mean the violent action implied in the word, not the necessary raising of the point of the rod when the fish is supposed to have taken a fly. I must say that I am inclined to think that the direction of pull in the turneddown eyed-hooks gives them an advantage over those with the eye turned up; but I have not practically proved this. In fact, as I have said above, it is a very difficult matter to prove these things, as it is, undoubtedly, often a question merely of a run of luck.

Your correspondent, "H.H.," seems to forget the numerous advantages of the eyed-hook. They are these:-

Ist. You may change your fly certainly four times with the eyed-hook to once of the hook on gut, as the latter must always have at least three or four minutes' soaking in the mouth before tying on, while the last link of your footline that you are fishing with is always soft.

2nd. The gut of a fly that has been some time coiled up in a book will not come straight without long soaking or much trouble with indiarubber or some such means. A curly length of gut at the end of your cast is fatal to fine fishing.

3rd. On picking out a fly from your book, you continually find that the gut on it is much too coarse for use at the time. This can never happen with the eyed-hook.

4th. When your gut foot-line is properly tapered you can always fish fine or coarse at a minute's notice; for instance, when you have been using a small fly in the evening, and you suddenly see the fish taking a large Sedge, you can break off one or more of the finer links of your tapered collar, and put the heavy fly on whatever thickness of gut you fancy.

5th. You never lose a fish from the gut on your fly being old, or rotten, or worn at the head-a very common occurrence where a gut hook has been for some time in your fly-book. 
6th. Flies on eyed-hooks stand an immense deal of whipping in drying them, while the gut-hooks continually break just at the junction of hook and gut.

7th. Eyed-hook flies are so much more conveniently carried about with one when fishing than hooks with a coil of gut attached.

All these are immense advantages, . . . - [Extract $]$.-F.R.C.S., July Ioth, I886.

I am glad to see that Messrs. Warner and Sons have shown their usual good sense by falling in with your excellent suggestion as to numbering hooks. The plea of most of the other manufacturers is absurd; a circular to their customers notifying the change and showing the different sizes for the new numbers would meet all objections, and the cost of this would not be breaking. I have tried different kinds of eyed-hooks, and I must say that Mr. Pennell's appear to me out-and-out the best as far as shape, bend, and turn of eye are concerned. The only thing required to make them very near perfection is ( $I$ ) to make the barb much smaller, and (2) to make the distance from point to barb shorter. This latter would follow as a natural consequence from the first improvement, as, the barb being lower, it would not require so long a slope in order to obtain the necessary penetrating power; there would then be more room between the barb and the bend, which would, I think, be another advantage.

Oct. 30, 1886 .

Green Wren.

\section{TYING FLIES ON EYED HOOKS.}

I tie my own flies, and certainly in this respect the eyed hook has a great advantage. When one has some half-a-dozen fragile articles to attach to a tiny bit of wire, it is a vast convenience to be able to dispense with the gut. It is one trouble less. $-[$ Extract $]$.-H.W., 26th June, $\underset{*}{\mathbf{1} 886 .}$

I have lately tried Pennell's eyed hooks on some lochs in the North, and I was very satisfied with them.

I tie my own flies, and in this respect there is no comparison, and I hope I shall never have to use the old style of hooks again. [Extract].-J.H.W., Sept. I8th, 1886 .

" Before many years are passed the old-fashioned fly, dressed on a hook attached to a length of gut, will be practically obsolete, the advantages of the eyed hook being so manifest that even the most conservative adherents of the old school must, in time, be imbued with the most salutary reform." F. M. HALFord, Floating Flies and How to Dress Them, p. $\boldsymbol{x}$. 
"Flies dressed on eyed-hooks float better and with less drying than those constructed on the old system. . . . Another and, in my opinion, paramount benefit is, that at the very earliest symptom of weakness at the point of uncture of the head of the fly and gut (the point at which the maximum wear and tear takes place) it is only necessary in the case of the eyed fly to break it off and tie on afresh, sacrificing at most a couple of inches* of the fine end of the cast ; while in the case of the hook on gut, the fly has become absolutely useless and beyond repair. It must also be remembered that with eyed hooks the angler can use gut as coarse or as fine as he may fancy for the particular day, while with flies on gut he would require to have each pattern dressed on two or three different thicknesses."-1dem, p. 2.

"For nearly six weeks I rang the changes on the Sproat, Sneck, and Pennell hook, in the endeavour to determine practically the relative value of each ; and as far as such a trial justifies an opinion I believe the Pennell hook to be all that its inventor claims for it." . . " Whenever during the latter part of my trip I wished to tie a new fly I invariably ignored the Sproat and Sneck hooks, and selected the Pennell."-H. P. Wells, Fly Rods and Fly Tackle, $p .32$.

“The O'Shaughnessy, the Limerick, and the Sproat are the forms of hooks most used in this country. . . . But a so-called modification of the Limerick hook, the invention of Mr. Cholmondeley-Pennell, the well-known angling author, has recently appeared in England, which I believe to be far superior to any of these. I recommend this hook with the greater confidence, since I' have used Mr. Pennell's modification of the sneck bend for three or four years under conditions designed to thoroughly test its efficiency and strength. Gradually it superseded every other form of hook in my esteem, until last year I used no other, except upon compulsion and with reluctance. It will be noticed the point [of the Pennell-Limerick] is set in toward the shank so as to secure all the certainty of penetration which the original form of Sproat possessed-or, indeed, which is possible in a hook; that the point is long and conical; that the wire is but little weakened in the formation of the barb; that it is deep on the shank side ; that the wire is of sufficient thickness to prevent change of form; and that the shank is straight, thus facilitating the tying of the fly. . . . Though its name and shape might lead a casual observer to consider it really a modification of the hook from which it is named, careful consideration of the following diagram of the three sizes most useful to the salmon-fisherman in this country, will show that it is really nothing but the Pennell sneck-bend hook, with the angle where the shank merges into the bend softened to an easier curve."-H. P. WeLls, American Salmon Fisherman (pp. Iog-IO).

* With the Jam Knot half an inch.-H.C.-P. 


\section{HOLDING POWERS OF EYED HOOKS.}

"In July last you inserted a note of mine as to the holding powers of eyed hooks, and I attributed the loss of many fish after being apparently; well hooked to the use of these instead of gut-tied hooks, at the same time stating that I would give the eyed hooks a good trial and note the results. Since July 22nd, in 20 days' fly-fishing, I have used the eyed hooks and gut-tied hooks alternately in this way : eyed hook in the morning and gut-tied hook in the afternoon of one day, and the reverse on the next day; and at times, after taking two or three fish with one kind of hook, I have changed to the other with the same fly, and so on. The result is slightly in favour of the eyed hook so long as the hook did not break ; but I lost many a fine fish by the barb of the hook giving way, more particularly in the small bronzed eyed hooks. This causes more vexation than the loss of a fish from not being well hooked. The manufacturer's attention should be drawn to this very serious defect, which I should think could be easily remedied. [I can guarantee that this will not occur with the hooks of my present Hookmakers, Messrs. Wm. Bartleet and Sons, Abbey Mills, Redditch, and 53, Gresham Street, E.C., who are now my sole wholesale agents. - H.C.-P.]

I8th December, 1886.

\section{EDWARD HAMILTON, M.D., Author of Fly Fishing for Salmon, Trout and Grayling.}

[We are very glad, indeed, to get this practical testimony to the holding power of the eyed hook. It is the more valuable because Dr. Hamilton started on his experiment under the impression that the eyed hook was deficient in holding power.-ED. Fishing Gazette.]

\section{AS TO SALMON HOOKS.}

\section{"EYED HOOKS FOR SALMON FLIES."}

There has been a very long controversy upon this subject, and I am glad to find that $\mathrm{Mr}$. H. Cholmondeley-Pennell has now come to the conclusion that the turned-down eyes are better for his purposes-viz., trout flies, than those which are turned up, because it exactly agrees with the result of my experiment with these hooks for salmon flies, which I told him of at the time.

A few weeks since Messrs. Woodfield and Co., of Redditch, kindly sent me through you, sir, a number of these hooks, and, with a view of giving the readers of the Gazette conclusions drawn from practical experience, I tried flies which I had especially dressed upon them, critically examining each and every performance. There were various descriptions, some with turned-up and turned-down eyes at different angles, and also others in which the eye was simply made at the end of the straight shank. I found, as I fully anticipated (and I will tell you why presently), that the more the eye was turned up the worse the fly fished. As to that I had no doubt whatever in my own mind 
beforehand, and was perfectly certain what would happen, for the first thing a fisherman does while mounting his fly after the adjustment-still holding by the bend of the hook-is to take the gut between the thumb and forefinger of the right hand, about a foot from the work, and give a few hardish tugs to see that the line is direct from the one point to the other. If it deviates the least atom-and it is obvious it would with the turned-up eyes-the fly cannot behave as it ought, or, rather, very often, as it must. We have only to ask ourselves the question, upon which I laid so much stress in the current flydressing articles-Why are we so particular in tying our gut loop perfectly straight under the shank? Because we find the hook penetrates more readily, and digs deeper and deeper in during a conflict. But with the loop above (and the higher the metal-eyed one is turned up the greater the inclination), the moment you strike at a fish the head of the hook bears down, and the bend of the hook lifts up, the result being that its point scratches along, tearing its way without taking hold at all. Moreover, were it to become accidentally imbedded, you could put little or no pressure on to the rod, for, if you did, the hook would be gradually working its way up and out all the time.

Old salmon anglers know full well the importance of a steady give-andtake movement of the rod in playing the fly, and the moment I began that motion the nez retrousse fly lifted its head coming up stream, and its tail going down; in fact, it was like the action of a nursery rocking-horse.

This is doubtless what Mr. Field means when he says his fly did not "play well in the water."

If, as Mr. Pennell correctly but mildly puts it, "dropping the head is a trifling blemish," or words to that effect (but we must bear in mind he was alluding to trout flies), and that the erratic and fatal distinction-as I would rather have it-is the same whether the fly be tied or looped on, how much this dreadful drawback is increased may be easily imagined when, comparatively speaking, such monster hooks as ours are' being used.

I did not observe the fault with the turned-down eyes; indeed, how could it be so? And if they are found in practice to answer, it occurs to me flies will last so much longer as to justify anglers in paying more to have them dressed with natural instead of dyed feathers. That the former are superior in every way I have long since determined. No matter how ably the dyeing process is managed, our artificially-coloured feathers and hackles-fiery browns excepted -never look so well, or are so advantageous.

Hitherto, being well aware that the gut loop would not be trustworthy, however well arranged, after a certain amount of wear and tear, we have naturally hesitated to incur the extra expenditure involved in having our flies dressed so extravagantly.

I, for one, shall certainly try the turned-down eyed-hooks, and should not hesitate to adopt them if I derive ever so little benefit. The ordinary gut-loop accommodates itself in use, whichever way we knot or loop the trace to it, turning up with our adjustment commenced from below. But were we to 
make our knot, or loop our trace dozen through, instead of the gut-loop turning up, when it has been soaked it would turn down; therefore, it is perfectly clear either of these fastenings must be made down through instead of up through the metal eye.

It may be argued that knots throw each strand of gut out of the straight line, but practically, "the pull" is just the same whether the gut-trace be a knotted one or only a single strand married to the line.

Flies can be made with much slighter bodies-not by any means a trivial consideration for many of the Irish rivers. Nor need there be any difficulty in dressing them; but-in answer to another correspondent-the work would eventually become loose, unless the hooks were prepared to receive it. What I suggest, first of all, is to run a single layer of closely-coiled, well-waxed gossamer silk along the shank, whipping in underneath a single strand of gut (tapered at the point), extending far enough to secure it, to serve the purpose of "making off" the tying silk.

All fly-dressers know the ordinary loop is used for that. The gut could be nipped off a shade longer than the iron, so as to project in the same manner as a loop, and there you have it. But after the body is completed it would be better to cut the gut flush with the work, because the wings could be fixed firmer on merely a fresh single layer of the fine silk, and also because the head would be smaller. - I am, \&c.,

\section{Geo. M. Kelson, 25th April, 1885.-[Extract.]}

Mr. H. P. Wells, author of "Fly Rods and Fishing Tackle," \&c., \&c., to Mr. A. N. Cheney, author of Fishing with the Fly.

"I like the Pennell hook better than any other I have tried, especially for salmon fishing. . . - - showed me some very good Sproats he said he got from you. Where did they come from? But I think the Sproat inferior to the Pennell, any way. The fish plays too near the barb, and indeed it must be in use all the time to prevent his escape. I am inclined to attribute the proneness of the Sproat to break at the barb partly, if not wholly, to this. A large and powerful fish is wrenching and twisting on it all the time. According to my ideas the fish should play on the bend of the hook, and quite away from the barb, which should only be brought into use during some sudden and unusual evolution on his part. In this respect the Sproat is inferior to any hook I know of unless it be the kinsey. I tried the Pennell salmon fishing, and also this September in Maine using nothing else, and am confirmed in my opinion that for fly-fishing-large flies at all events-it is the hook of hooks."

"There can be no question that a fly so made will last much longer, be less likely to snap off in the back cast, swim straighter, and that the connection between the fly and the outside world will be much more closely disguised." . . .

"Mr. Pennell has improved on this feature [the eye] by turning it downward, as shown in the figure, instead of upward. The draft line-or in other words, the sureness of the hook-is certainly improved by the change. It 
would also seem that the gut should then lead in a line more coincident with that of the shank of the hook, with a consequent improvement in the swim of the fly. . . . [Here follow instructions and diagrams for knotting on.] I cannot but think this a very decided advance on the method at present in use in this country. It is adapted to all sizes of flies from the minutest midge to the largest salmon fly."-H. P. Wells, The American Salmon Fisherman, p. II2.

\section{Mr. A. N. Cheney writes :}

" The more I examine the 'Pennell-Limericks' the more I am convinced that he has solved the hook question, and a halt may be called to any further attempts at improvement."-A. N. Cheney, President Fish and Game Protection Association, New York.

\section{"EYED SALMON HOOKS. THE NUMBERING OF HOOKS," \&C.}

It is to be hoped that the makers will agree among themselves as to the numbering of their hooks, starting from I and going up to shark hooks, if they like.

The eyed-hook for dressing salmon-flies on has many advantages, as the eye will not rot as in gut, and they won't draw, as some I have seen do with a fish on - through their being put away damp, perhaps. . . .

$$
\text { JuNGLE CocK, 18th October, 1886.-[Extract.] }
$$

Kindly allow me to say something about the shape of hooks. Four of us from this town have done a little salmon-fishing this last season, and we have used two kinds of eyed-hooks-one made by Messrs. Hutchinson and Son, of Kendal, with turned-up eyes, and bent something similar to Mr. Hall's; the other, Mr. Pennell's turned-down eyes. . . . . The latter are very finely tapered at the eye-many here saying too much so; so I thought I would try what they would break at, and got a smali - sized Kendal and put a string through the eye, and attached it to a spring balance, and it broke at the eye with a strain of $26 \mathrm{lb}$. I tried the other of similar size and pulled $16 \mathrm{lb}$, and then left off, thinking it was good enough. We are unanimous in favour of the turned-down eye, but think the smaller-sized ought to have the same size of eye as the larger, for it is hard work to get two fold of salmon gut through the small ones; but I think the fly hangs better on the gut when it is tight in the eye, and it would be impossible to get twisted gut through any of the sizes. Two are in favour of one bend, and two the other. Those in favour of Kendal say that with standing off a little it hooks better; the others that Mr. Pennell's are equally as good for that purpose, besides swimming straight, and therefore looking more like a thing of life. JAmes WooD, 7, Barlow Street, Oldham, 27th November, 1886.-[Extract.] 
I would here recommend the use of eyed-hooks, especially to those who only get an occasional day's salmon-fishing. I have now in my book flies on eyed-hooks four or five years old as good as the day they were tied, while you never can depend absolutely on a gut loop after one season, and frequently they get worn and unreliable after one day's fishing. With eyed-hooks, on the contrary, by exercising a little care in shifting the foot link occasionally, a salmon fly is almost indestructible, and one of their chief recommendations is the ease .with which this can be done-unlike the heart-breaking work of changing the link of a gut-looped fly when the gut has got jammed by use.

Green Wren.-[Extract.]

\section{AS TO EYED-HOOKS FOR BLACK BASS FISHING.}

I have said nothing about the kind of hooks to use, for there are so many to choose from and anglers have such different views upon the matter, but as I have mentioned other tackle, I will say that Pennell-Limerick, improved Pennell, or O'Shaughnessy hooks are, in my opinion, best.-A. N. Cheney, The American Angler. Special edition, Ist April, I 886.

\section{“PENNELL-LIMERICK" BEND FOR TREBLE HOOKS OR TRIANGLE.}

\section{From the same article.}

The last of the tackle to mention is what is fastened to the end of the linethe minnow gang, or flight of hooks, as our British cousins call it. The treble hooks for the gangs are made by soldering three first quality, round wire, O'Shaughnessy hooks together back to back. Since the above was written, I have become favourably impressed with the improved Pennell hooks; and more recently with the "Penneli-Limerick," which I consider the best hooks" as to shape that are made.

\section{EYED HOOKS FOR FLOAT FISHING.}

From Editorial Notes, Fishing Gazette, 3rd October, 1885.

We do not see why eyed-hooks should not be used extensively for bottomfishing-roach fishing, perhaps, excepted. It is no more trouble to tie on an eyed-hook than:to loop on one tied on gut, and there would be none of the danger caused by the binding coming off. We threaded a worm up the shank and over the eye of an eyed-hook we tied on as an experiment the other day. The result was satisfactory, the knot in the gut acting much as does the little barb of the sliced hook we invented, though not quite so well.

It is rather a difficult thing to get good eyed-hooks at the tackle-makers. They do not seem at all anxious to circulate them among their customers. 
Possibly the reason is that flies on eyed-hooks last five times as long as those on gut. When anglers insist on being served with eyed-hooks the tackle-makers will get them, but not before.

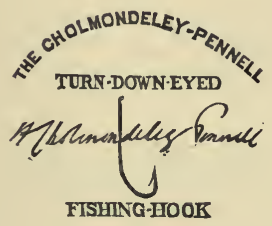

SOLE MANUFACTURERS,

WM. BARTLEET AND SONS, ABBEY MILLS, REDDITCH ; LONDON HOUSE : H. WALKER, 53, GRESHAM STREET, E.C. 



$$
\text { I N D E X. }
$$





\section{N D E X.}

Appendix, I73

Bags, fishing (see ' creels')

Baskets, fishing (see 'creels')

Boxes and Books for flies, \&c., 36-44 Eyed Trout Flies.

, $\quad$ Farlow's pocket box; 36

" Bowness' ditto, 39

", Bartleet's 'book-box,' 37

Eyed Salmon Flies.

" Farlow's stock box, 42

,, Ashley Dodd's pocket box, 43

, Malloch's ditto, 44

'Climax' box for gut-flies, 39

The 'Lathan' cast box, 40

The 'Safety' ditto, 40

Foster's Fly book, 4I

Farlow's ditto, 4I

Pike and General Tackle boxes, I 59-60

Rod-boxes, 122

Brogues, \&c., I I 5

'Buffer-knot' (see ' knots'), 125

Combination Rods, 77-8

Combined cutters and pliers, 2I , 45

\section{Creels and Fishing Bags, 55}

"Carry-all " Creel, 55

Desideratum basket, and Farlow's new Creel strap, 56-7

Tin creels, $58-9$

Papier-maché creels, $58-9$

Wooden creels, $58-9$

Leather creels, $58-9$

'Seat' creels, 58-9, 62, 170

'Fishing ' bags, 59

Expanding ditto, 60

'Freke' bag, 6r

Combined Basket and bag, 6r

Waterproof attached to bag or basket, 62

'Usk Salmon Basket,' 63

Cups, leather drinking, I66

Double slip-knot (see 'knots,')
Dress for fishing and shooting, I I7-22. For ladies, I 19 Jaëger's "all wool - clothing," I $17-22$

Dry fly and 'wet' fly-fishing, Io9 Eyed-fly cutter and pliers, 2I, 45 Eyed Hooks, \&c. (see 'Hooks, eyed') Fish-carriers (see 'creels')

Fishing bags, \&c. (see 'creels')

Flies on eyed hooks (see 'Hooks, eyed ')

'Hackle' flies, I 10

For 'wet' and 'dry' fishing, Io9

Floating, and eyed hooks, I2, I IO

Detached bodied, 23-4

Typical, and exact imitation, IO3-109

Pike scale wings, 25

On hooks with points turned up, 26

On 'Invisible Double hooks,' 25

Price of flies on Eyed hooks, 27

\section{Float-fishing.}

Floats, the 'Traveller,' 160

,, the 'Glow-worm,' I60

Cumberland Clearing Ring, I6I

Foster's 'Tackle Liberator,' I6 I

Holt's clearing knife, I63

Floating flies on eyed hooks, I2, I IO

Ditto, detached bodied, 23-4

Fly boxes (see 'Boxes')

Fly-fisher's knife, I64

Fly rods (see 'Rods')

Fly-vice, Ogden's, 166

Gaffs, 63

'Combination net' gaff, 63

Wading staff and gaff, 64

Field's protector gaff, 65

Gut, 122-5

Gut cutter and pliers for eyed flies, 2I, 45 
Gut knots (see ' Knots')

Half-hitch knot (see 'Knots')

\section{Hooks, Tapered Shank.}

' Pennell Sneck,' I 3

' Pennell Limerick,' I4

Mechanical principles of constructing hooks, 15

\section{Hooks, Turned-down Eyed.}

Advantages of, 6-9, 108

'Pennell Sneck' bend, ro

' Pennell Limerick' bend, 9 ditto for Salmon flies, I I, 29 ditto 'double,' I I ditto new eyes for salmon, ' backended,' 32

Testimony in favour of, appendix, \&c., 12, 15, 19

Prices of Flies dressed on, 27

The 'Jam Knot' for fly-fishing, 16-19

Float fishing and sea fishing Knots, 20-2I

Knots for salmon flies (see also 'Knots'), 32

Trade Mark, 34

Combined gut-cutters and pliers, 21, 45

Hooks, new system of numbering, 36

, Marston's 'Sliced,' 22

", Foster's 'Invisible,' 25

", Hall's turned-up eyed, 23

", Lip-hooks, I4I

", Triangles, 146

", Pennell's 'Straight reverse' hooks, I33

Jaëger's all wool fishing clothing, II7 $-122$

Jam knot (see 'Knots')

Knives, 'The Troller's,' I 53

", 'The Fly-fisher's,' I64

Knots, General for eyed hooks, II Jam Knot, 16-19 Single Slip Knot, 31
Double Slip Knot, 29-32

Half-hitch Jam Knot, 20-2I

'Turle' Knot, 20

Hall's Knot, 24, 32

'Buffer' Knot for gut lines and traces, 125

Ladies' fishing dress, I I9

\section{Iranding Nets.}

For Salmon-fishers, 47

For Pike-fishers, 47

For Punt-fishers, 46

For Bank-fishers, 46

For Trout-fishers.

'Pocket nets' and carrying, 48

New creel strap, 42

Spring-jointed, folding, 49

Collapsing nets, 50,54

Hardy's 'V-shaped ' net, $5^{\mathrm{I}}$

Williams' net handle, 52

The 'Combination net,' 53

Foster's collapsing net, folding handle, 54

' Life belt' waders, I I I-I 2

Line Drier, 169

Marston Fishing Pliers, 165

Marston 'Sliced' Hooks, 22

Minnow Spinning (see 'Spinning')

\section{Miscellanea.}

Pennell eyed - fly gut - cutter and pliers, 2 I, 45

Ogden's Fly Vice, 166

Marston's Fishing pliers, 165

Drinking Cup, leather, 166

Hardy's Rod rack, 168

Farlow's Line drier, 169

Adjustible Rod rest, I70

Fly-tyer's vade mecum, 122

Sans bouton fishing leggings, I 2 I

Nets (see 'Landing nets')

Panniers (see 'creels')

\section{Pike Fishing.}

Spinning Tackle, 133-149

Pennell Flights, I $34-5$

Ditto without lip-hook, I43

Metal lip-hooks, 14I

Straight reverse hook, I33

Flying triangles, I46 
Pike Fishing. Spinning continued. Traces and leads, 135-14I

, Double hook-swivels, 135

, Staining Gimp, I43

, Buffer Knot, 125

Rods for Spinning, \&c., 144

, short recommended, 145

", rod described, 145

Reels and Reel lines, 145

Artificial baits, $\mathbf{I} 46$

, $\quad$ Thuted Spoon, 146
, extinguisher head,
I 48 Mother of Pearl bleak,
I 48

\section{Live Baiting.}

Bait cans, 149-50

Field's Arating can, I5I

Aspray's folding-up can, 152

Jardine's Snap tackle, \&c., 153 $-7$

A Troller's Knife with 'disgorger blade,' 153

"Pike-Gag," I58

Disgorger scissors, 165

Pike-Tackle boxes, 159-60

Pike-scale flies, 25

Prawn tackle for salmon, 132

\section{Reels.}

General remarks, 86

Slater's 'Combination,' 86-8

'Strike from the winch reel,' 88

Farlow's 'lever salmon reel,' 89

Chevalier and Bowness' salmon Reel, 89

Malloch's 'Sun and Planet' Reel, 9I

Anderson's 'Excelsior' Reel, 92

Hardy's 'Revolving Plate' Reel, 92

Williams' 'Safety bound ebonite winch,' 93

Little's Aluminium Reel, 94

Reels with 'Line Protector,' 95

Bernard's Line Protector, 95

Temporary ditto, 96

Foster's 'Skeleton Centre' Winch, 96

American Reels, 96

“'Orvis' Reel," 97
Reel fittings.

'Weeger's Wedge Fast' (Hardy), 97

'Universal Winch Fitting' (Farlow) 97

Reel-Lines for fly fishing.

Best material, 98

Level or taper?, 99, 100

"Whip-Last Line," 100

'Acme' line with steel centre (Foster's), 98, ror

Colours for reel-lines and Mr. Wells' experiments, IOI

ditto for gut lines, $102-107$

Rings (see 'Rod-fittings')

Rods and Rod Fittings.

Fly Rods, 66

Split cane, 66-9

ditto steel centre, $67-9$

For Salmon, short rods advocated, $69-72$

For Trout ditto, 72

$8 \mathrm{ft}$. 6 in. ladies' spliced rod, 72

ro ft. spliced rod, 72

Io ft. lake Trout fly rod, 73

Stiff and swishy fly rods, correct theory, 73-4

Varnish and polish bad, $74-5$

'Combination Rods,' 77-8

Rod-Rings.

Upright and 'Snake' ring, 75-6

Top-ring, 76

Rod Foints.

General remarks, 79

'Irish Joint,' 79

Farlow's joint Fastener, 79-80

Hardy's 'Lock fast,' 80-82

"Serrated Ferrules," 82-3

Parallel Joints and Sockets, 83-4

Anderson's 'Simplex' Joint, 84

Watson and Hancock's Joint, 84

Williams' 'screw cap' Joint, 84

Gregson's 'spring clasp,' $84-6$

Rod-boxes, 122

Rod-rest, 170

Salmon rods (see ' Rods')

"Sans bouton" fishing leggings 
Shoulder straps, Farlow's system, 48 Slip Knot for eyed hooks (see 'Knots') Spinning (Trout and Salmon), 125132

Minnow Spinning Tackle (natural bait) for trout or salmon, 125I27

Artificial Minnows, 127

," 'Excelsior' spinner, 128

", 'Halcyon' spinner, I 28

, Cummins' 'quill minnow,' 128

, 3-slot Devon minnow, 129

" Farlow's new brass minnow, 129

Pennell's'Hexagonal minnow,' 129
Swivel, double, I30

Lead and Double Swivel, I 30

Lead-wire Swivel-compeller for Lake Trout Spinning, I3I

Traces, I3I

Spinning (Pike) (see "Pike Fishing"), 133

Trout-rods (see ' Rods')

'Turle' Knot (see ' Knots')

Turn-down Eyed Hooks (see 'Hooks')

'Typical flies' and 'exact imitations' theory, I03-109

Waders and Wading-boots, management and drying, \&c., I I0-1 7 ," 'Life Belt' wading trousers, III-I 2

'Wet' and 'dry' fly-fishing, rog' 






YB 10540 
